\title{
IMPROVING MOTIVATION, RETENTION, AND EFFECTIVENESS OF COMMUNITY HEALTH WORKERS
}

\author{
by \\ TERALYNN LUDWICK - B.A. \\ A thesis submitted to \\ The Faculty of Graduate Studies and Research \\ in partial fulfilment of \\ the requirements for the degree of \\ Master of Arts \\ The Norman Paterson School of International Affairs
}

Carleton University

Ottawa, Ontario

12 January 2010

(C) 2010, Teralynn Ludwick 
Library and Archives
Canada

Published Heritage Branch

395 Wellington Street Ottawa ON K1A ON4 Canada
Bibliotheque et

Archives Canada

Direction du

Patrimoine de l'édition

395 , rue Wellington

Ottawa ON K1A ON4

Canada

Your file Votre référence

ISBN: 978-0-494-81614-1

Our file Notre référence

ISBN: 978-0-494-81614-1

NOTICE:

The author has granted a nonexclusive license allowing Library and Archives Canada to reproduce, publish, archive, preserve, conserve, communicate to the public by telecommunication or on the Internet, loan, distribute and sell theses worldwide, for commercial or noncommercial purposes, in microform, paper, electronic and/or any other formats.

The author retains copyright ownership and moral rights in this thesis. Neither the thesis nor substantial extracts from it may be printed or otherwise reproduced without the author's permission.
AVIS:

L'auteur a accordé une licence non exclusive permettant à la Bibliothèque et Archives Canada de reproduire, publier, archiver, sauvegarder, conserver, transmettre au public par télécommunication ou par l'Internet, prêter, distribuer et vendre des thèses partout dans le monde, à des fins commerciales ou autres, sur support microforme, papier, électronique et/ou autres formats.

L'auteur conserve la propriété du droit d'auteur et des droits moraux qui protège cette thèse. $\mathrm{Ni}$ la thèse ni des extraits substantiels de celle-ci ne doivent être imprimés ou autrement reproduits sans son autorisation.
In compliance with the Canadian Privacy Act some supporting forms may have been removed from this thesis.

While these forms may be included in the document page count, their removal does not represent any loss of content from the thesis.
Conformément à la loi canadienne sur la protection de la vie privée, quelques formulaires secondaires ont été enlevés de cette thèse.

Bien que ces formulaires aient inclus dans la pagination, il n'y aura aucun contenu manquant.

\section{Canadä}




\begin{abstract}
In the last few years, there has been a renaissance of support for scaling-up community health worker (CHW) programs. Renewed support for CHWs has emerged as part of global efforts to achieve progress on the Millennium Development Goals (MDGs) in health and strengthen health systems. Despite this growing enthusiasm, CHW programs have not always been effective. Low motivation and retention have repeatedly been cited as major hindrances to program effectiveness. In light of these chronic problems, a literature review was conducted to examine what factors contribute to motivation and retention. Given the knowledge gaps in this area, a case study was conducted with the Healthy Child Uganda project in order to test which factors are most strongly associated with motivation and retention and why. As countries and donors make increasingly large investments in $\mathrm{CHW}$ programs, this study aims to help strengthen our understanding of the determinants of motivation and retention in order to improve program effectiveness.
\end{abstract}




\section{ACKNOWLEDGMENTS}

I dedicate this work to the Healthy Child Uganda ( $\mathrm{HCU})$ project team and its community health workers who tirelessly and passionately strive to make a difference in the lives of children. They have forever inspired me. This research was conceived by the Healthy Child Uganda team in order to help build evidence-based strategies to strengthen HCU and other community health worker programs. In particular, I'd like to thank Ms. Teddy Kyomuhangi for her vision of this research, advice, dedication, and friendship. I am very grateful to the numerous individuals - Dr. Jenn Brenner, Dr. Jerome Kabakyenga, Mr. Moses Ntaro, Dr. Kathryn Wotton, Ms.Erin Kiley, Dr. Laura Davies, Dr.Edgar Mulogo, Ms.Angella Tumuhimbise, Ms.Adrama Faida, and countless other individuals who helped provide direction and oversight in designing and conducting this research and for the administrative and logistical support provided by Ms.Patricia Tushemereirwe and Mr.Nasser Samula. Without the hard work of my research assistants, Ms.Priscilla Tusiime, Ms.Doreen Ainembabzi, and Ms.Mutoni Ramulah, this study could not have been carried out. I would also like to acknowledge the Association of Universities and Colleges of Canada (AUCC) and the Canadian International Development Agency (CIDA) for their financial support in funding this internship and the work of the Healthy Child Uganda project.

I would also like to thank the members of my defense committee - Professor Valerie Percival, Professor Chantal Blouin, and Professor Lisa Mills - who worked under tight timelines and through illness to help me complete this thesis on time, and for the flexibility and accommodation of the NPSIA administration when I was struggling through sleepless nights. A special thank you to Prof. Percival who guided me from start to finish.

Finally, I would like to thank my friends and family for their patience and support over the many months that it took to complete this thesis. An immense thank you to my parents, who encourage me in everything I do, and to my friend, Katy Stockton, for her help in editing, constant moral support, and letting me turn the house into a thesis work zone. 


\section{TABLE OF CONTENTS}

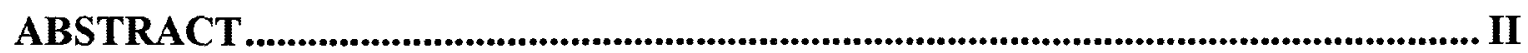

ACKNOWLEDGMENTS...............................................................

TABLE OF CONTENTS ….....................................................................................II

LIST OF DIAGRAMS AND TABLES ................................................................ VI

CHAPTER 1: INTRODUCTION.............................................................................. II

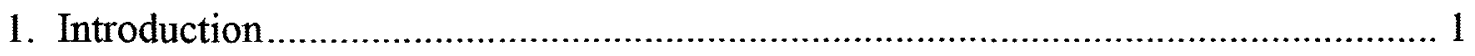

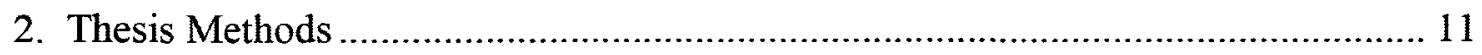

CHAPTER 2: THE ROLE OF COMMUNITY HEALTH WORKERS IN PROVIDING PRIMARY HEALTH CARE ................................................................................... 18

1. The Primary Health Care Movement ............................................................... 19

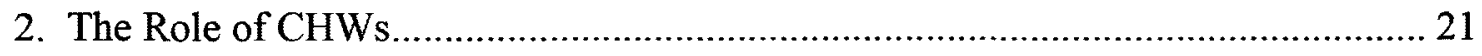

3. The Role of CHWs in Stimulating Community Participation ................................. 27

3.1 Empowerment Model ........................................................................ 28

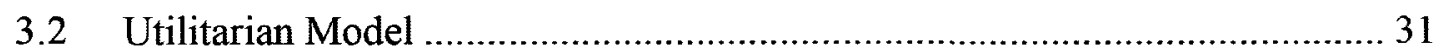

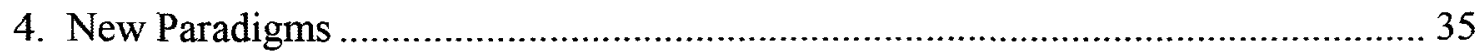

CHAPTER 3: THE ROLE OF COMMUNITY HEALTH WORKERS AS PART OF HEALTH SYSTEMS.............................................................................................. 37

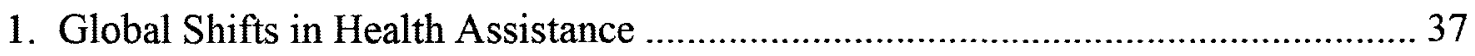

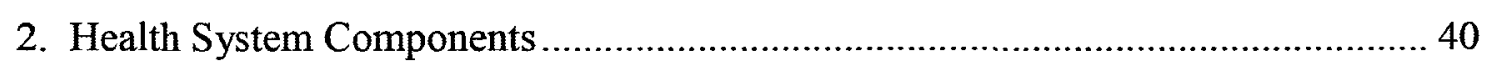

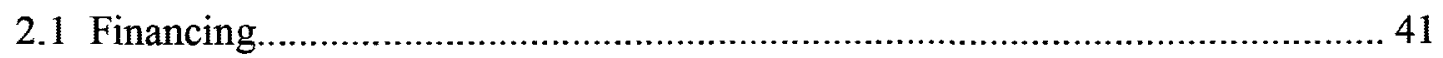

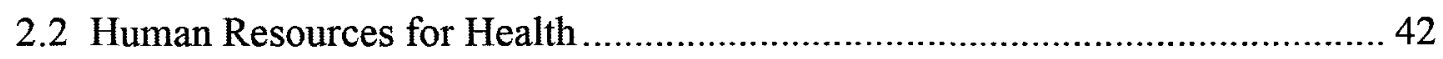

2.3 Health Information Systems .................................................................. 46

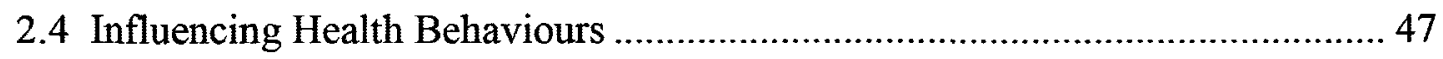

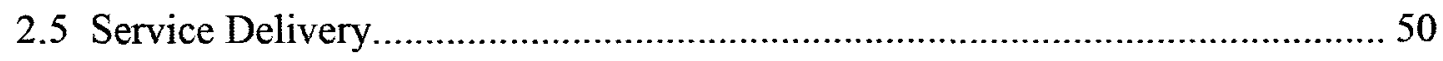

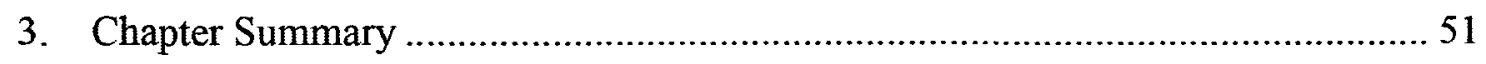

CHAPTER 4: ASSESSING THE EFFECTIVENESS OF CHWS ........................... 53

1. Evidence of CHW Effectiveness ................................................................. 53

1.1 Table 1 - Snapshot of Effective Child Health Interventions ............................. 55

1.2 Table 2 - Snapshot of Effective CHW Interventions ...................................... 56

2. The Challenges of Measuring CHW Effectiveness .......................................... 58

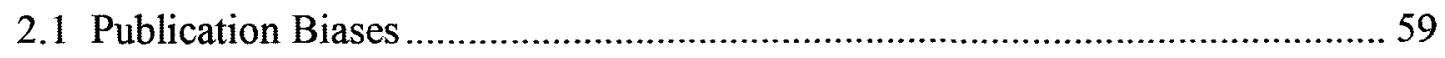




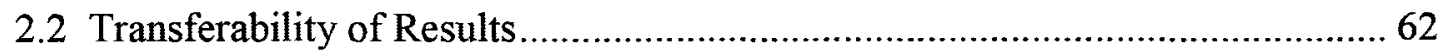

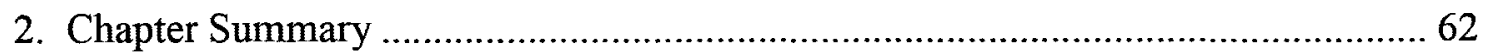

CHAPTER 5: PROBLEMS OF LOW MOTIVATION AND RETENTION ........... 63

1. Impact of Low Retention and Motivation.......................................................... 64

2. Community Participation in Recruitment ............................................................ 68

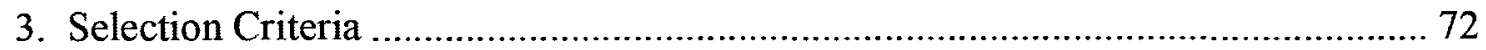

4. Training

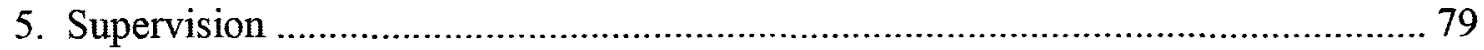

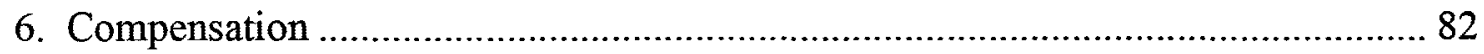

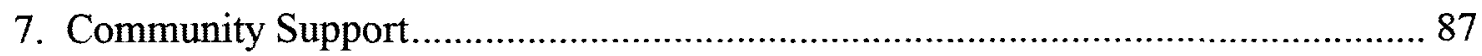

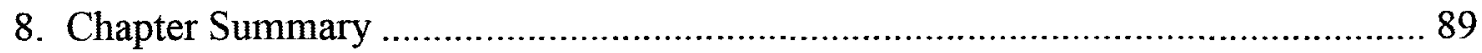

CHAPTER 6: CASE STUDY: HEALTHY CHILD UGANDA PROJECT..............92

1. Suitability of Case Study Location ................................................................... 93

2. Background: Healthy Child Uganda Project..................................................... 96

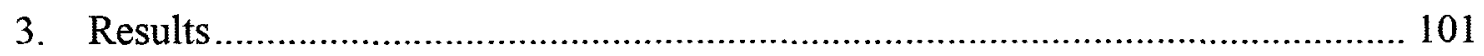

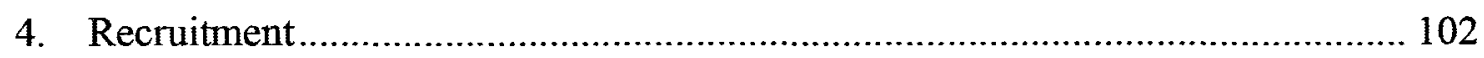

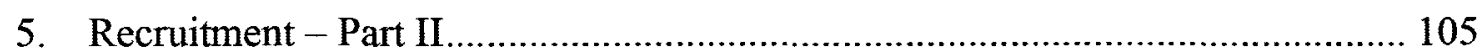

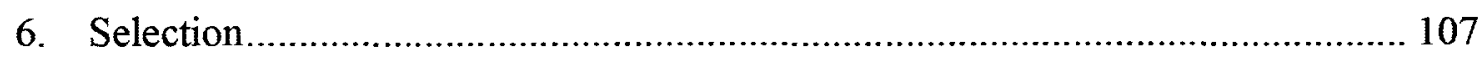

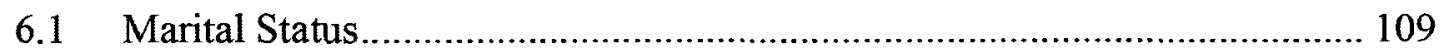

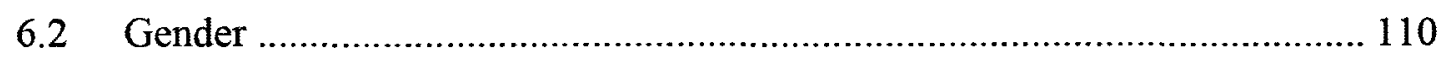

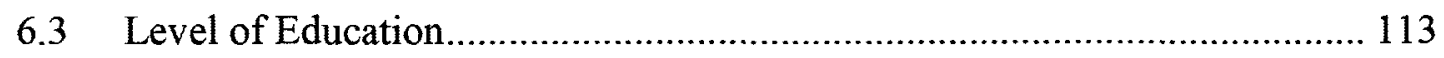

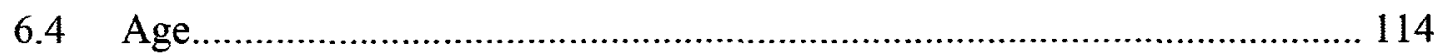

7. Selection Criteria - Part II .......................................................................... 115

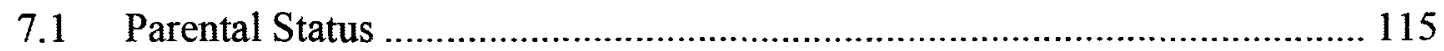

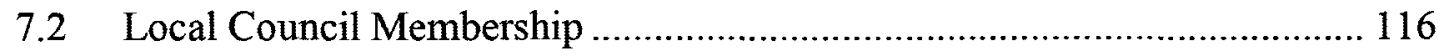

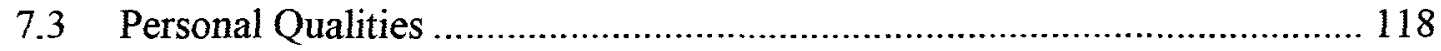

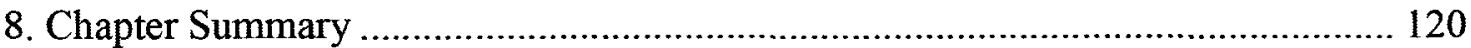

CHAPTER 7: TESTING THE IMPORTANCE OF TRAINING, SUPERVISION, COMPENSATION, AND COMMUNITY SUPPORT ON RETENTION, MOTIVATION, AND EFFECTIVENESS ................................................................................................. 121

1. Motivation Ranking Results .................................................................... 122

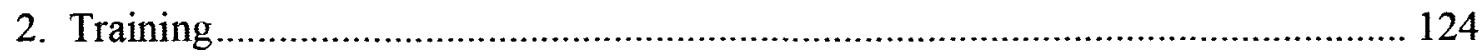

3. Peer Support - A Complementary Role to Supervision ...................................... 127

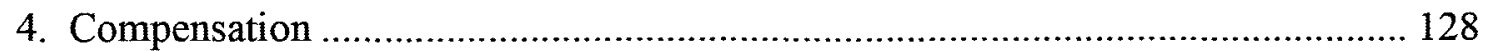

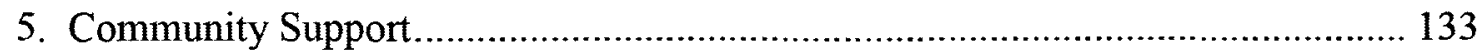


6. Additional Results - Level of Engagement ...................................................... 136

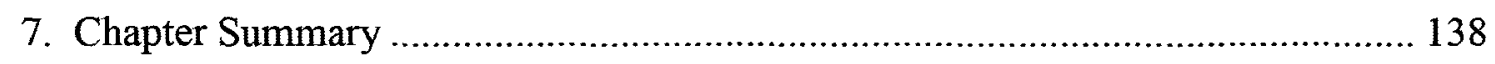

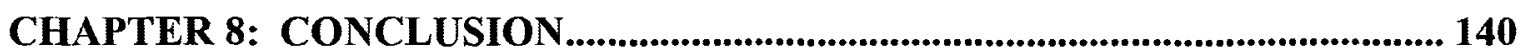

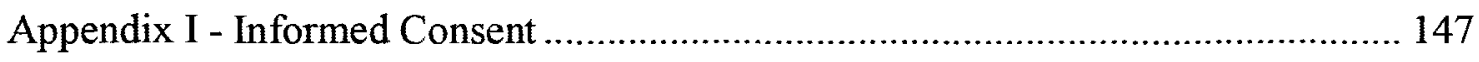

Appendix II - Study Methods and Ethical Considerations..................................... 148

Appendix III - Matrix Ranking Question............................................................ 151

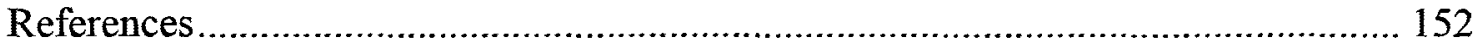




\section{LIST OF DIAGRAMS AND TABLES}

Page

Table 1: $\quad$ Snapshot of Effective Child Health Interventions 55

Table 2: $\quad$ Snapshot of Effective CHW Interventions 56

Table 3: Healthy Child Uganda Project (HCU) Community Health

Worker Demographics and Activities $\quad 99$

Table 4: $\quad$ HCU Retention Rates 100

Table 5: $\quad$ HCU Retention Rate by Gender $\quad 100$

Diagram 1: $\quad$ Determinants of Motivation, Retention, and Effectiveness $\quad 88$ 


\section{CHAPTER 1: INTRODUCTION}

\section{Introduction}

As the world entered the new millennium, calls to redress poverty and inequity in developing countries metamorphosed into a global commitment to the Millennium Development Goals (MDGs). These commitments catapulted health back onto center stage and highlighted the appallingly high levels of morbidity and mortality of the poor in developing countries. Child mortality is $72^{1}$ compared to 6 per thousand in industrialized countries while maternal mortality is $420^{2}$ per 100,000 live births compared to 8 . While the HIV/AIDS epidemic has spread throughout the world, Africa alone accounts for approximately $67 \%$ of the 22.4 million people infected with HIV/AIDS and $72 \%$ of the two million AIDS-related deaths that occur each year. ${ }^{3}$ Committed to reducing global health inequalities by marking progress on the MDGs, health development partners began to search for innovative, cost-effective, and high impact strategies to roll-out basic health interventions. Interest in community health workers (CHWs) has been revived based on growing evidence that community-based approaches to health service provision can play an integral role in extending interventions to the most underserved communities given the severe health worker shortages and other health system constraints.

The pervasive health worker shortage plaguing most developing countries is particularly severe in Sub-Saharan Africa. The 2006 World Health Report estimates that

\footnotetext{
1 "Monitoring the situation of children and women," Available from http://www.childinfo.org/mortality.html.

2 "Safe Motherhood," [cited Dec. 1, 2009]. Available from http://www.unfpa.org/mothers/statistics.htm.

${ }^{3}$ UN AIDS Epidemic 2009, United Nations Program on HIV/AIDS (UNAIDS), 2009: 21.
} 
there is a global shortage of approximately 4.3 million health workers, ${ }^{4}$ including 1.5 million needed for Africa alone. 5 The Global Equity Initiative estimates that "SubSaharan countries must nearly triple their current number of workers by adding the equivalent of 1 million workers...if they are to come close to approaching the MDGs for health." A massive scale-up of health interventions requires a corresponding scale-up of the health workforce.

Training CHWs is increasingly being adopted as a practical way to rapidly scaleup the health workforce and extend the delivery of outreach services. In contrast to typical health professionals, community health workers are generally individuals with limited education selected from the communities where they reside to receive condensed, simplified training on a range of health topics. They generally perform services on a part-time basis and are compensated only marginally, if at all, as most donors and governments consider salaries too expensive and unsustainable. ${ }^{7}$

Over the last few years, support for training CHWs has gained momentum as a way to simultaneously strengthen country health systems while quickly securing the human resources to scale-up health interventions and progress on the MDGs. The rise in popularity of CHWs has been precipitated by the 2005 United Nations Millennium Project report "Investing in Development" which recommended a number of 'quick wins' for reaching the health MDGs, including a "massive training program of community based workers." ${ }^{\prime 8}$ Subsequently, key donors have begun funding the implementation of

\footnotetext{
${ }^{4}$ Nigel Crisp, Bience Gawanas, and Imogen Sharp, "Training the health workforce: scaling up, saving lives," The Lancet 371, no. 9613 (2008): 689.

${ }^{5}$ ibid., 690 .

${ }^{6}$ Fred Abbatt, "Scaling Up Health and Education Workers: Community Health Workers Literature Review," DFID Health Systems Resource Centre (March 2005), 12.

${ }^{7}$ The Global Burden of Disease: 2004 Update, Anonymous World Health Organization, 2008), 2.

${ }^{8}$ Abbatt, Scaling Up Health and Education Workers: Community Health Workers Literature Review, 12.
} 
large-scale, multi-million dollar CHW programs. The newly launched Catalytic Initiative to Save a Million Lives sponsored by CIDA in partnership with USAID, the Government of Norway, AusAID, UNICEF, the WHO, the Bill and Melinda Gates Foundation, the Doris Duke Charitable Foundation, and the World Bank pledges $\$ 500$ million between 2007-2012 to scale up child and maternal health interventions and achieve progress on the health MDGs in nine African countries and two in Asia. ${ }^{9}$ This includes a $\$ 105$ million dollar pledge by Prime Minister Harper to train 40,000 CHWs between 20072012 in seven African countries and a commitment by USAID to train 100,000 CHWs by 2013 in maternal and child health interventions. ${ }^{10}$ DFID too, seems on board with the CHW movement - supporting a ten-fold increase in community health workers in Ethiopia between 2004 and 2008. ${ }^{11}$ While the current focus is dedicated to maternal and child health, CHW programs are equally applicable for assisting with home-based monitoring of HIV/AIDS antiretroviral and tuberculosis treatment regimes, treatment of trachoma, and many other functions depending on the specific needs and priorities of countries and communities.

Despite the current popularity and enthusiasm for CHWs, CHWs are not a new concept. Following the 1978 Alma Ata Declaration of Health for All by 2000, CHW programs were hailed as a promising strategy for addressing the social determinants of health and improving equity and access, given the health worker shortages and scarce

\footnotetext{
9 "The Catalytic Initiative to Save a Million Lives," in Canadian International Development Agency (CIDA) [database online]. Sept. 9, 2009Available from http://www.acdi-cida.gc.ca/acdi-cida/acdicida.nsf/eng/NAD-1249841-JLG.

${ }^{10}$ Lauren Crigler and Kathleen Hill, Rapid Assessment of Community Health Worker Programs in USAID Priority MCH Countries: Draft Tool for Field Testing, Anonymous United States Agency for International Development, September 2009), http://www.hciproject.org/node/1224.

11 "Africa Day 2009: A snapshot of progress towards meeting the Millennium Development Goals," in U.K. Department for International Development (DFID) [database online]. Available from http:/www.dfid.gov.uk/Media-Room/News-Stories/2009/Africa-Day-2009/.
} 
financing available - a mirror of today's rationale. The effectiveness of early CHW programs implemented in the 1980 s, however, was decidedly mixed. ${ }^{12}$ Top-down management and lack of community support, difficulties delivering and generating community demand for health education and preventative services, weak supervisory and health systems support, and unsuccessful community financing contributed to the failure of many CHW programs. Many countries also had difficulty replicating the success of small programs on a national scale. ${ }^{13}$

Despite the current push to rapidly implement large-scale CHW programs and the considerable sums of money earmarked for this purpose, the determinants that enhance or encumber program effectiveness are not clearly understood. I therefore conducted a literature review to explore the evidence for $\mathrm{CHW}$ effectiveness and identify the enabling factors that contribute to program success. Retention and motivation of CHWs emerged as critical determinants of effectiveness. Attrition rates for CHWs have been reported as high as $77 \%$ in the literature. ${ }^{14}$ Rapid turn-over creates disruptions and discontinuity in service delivery which ultimately hampers program impact. Conversely, $\mathrm{CHWs}$ who are able to consolidate their skills over time and build relationships with the community are also more likely to be effective. ${ }^{15}$

Retaining CHWs, however is not enough - individuals must be motivated to carry out their responsibilities if they are to be effective. On the whole, volunteerism is poorly understood in developing countries. The literature on volunteerism has primarily been

\footnotetext{
${ }^{12}$ Abbatt, Scaling Up Health and Education Workers: Community Health Workers Literature Review, 4.

${ }^{13}$ Karabi Bhattacharyya et al., Community Health Worker Incentives and Disincentives: How They Affect Motivation, Retention, and Sustainability, Basic Support for Institutionalizing Child Survival Project (BASICS II) published for the United States Agency for International Development, Oct. 2001, 4.

${ }^{14}$ ibid., 2.

${ }^{15} \mathrm{~S}$. Shrestha, "A conceptual model for empowerment of the female community health volunteers in Nepal," Education for Health 16, no. 3 (2003): 323.
} 
conducted in industrialized countries where volunteers donate their time from a secure financial base. ${ }^{16}$ In developing countries where poor people, especially women are already considered 'over-burdened' by their daily home and family responsibilities, their motivations for working voluntarily are less clear.

Today's programs, however, must not only be effective, but cost-effective and efficient. Understanding how programs can be designed to retain CHWs with nominal or no remuneration is particularly important for the most cash-strapped countries that simply do not have the resources to fully compensate CHWs for their services. Given the fact that the selection and training of CHWs represents a considerable financial, time, and human resource investment, rapid turn-over of $\mathrm{CHWs}$ is a serious consideration for policy makers as they grapple to allocate scarce resources efficiently and endeavor to build sustainable systems of service delivery.

The literature suggests that there are a number of key elements that are associated with retention and motivation, particularly community recruitment of $\mathrm{CHWs}$, selection criteria, training, supervision, compensation, and community support. While there is growing understanding of how $\mathrm{CHW}$ programs can be better supported to improve retention and motivation, there are still numerous knowledge gaps. While the theoretical benefits of community participation in recruitment of CHWs is strongly encouraged in the literature based on the presumed benefits of enhanced community ownership and empowerment, little is known about how CHWs perceive community selection as important to their work and motivation. Although some reviews suggest that communities are best placed to select CHWs that are more likely to remain on the job, few studies investigate how personal attributes and characteristics affect CHW retention.

\footnotetext{
${ }^{16}$ Gill Walt, "CHWs: Are National Programmes in Crisis?" Health Policy and Planning 3, no. 1 (1988): 3.
} 
The importance of refresher training has often been cited, but few studies identify why CHWs are so strongly motivated by opportunities for ongoing education. In a similar vein, the role of adequate supervision is well documented, but auxiliary support systems remain scantily investigated. And lastly, given that lack of compensation has frequently been cited as a reason for low retention, how do we explain motivation in primarily volunteer programs with high retention and what lessons might this hold for programs as they attempt to keep costs down while improving retention?

Despite the donor focus on CHWs in sub-Saharan Africa, I found comparatively fewer studies on this topic in Africa relative to the number of studies emerging from Asia. This paper helps fill the knowledge gap by presenting results from a case study conducted in Uganda. The Healthy Child Uganda (HCU) project was selected as the location of the case study based on the program's high retention rate - $94 \%$ over 5 years despite the essentially voluntary role of the CHWs. Although the choice of the $\mathrm{HCU}$ project based on the dependent variable, high retention, limits the generalizability of the findings, the purposeful selection of $\mathrm{HCU}$, is nevertheless pertinent for elucidating a fuller understanding of the factors that influence retention and motivation given the gaps in the literature.

The findings of the study supported the research from the literature review and provided further details on how community participation in recruitment, selection criteria, training, supervision, compensation, and community support affect motivation and retention of project CHWs. According to project $\mathrm{CHWs}$, community participation in recruitment helps locate individuals who are well-suited, willing to perform the role of CHW, and supported by their communities, thus influencing retention and motivation. 
Developing specific selection criteria to guide community selection may help enhance $\mathrm{CHW}$ retention and effectiveness. Project $\mathrm{CHWs}$ were highly motivated by opportunities to gain health-related knowledge and skills, reinforcing previous findings in the literature that training can be one of the most effective ways of improving retention and motivation. In contrast to much of the literature, project CHWs were highly motivated by community adoption of preventative behaviours that improve health. Project CHWs also emphasized the importance of peer support mechanisms, suggesting that these mechanisms can play an auxiliary support role to that provided by supervisors. Although the CHWs surveyed ranked compensation as the weakest motivator, they perceive lack of compensation as a key reason contributing to the resignation of the six percent of project CHWs who have dropped out. Thus, finding a balance between compensation and other forms of motivation appears important for retention and motivation.

This study has also highlighted new areas for future research. This research, along with most other studies, underscored the importance of community participation during the recruitment phase. New operational research could consider exploring how communities can participate in evaluation and how that participation affects motivation, retention, and effectiveness. This study produced new findings on selection criteria - an area of research that has received little attention. The positive association between the CHW's marital status, education, and gender on their retention, motivation, and effectiveness suggests that future research into this area would be worthwhile. Of particular note, the results suggest that balanced representation between male and female CHWs - a strategy not previously identified in the literature - may improve effectiveness, and thus, warrants further research. More research investigating what 
length and frequency of training is required to retain skills and motivation, and innovative ways to demonstrate community support would also help improve program design and implementation.

Given the shaky, inconsistent performance of early CHW programmes and ongoing challenges of low retention and motivation, improving program design to better support and ultimately retain CHWs will be important for achieving more consistent results, cost-effectiveness, and reducing the number of failed investments. Improved CHW effectiveness could help accelerate progress on the health MDGs and contribute to stronger, more equitable health systems. 


\subsection{Structure:}

This paper will be organized into eight chapters. Chapter 1 introduces the purpose of the research and the methods used to conduct the case study. The following four chapters analyze the literature on CHWs. Chapter 2 outlines the historical role of CHWs in providing primary health care. The chapter demonstrates how the empowerment and utilitarian models have shaped and influenced the role of CHWs and have contributed to new paradigms that build on the strengths of both models. Chapter 3 then situates the role of CHWs within the context of health systems. It examines international trends in supporting vertical and horizontal health programming, components of a health system, and how CHWs support and are supported by health systems.

Chapter four and five complete the literature review by analyzing the effectiveness of CHWs. Chapter 4 provides evidence of CHW impact on increasing utilization of health services, promoting healthy behaviours and improving health outcomes while realistically presenting the difficulties in measuring effectiveness.

Chapter 5 focuses on the determinants of retention, motivation, and effectiveness. It analyzes the strengths and limitations of using each of the six elements (community participation in recruitment, selection criteria, training, supervision, compensation, and community support) to improve retention, motivation, and effectiveness and identifies knowledge gaps in each area.

The succeeding two chapters discuss the results of the case study conducted with the Healthy Child Uganda (HCU) project, testing the nine hypotheses and examining the two exploratory questions. Chapter 6 provides background on HCU and analyzes how 
the first two factors - community participation in recruitment and selection criteria influence retention, motivation, and effectiveness. Chapter 7 examines how and to what extent the remaining four factors - training, supervision, compensation, and community support - influence retention, motivation, and effectiveness.

In conclusion, Chapter 8 summarizes the findings of the literature review and case study, highlights areas for further research, and outlines the relevance of the results for policy makers working in the field of health and international development. A series of Appendices (sampling methods, participant consent forms, and an example of a matrix ranking question) are provided at the end. 


\section{Thesis Methods}

\subsection{Research Questions}

Noting the increased global investments in $\mathrm{CHW}$ programs in the face of a historically mixed record of success, my literature review examined three questions:

- How were CHWs used in the past and what lessons have been generated from early program experience?

- What role do CHWs play within the context of health systems?

- How can CHW programs be made more effective?

\subsection{Literature Review}

The literature review ${ }^{17}$ highlighted several key paradigm shifts which have taken place since the emergence of $\mathrm{CHW}$ programs in the late $1970 \mathrm{~s}$ and that are helping to create a stronger, more realistic framework in which to situate CHWs. CHWs are no longer viewed as agents for community empowerment, but bridges between the health system and communities. As such, efforts are being made to better anchor and support CHWs within health systems.

${ }^{17}$ The literature review was conducted using the databases Pub Med (including Medline) and Scopus, as well as several prominent health journals including the Lancet, British Medical Journal, Social Science and Medicine and Oxford Journals using combinations of the terms: village health volunteer, village health worker, community health volunteer, community health worker, community participation, health promotion, and primary health care. A complementary search using Google Scholar helped locate some additional peer-reviewed publications and grey literature. Additional literature on community participation in development was chosen based on referrals by Prof. Cristina Rojas from the Norman Paterson School of International Affairs (NPSIA) and a complementary search of books on "community participation" available at the Carleton University library. WHO publications and the textbook, Getting Health Reform Right by Marc Roberts et al., referred by Prof. Valerie Percival from NPSIA, were used to provide an overview of health systems. 
While there is strong evidence that CHWs can have an impact on improving service coverage, healthy behaviours, and health outcomes, perennial problems of low retention and motivation continue to plague $\mathrm{CHW}$ effectiveness. The literature suggests that retention and motivation are influenced by community participation in recruitment, selection criteria, training, supervision, compensation, and community support.

\subsection{Research Hypotheses}

Based on the six key elements associated with low motivation and retention that were identified in the literature, nine hypotheses and two exploratory questions emerged from the literature. A case study was therefore conducted to test how and to what extent each of these elements influences retention and motivation.

\begin{tabular}{|c|c|}
\hline OTHESES & 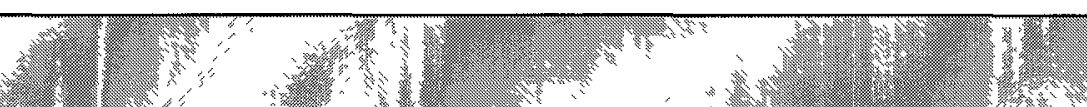 \\
\hline Recruitment & $\begin{array}{l}\text { 1. Community participation in recruitment is important to } \\
\text { motivation and retention because it generates community } \\
\text { support for the work of the CHW and reduces selection } \\
\text { bias. }\end{array}$ \\
\hline Selection Criteria & $\begin{array}{l}\text { 2. Marital status affects retention and effectiveness because } \\
\text { unmarried individuals are more likely to leave the } \\
\text { community. } \\
\text { 3. Gender affects CHW effectiveness because women are } \\
\text { more comfortable approaching female CHWs. } \\
\text { 4. Age and education do not influence effectiveness. }\end{array}$ \\
\hline Training & $\begin{array}{l}\text { 5. Training contributes strongly to motivation, retention, and } \\
\text { effectiveness because it gives CHWs confidence in their } \\
\text { skills. } \\
\text { 6. CHWs are not motivated to deliver preventative and } \\
\text { promotive health activities because of low community } \\
\text { demand. }\end{array}$ \\
\hline Supervision & $\begin{array}{l}\text { 7. Peer interactions between CHWs contribute to the } \\
\text { retention and motivation of CHWs. }\end{array}$ \\
\hline Compensation & $\begin{array}{l}\text { 8. CHWs are more strongly motivated by compensation than } \\
\text { an ethos of community service. }\end{array}$ \\
\hline
\end{tabular}




\begin{tabular}{|c|c|}
\hline $\begin{array}{l}\text { Community } \\
\text { Support }\end{array}$ & $\begin{array}{l}\text { 9. Community participation in recruitment, community } \\
\text { appreciation for services, and community respect for } \\
\text { CHWs are forms of community support that contribute to } \\
\text { CHW retention and motivation. }\end{array}$ \\
\hline $\begin{array}{l}\text { EXPLOR } \\
\text { QULSTI }\end{array}$ & \\
\hline Recruitment & $\begin{array}{l}\text { 1. Do CHWs feel that community participation in recruitment } \\
\text { contributes to their motivation and continued service? }\end{array}$ \\
\hline Selection Criteria & $\begin{array}{l}\text { 2. What personal characteristics and attributes do CHWs } \\
\text { associate with effectiveness and long-term service? }\end{array}$ \\
\hline
\end{tabular}

\subsection{Rationale for Selection of Case Study}

I carried out field research in Healthy Child Uganda project areas in southwestern Uganda (from September to December 2008) to confirm or disprove the hypotheses mentioned above. $\mathrm{HCU}$ is a research pilot project conceived and administered by the Department of Community Health and the Department of Medicine at the Mbarara University of Science and Technology (MUST) in partnership with Canadian institutions. As such, the purpose of the project is to generate lessons learned for CHW programs in Uganda and elsewhere in sub-Saharan Africa. The choice is also relevant given the current donor focus on Africa and the Ugandan government's support for scaling up child health CHW programs as part of community village health teams. This case study contributes to the body of literature on sub-Saharan African experiences with CHWs in light of the comparatively limited number of studies originating from Africa relative to Asia.

\subsection{Study Design}

In consultation with the $\mathrm{HCU}$ project team, I developed questionnaires and interview guides for three categories of respondents: currently-serving CHWs, resigned 
CHWs, and key informants. I then assembled a team of three local researchers to help administer the questionnaires in the local language. The research assistants administered a questionnaire comprised of qualitative and quantitative questions to twenty-five percent of all CHWs in each project area (locally referred to as a parish). Qualitative questions were combined with the more quantitative ones in order to determine why CHWs associated certain variables with retention, motivation, and effectiveness. ${ }^{18} \mathrm{CHWs}$ were randomly selected.

After reviewing the first 46 questionnaires, I noted that few new themes were emerging in the responses. Consequently, the HCU project team and I decided that for the remainder of the field visits, we would administer a shortened questionnaire comprised of entirely open-ended, qualitative questions in order to elicit more nuanced answers and help respond to some questions that emerged during the preliminary review.

In addition to interviews with the 46 currently-serving $\mathrm{CHWs}$, the research team was scheduled to interview fourteen CHWs who had resigned for reasons other than death, sickness, divorce and/or changed residence. The research team administered an abbreviated version of the questionnaire for currently-serving $\mathrm{CHWs}$. Due to time and travel constraints and difficulties locating resigned CHWs, only 7 such interviews were conducted.

Local council representatives and senior $\mathrm{CHW}$ trainers formed part of the third category of respondents. These two groups were identified as key informants who could provide complementary perspectives and additional information to that provided by the CHWs. I randomly selected nine local council chairpersons across project districts and

\footnotetext{
${ }^{18}$ Priscilla Ulin, Elizabeth Robinson, and Elizabeth Tolley, Qualitative Methods in Public Health: A Field Guide for Applied Research, (San Francisco: Jossey-Bass, 2005), 335.
} 
developed a brief questionnaire which was administered by the research assistants. In order to gain additional insight, I interviewed two CHW trainers with at least three years of experience who were purposively selected based on project management referral. ${ }^{19}$ Appendix II provides a detailed explanation of sampling methods, participant recruitment and compensation, language considerations, and ethics approval.

\subsection{Analysis}

I entered all responses into Excel spreadsheets and used deductive coding ${ }^{20}$ to calculate the frequency of answers chosen in closed-ended, multiple-choice questions. I then grouped open-ended answers thematically and multiple-coded the responses by hand using Excel spreadsheets to organize responses.

\subsection{Strengths and Limitations of Study Design}

I was asked to undertake this study as part of my internship with the HCU project. This research was conducted over the course of my internship from September to December 2008. As a pilot research project managed by the Mbarara University of Science and Technology in Uganda, the HCU project was interested in learning what factors were contributing to the high retention rates documented by the project despite the incredibly minimal payment CHWs receive. The purposeful selection of the case study based on the dependent variable of high retention is helpful in identifying new

\footnotetext{
${ }^{19}$ Priscilla Ulin, Elizabeth Robinson, and Elizabeth Tolley, Qualitative Methods in Public Health: A Field Guide for Applied Research, (San Francisco: Jossey-Bass, 2005), 338.

${ }^{20}$ Ann Bowling, Research Methods in Health: Investigating Health and Health Services, (Philadelphia: Open University Press, 2000), 296.
} 
variables. ${ }^{21}$ In light of the considerable knowledge gaps on the topic of motivation, retention, and effectiveness - particularly concerning the influence of various selection criteria such as the CHW's gender, level of education, and parental status - this case study is useful in generating new hypotheses in these areas. Although the purposeful selection of the case study reduces the generalizability of the study, results from this study can be tested in future studies "in which there is variation on the dependent variable."22

As well as helping to generate new hypotheses, case studies are equally useful in confirming hypotheses. ${ }^{23}$ Thus, a case study provides a good way to test how the variables identified in the literature - community participation in recruitment, selection criteria, training, supervision, compensation, and community support - influence retention, motivation, and effectiveness. Although the sample size is fairly small, the open-ended questions provide rich qualitative data that help explain not only which factors are important to motivation, retention, and effectiveness, but why CHWs are motivated by those factors. ${ }^{24}$

While this study can help identify the 'contributing' factors, it cannot demonstrate which factors are absolutely 'necessary' requisites for high motivation, retention, and effectiveness. ${ }^{25}$ Furthermore, as the conditions which produce high motivation, retention, and effectiveness in a rural setting may differ from those in urban settings, this study may be less applicable to urban CHW programs.

\footnotetext{
${ }^{21}$ Alexandre George and Andrew Bennett, Case Studies and Theory Development in the Social Sciences, (Massachusetts: MIT Press, 2005), 23.

${ }^{22}$ Ibid., 23.

${ }^{23}$ Tbid., 19.

${ }^{24}$ Priscilla Ulin, Elizabeth Robinson, and Elizabeth Tolley, Qualitative Methods in Public Health: A Field Guide for Applied Research, (San Francisco: Jossey-Bass, 2005), 335.

${ }^{25}$ George and Bennett, Case Studies and Theory Development in the Social Sciences, 26.
} 


\subsection{Working Definitions ${ }^{26}$}

Effectiveness will be assessed in terms of increased utilization of health services, adoption of health-seeking behaviours, and ultimate impact on child morbidity and mortality. Retention is defined as the "length of time that an individual CHW actively performs appropriate community primary health care tasks. ${ }^{27}$ Motivation refers to the "desire to serve and perform effectively as a CHW."28

\subsection{Scope}

Although many other elements such as financing, management capacity, and procurement and delivery of equipment and medicine are essential to program effectiveness, the focus of this paper will solely concentrate on the influence of retention and motivation.

\footnotetext{
${ }^{26}$ The definitions for motivation and retention used in this paper were extracted from the paper "Community Health Worker Incentives and Disincentives: How They Affect Motivation, Retention, and Sustainability" published for the United States Agency for International Development by the project, Basic Support for Institutionalizing Child Survival (BASICS II).

${ }^{27}$ Bhattacharyya et al., Community Health Worker Incentives and Disincentives: How They Affect Motivation, Retention, and Sustainability, 3.

${ }^{28}$ ibid., 3
} 


\section{CHAPTER 2: THE ROLE OF COMMUNITY HEALTH WORKERS IN PROVIDING PRIMARY HEALTH CARE}

In the last few years, enthusiasm for community health workers (CHWs) has gained momentum as a practical strategy to scale-up basic interventions, rapidly improve health outcomes, and improve progress towards the MDGs. CHWs are being looked to with great expectation - to help achieve 'quick wins' by 2015.' Major donors such as USAID, CIDA and DFID are all supporting large-scale CHW programs. The concept of CHWs, however, is not a new one. In the late 1970s, CHWs were proposed as the main vehicle to achieve the grandiose goal of Health for All by 2000 . The high expectations placed on CHWs, however, were not always realized. As one global health goal has faded out and another faded in, a realistic appraisal of CHWs is necessary to help avoid the pitfalls of over-expectation encountered during the first $\mathrm{CHW}$ movement.

This first chapter of the literature review outlines the historical development of primary health care $(\mathrm{PHC})$ and the role of $\mathrm{CHW}$ in delivering $\mathrm{PHC}$ services. It then demonstrates how the empowerment and utilitarian frameworks influenced the way in which programs engaged CHWs. Criticisms of the empowerment and utilitarian frameworks - token community engagement, over-emphasis on health promotion and prevention, lack of supervisory support, failures of community financing, and weak $\mathrm{CHW}$ relationships with the community - provide early evidence that community participation in recruitment, training, supervision, compensation, and community support contribute to motivation, retention, and effectiveness.

\footnotetext{
${ }^{1}$ Fred Abbatt, Scaling Up Health and Education Workers: Community Health Workers - A Literature Review, UK Department for International Development (DFID), March 2005); 12.
} 
The weaknesses identified in these early frameworks have also led to modifications in thinking, which in turn, have supported renewed interest in CHWs despite their early failures. These changes have influenced mainstream views on the roles CHWs are expected to fulfill and the supportive environment in which CHWs need to be placed. CHWs are no longer viewed as community change agents for empowerment, but as bridges to the health system that require the support of that health system. This chapter serves as a foundation for subsequent chapters analyzing the role of CHWs within the context of a health system and the supporting elements that contribute to motivation, retention, and effectiveness.

\section{The Primary Health Care Movement}

The concepts of primary health care and community health workers gained ascendancy in the late 1970s as part of a wider shift in development philosophy that sought to address the socio-economic barriers to development and empower peripheral communities that had been bypassed by urban-biased development. ${ }^{2}$ Emulating the Western system of medical specialization and hospital care, the average developing country during the 1970 s devoted $65-70 \%$ of its health budget to urban hospitals, ${ }^{3}$ leaving the majority of the rural population without access to primary health care. On average, "professional health services cover only $15-30 \%$ of the population" in developing countries. $^{4}$

\footnotetext{
${ }^{2}$ M. I. Roemer, "Priority for primary health care: its development and problems." Health policy and planning 1, no. 1 (1986): 58.

${ }^{3}$ ibid. 60.

${ }^{4}$ R. Sauerborn, A. Nougtara, and H. J. Diesfeld, "Low utilization of community health workers: Results from a household interview survey in Burkina Faso," Social Science and Medicine 29, no. 10 (1989): 1136.
} 
The primary health care (PHC) movement sought to reverse this trend by providing an alternative strategy to provide universal coverage of basic health services. It brought the democratic principles of empowerment, health promotion and collective action to the fore. ${ }^{5}$ This revolutionary approach was formally launched as a mainstage movement by the World Health Organization (WHO) and the United Nations Children's Fund (UNICEF) in 1978 at the Alma Ata conference in Kazakhstan where WHO member states pledged to achieve "Health for All by 2000 " through PHC. ${ }^{6}$ The Alma-Ata declaration defines $\mathrm{PHC}$ as:

"essential health care based on practical, scientifically sound, and socially acceptable methods and technology made universally accessible to individuals and families in the community through their full participation and at a cost that the community and country can afford to maintain at every stage of their development in the spirit of self-reliance and selfdetermination. It forms an integral part both of the country's health system, of which it is the central function and main focus, and of the overall social and economic development of the community. It is the first level of contact of individuals, the family, and community with the national health system, bringing health care as close as possible to where people live and work, and constitutes the first element of a continuing health-care process."7

The PHC movement emphasized a multi-sectoral approach that considered the interrelationship of environmental, economic, and social factors on the health of groups, communities, and populations. ${ }^{8}$ PHC was viewed through a public health lens - a social and political paradigm that focused on improving the health of whole populations through health promotion, disease prevention and other forms of health intervention. ${ }^{9}$ Vocal

\footnotetext{
${ }^{5}$ David Zakus and Catherine Lysack, "Revisiting Community Participation," Health Policy and Planning 13, no. 1 (1988): 1-13.

${ }^{6}$ Roemer, Priority for primary health care: its development and problems., 58.

${ }^{7}$ Declaration of Alma-Ata International Conference on Primary Health Care, Alma-Ata, USSR, September 1978), http://www.who.int/hpr/NPH/docs/declaration almaata.pdf.

${ }^{8}$ R. Jewkes and A. Murcott, "Community representatives: Representing the 'community'?" Social Science and Medicine 46, no. 7 (1998): 845.

${ }^{9}$ World Health Organization, Health Promotion Glossary, Anonymous, 1998), 3.
} 
policy-setter and WHO head, Halfdan Mahler (1973-88), argued that 'Health for All' "implies the removal of the obstacles to health - that is to say, the elimination of malnutrition, ignorance, contaminated drinking water and unhygienic housing - quite as much as it does the solution of purely medical problems." ${ }^{10}$ During this period it was increasingly recognized that poor health was a symptom of a wider range of impediments than simply lack of access to the formal health care system; ${ }^{11}$ improving health for the poor required addressing the root causes of health inequity and underdevelopment.

\section{The Role of CHWs}

Alternative strategies were needed to address the range of cultural, social, economic, political and environmental factors - today known as the social determinants of health $^{12}$ - that influence health. The primary health care movement sought not only to improve health, but to empower communities to chart their own path towards development. CHWs were perceived as an untapped, cost-effective resource who could serve as health extension workers to bring doorstep services to their communities, improving coverage and equity, and catalyze community development. CHWs represented a group of workers who could be recruited from and work directly with the poorest communities to serve this purpose.

The term 'CHW' has been used to encapsulate a wide range of actors. Generally speaking, CHWs are individuals who are selected by the communities where they reside

\footnotetext{
${ }^{10}$ Melitta Jakab and Chitra Krishnan, Community Involvement in Health Care Financing: A Survey of the Literature on the Impacts, Strengths, and Weaknesses, Anonymous Health, Nutrition, and Population Family (HNP), World Bank, September 2001).

${ }^{11}$ M. Carpenter, "Health for some: Global health and social development since Alma Ata," Community Development Journal 35, no. 4 (2000): 328.

${ }^{12}$ Although the term 'social determinants of health' did not come into common usage until the $1990 \mathrm{~s}, \mathrm{I}$ apply the term throughout this chapter as a concise way to refer to the environmental, economic, and social influences on health that the primary health care movement sought to address.
} 
to receive condensed, simplified training on a range of health topics. ${ }^{13}$ CHWs typically deliver preventative and curative health services on a part-time, voluntary basis or receive only nominal remuneration. ${ }^{14}$ Although $\mathrm{CHW}$ s may be financially and/or technically supported by the health system, they are generally not considered formal employees of the Ministry of Health. ${ }^{15}$ They also differ from conventional health professionals as they generally have only low levels of education, in some cases, none at all, ${ }^{16}$ and therefore, have few opportunities for promotion. ${ }^{17}$

In accordance with the multi-sectoral approach to PHC envisioned at Alma Ata, CHWs were used to provide a wide range of curative and preventative health services.

Responsibilities typically encompassed one or more of the following tasks:

"home visits, environmental sanitation, provision of water supply, first aid and treatment of simple and common ailments, health education, nutrition and surveillance, maternal and child health and family planning activities, communicable disease control, community development activities, referrals, recordkeeping, and collection of data on vital events." 18

\subsection{CHWs as Curative Service Providers}

CHWs have been trained as distributors of health commodities and in the diagnosis and treatment of a wide range of diseases. In West Africa, CHWs are trained to

\footnotetext{
${ }^{13}$ David Sanders Uta Lehmann, "Community health workers: What do we know about them? The state of the evidence on programmes, activities, costs and impact on health outcomes of using community health workers," (January 2007)

${ }^{14}$ A. Haines et al., "Achieving child survival goals: potential contribution of community health workers," Lancet 369, no. 9579 (2007): 2121-2131. (L12 2007 p2122).

${ }^{15}$ Karabi Bhattacharyya et al., Community Health Worker Incentives and Disincentives: How They Affect Motivation, Retention, and Sustainability, Anonymous Basic Support for Institutionalizing Child Survival Project (BASICS II) published for the United States Agency for International Development, Oct. 2001) (ZI Basics pl).

${ }^{16}$ Abbatt, Scaling Up Health and Education Workers: Community Health Workers - A Literature Review, 5.

${ }^{17}$ Lucy Gilson et al., "National Community Health Worker Programs: How Can They Be Strengthened?" Journal of public health policy 10, no. 4 (1989): 518-532., p589.

${ }^{18}$ Bhattacharyya et al., Community Health Worker Incentives and Disincentives: How They Affect Motivation, Retention, and Sustainability, (Z1 2001 BASICS P11).
} 
distribute ivermectin for river blindness and assist in prevention and surveillance of the disease. ${ }^{19}$ Indonesian CHWs have focused on supplying condoms and increasing demand for family planning. ${ }^{20}$ Among several high impact child health interventions, UNICEF and WHO emphasized distribution of oral rehydration salt (ORS) packets for children with acute diarrhea.

In other programs, CHWs have delivered direct short course therapy (DOTS) for tuberculosis, provided mebendazole for intestinal worms, treated scabies, and provided first aid for minor injuries, among many other roles. In some countries like Botswana, CHWs directly support clinical staff by working in health facilities. ${ }^{21}$

New roles for $\mathrm{CHWs}$ as curative service providers continue to emerge. Since 1997, WHO and UNICEF have supported community treatment of pneumonia, diarrhea, malaria, measles, and malnutrition - the five leading causes of childhood death. ${ }^{22}$ Looking towards the MDGs, $\mathrm{CHWs}$ are increasingly being trained to diagnose and treat pneumonia and malaria. In Nepal, nearly $70 \%$ of Nepalese children are covered by CHWs trained in the treatment of pneumonia. ${ }^{23}$ A large project in Africa covering over two million people across Nigeria, Cameroon and Uganda recently piloted communitybased treatment of malaria and TB using CHWs, as well as using CHWs to distribute

\footnotetext{
${ }^{19}$ Special Programme for Research \& Training in Tropical Diseases (TDR), Community-directed interventions for major health problems in Africa: A multi-country study Final Report, 12.

${ }^{20} \mathrm{~J}$. Shiffman, "The construction of community participation: Village family planning groups and the Indonesian state," Social Science and Medicine 54, no. 8 (2002): 1199-1214., 1208.

${ }^{21}$ Gilson et al., National Community Health Worker Programs: How Can They Be Strengthened?, 519.

${ }^{22}$ "WHO/UNICEF strategy of Integrated Management of Childhood Illness (IMCI)," Available from http://www.icatt-training.org/IMCI/AboutIMCI/tabid/84/Default.aspx.

${ }^{23}$ P. Dawson et al., "From research to national expansion: 20 Years' experience of community-based management of childhood pneumonia in Nepal," Bulletin of the World Health Organization 86, no. 5 (2008): 339.
} 
malaria bed nets. ${ }^{24}$ Use of CHWs to provide treatment and care for individuals with HIV/AIDS represents one of the fastest growing areas of responsibility. ${ }^{25}$ Other new areas of responsibility include the detection of trachoma and administration of injectable birth control, depo provera. ${ }^{26}$

Merely recruiting CHWs to provide specific health services, however, does not necessarily translate into improved outcomes. Because of lack of support, low compensation, the long distances CHWs were required to travel and other factors that contributed to poor morale, many CHWs simply stopped working after they had distributed the first shipment of health commodities and medicines. ${ }^{27}$

\subsection{CHWs as Health Promoters}

While CHWs often carried out curative services, they were equally expected to function as health promoters. Global leaders on the PHC policy front, such as the head of WHO, Halfdan Mahler, propounded that the removal of ignorance, malnutrition, and unhygienic living conditions were as important as increasing access to medical treatment. ${ }^{28}$ Academics like Milton Roemer supported this view, contending that "the

\footnotetext{
${ }^{24}$ Special Programme for Research \& Training in Tropical Diseases (TDR), Community-directed interventions for major health problems in Africa: A multi-country study Final Report, 6.

${ }^{25}$ Uta Lehmann and David Sanders, Community health workers: What do we know about them? The state of the evidence on programmes, activities, costs and impact on health outcomes of using community health workers, Anonymous, January 2007), www.who.int/hrh/documents/community health_workers brief.pdf, 13 .

${ }^{26}$ John Stanback, Anthony Mbonyeb, and Martha Bekiitac, "Contraceptive injections by community health workers in Uganda: a nonrandomized community trial," Bulletin of the World Health Organization 85, no. 10 (2007).

${ }^{27}$ F. Curtale et al., "Improving skills and utilization of community health volunteers in Nepal," Social Science and Medicine 40, no. 8 (1995): 1119.

${ }^{28}$ Jakab and Krishnan, Community Involvement in Health Care Financing: A Survey of the Literature on the Impacts, Strengths, and Weaknesses, 181.
} 
entire primary health care concept, especially in developing countries, rests on the proven accomplishments of a strategy of prevention." 29

Health promotion was first defined in the 1986 Ottawa Charter as "the process of enabling people to increase control over and improve their health." ${ }^{30}$ Health promotion

"represents a comprehensive social and political process; it not only embraces actions directed at strengthening the skills and capabilities of individuals, but also action directed towards changing social, environmental and economic conditions so as to alleviate their impact on public and individual health. Health promotion is the process of enabling people to increase control over the determinants of health and thereby improve their health. Participation is essential to sustain health promotion action." 31

By promoting awareness of the behaviours that affect health, $\mathrm{CHWs}$ were expected to empower individuals to gain control over their own health and in doing so lower morbidity and mortality from common diseases. Health promotion formed an integral component of PHC that sought to address the social determinants of health head-on.

Recognizing that "people tend to view disease from the perspective of their culture" it was assumed that CHWs - local individuals with intimate understanding of community practices - would be effective peer communicators. ${ }^{32}$ Behaviours related to health emerge from complex social networks. A study in Gambia, for example, found "attempts to change the breastfeeding habits of mothers need to take into account the attitudes and influence of husbands and elders, and especially the mothers of those

\footnotetext{
${ }^{29}$ M. I. Roemer, "Priority for primary health care: its development and problems." Health policy and planning 1, no. 1 (1986): 64.

${ }^{30}$ G. S. Guldan, "Obstacles to community health promotion," Social Science and Medicine 43, no. 5 (1996): 688.

${ }^{31}$ World Health Organization, Health Promotion Glossary, 1998,1.

${ }^{32}$ J. G. Linn, "Community participation, cultural discourse, and health education projects in developing areas: The case of the radio communication project in Nepal," Health Education and Behavior 35, no. 4 (2008): 457.
} 
childbearing mothers. ${ }^{233}$ It was understood that strategies for health promotion had to "move beyond the attribution of individual responsibility for risky behaviours, to emphasize...the social determinants and roots both of individual habits and of collective values and behavior" that are rooted in structural conditions and social processes. ${ }^{34}$

On the whole, however, the conditions that produce health behaviour change were not (and continue to be not) fully understood.$^{35}$ Lacking this understanding, many programs tended to emphasize the provision of information alone and failed to "address other issues such as resources and social support, which are often the more salient behavioural antecedents. ${ }^{36}$ As a result, many CHWs struggled with health promotion. ${ }^{37}$ Lacking training in community health and participatory methods, many supervisors did not have the skills to support CHWs in this difficult task. ${ }^{38}$ From these past experiences, it has become clear that CHWs do not automatically excel as health promoters simply because they are recruited from poor communities.

While public health practitioners and advocates of comprehensive PHC valued health promotion activities as integral to lowering the burden of disease and promoting health and development, many communities did not display the same enthusiasm. ${ }^{39}$ According to academics such as Gill Walt, communities tend to demonstrate a preference for curative services over preventative ones, further complicating the health promotion

\footnotetext{
${ }^{33}$ Marc J. Roberts et al., Getting Health Reform Right: A Guide to Improving Performance and Equity, Oxford University Press USA, 288.

${ }^{34} \mathrm{R}$. Bodstein, "The complexity of the discussion on effectiveness and evidence in health promotion practices." Promotion \& education Suppl 1 (2007): 18.

${ }^{35}$ Guldan, Obstacles to community health promotion, 689-695.

${ }^{36}$ Haines et al., Achieving child survival goals: potential contribution of community health workers, 2123.

${ }^{37}$ World Health Forum, 1984;5(4):303.

${ }^{38}$ Guldan, Obstacles to community health promotion, 691.

${ }^{39}$ Curtale et al., Improving skills and utilization of community health volunteers in Nepal, 1118.
} 
role of the $\mathrm{CHW}^{40}$ Furthermore, health promotion often produces less quantifiable outcomes and requires more time to produce results. ${ }^{41}$ As a result of the difficulties encountered and slow impact, support for CHWs as health promoters has eroded over the years.

\section{The Role of CHWs in Stimulating Community Participation}

The empowerment framework and utilitarian framework produced two competing views on the role of CHWs in stimulating community participation in health, which in turn, has influenced their effectiveness. Community participation in health formed a key tenet of primary health care and CHWs were positioned as agents who could engender this participation.

The concept of community participation emerged in response to the shortcomings of top-down development approaches. ${ }^{42}$ Top-down approaches were criticized for being costly, poorly aligned with recipient priorities, and lacking ownership and sustainability. ${ }^{43}$ Community participation was seen as a bottom up approach and the means by which to achieve health for all. In the Alma-Ata Declaration, the World Health Organization (WHO) defined citizen participation as "the process by which individuals and families assume responsibility for their own health and welfare and for those of the community, and develop the capacity to contribute to their and the

\footnotetext{
${ }^{40}$ Gill Walt, "CHWs: Are National Programmes in Crisis?" Health Policy and Planning 3, no. 1 (1988): 11.

${ }^{41}$ Guldan, Obstacles to community health promotion, 691.

${ }^{42}$ Samuel Hickey and Giles Mohan eds., Participation: From Tyranny to Transformation? Exploring New Approaches to Participation in Development, Anonymous (New York: Palgrave Macmillan, 2004), 5.

${ }_{3}^{43}$ Nici Nelson and Susan Wright eds., Power and Participatory Development Theory and Practice, ed. Robert Chambers, Anonymous (London: Intermediate Technology Publications, 1995), 30.
} 
community's development." ${ }^{44}$ The 1986 Ottawa Charter declared "the community as an essential voice in the matters of health." In its fullest form, community participation endeavors communities to:

develop the capability to assume greater responsibility for assessing their health needs and problems; plan and then act to implement their solutions; create and maintain organizations in support of these efforts; and evaluate the effects and bring about necessary adjustments in goals and programs on an ongoing basis. ${ }^{46}$

The goal of community participation was to intimately involve and empower communities to contribute to their own health and well-being. CHWs were promoted as catalysts of community participation in health. Proponents of the empowerment and utilitarian models of community participation, however, held different conceptions about the purpose of community participation and role of CHWs in stimulating that participation.

\subsection{Empowerment Model}

The empowerment model viewed CHWs principally as community change agents - individuals who would function "as a community mouthpiece to fight against inequities and advocate community rights and needs to government structures. ${ }^{247}$ The empowerment frame was heavily influenced by the radical language and battles for democracy and equality being fought by African-Americans, feminists, liberation theologians in former colonies, and other social justice groups in developed and

\footnotetext{
${ }^{44} \mathrm{~N}$. Bracht and A. Tsouros, "Principles and strategies of effective community participation," Health promotion international 5, no. 3 (1990): 205.

${ }^{45}$ Jewkes and Murcott, Community representatives: Representing the 'community'?, 849.

${ }^{46}$ Zakus and Lysack, Revisiting Community Participation, 2.

${ }^{47}$ Lehmann and Sanders, Community health workers: What do we know about them? The state of the evidence on programmes, activities, costs and impact on health outcomes of using community health workers, www.who.inthrh/documents/community health workers brief.pdf., 5 .
} 
developing countries alike. The discourse of participatory development drew heavily on the works of Paulo Freire and liberation theologians, Gutierrez, Bonino, and Tamez.

Freire contended that alienation and isolation generate a state of dependency and domination by the established powers, and thus, called for processes that could lead to critical consciousness - "a critical reflection on reality, followed by action that carries an ideological option up to and including the transformation of one's own world, be it a community, a local condition, or something else." ${ }^{28}$ In a similar vein, Gutierrez, Bonino, and Tamez propounded that "the traditional work of charity and assistance to the poor that treats them as objects is not acceptable. The poor must be treated as subjects of their own transformation and participate actively in the formation and execution of development initiatives." ${ }^{\text {49 }}$ This discourse formed the basis of the empowerment model and was adopted by countries such as Tanzania and Zimbabwe as part of the decolonization and liberation movements. ${ }^{50}$

In the empowerment model, participation is a tool through which local communities take responsibility for diagnosing and solving their own health and development problems. ${ }^{51}$ Imparting communities with the skills to articulate and prioritize needs and implement strategies to address health problems could create a selfgenerating momentum for broader community development and eradication of poverty. CHWs would act as catalysts for this empowerment.

\footnotetext{
${ }^{48}$ Hubert Campfens ed., Community Development Around the World: Practice, Theory, Research, Training, Anonymous (Toronto: University of Toronto Press, 1997), 37.

49 ibid., 37.

${ }^{50}$ Lehmann and Sanders, Community health workers: What do we know about them? The state of the evidence on programmes, activities, costs and impact on health outcomes of using community health workers, www. who.int/hrh/documents/community health workers brief.pdf., 5 .

${ }^{51}$ S. B. Rifkin, "Paradigms Lost: Toward a new understanding of community participation in health programmes," Acta Tropica 61, no. 2 (1996): 83.
} 


\subsubsection{Weaknesses of the Empowerment Model}

In the empowerment model, CHWs were presented as moral, change agents working for their communities, but in reality communities and CHWs themselves considered their positions as part of the health system. ${ }^{52}$ Because many CHWs were being directed and often paid at least some form of honorarium, CHWs were often considered MoH or donor employees. ${ }^{54}$ Though CHWs were meant to promote empowerment and 'conscientization' through education, due to the difficulties previously discussed in providing health promotion, CHWs tended to focus on curative services, thus diminishing their role as empowerment agents. ${ }^{55}$ It has become apparent that CHWs are considered as extensions of the health system and not change agents. ${ }^{56}$

In some countries, community financing was adopted in order to engender community ownership for the CHWs in their villages. ${ }^{57}$ The 1987 Bamako Initiative promoted community financing as "a political process that involved changing the prevailing patterns of authority and power" by involving communities in the management and control of resources for local health services. Although many African countries implemented cost-recovery mechanisms, few were ever scaled-up. ${ }^{58}$ The expected $^{2}$ voluntary contributions often did not materialize. For example, in Burkina Faso, "only

\footnotetext{
${ }^{52}$ Walt, CHWs: Are National Programmes in Crisis?, 2.

${ }^{53}$ Gilson et al., National Community Health Worker Programs: How Can They Be Strengthened?, 519.

${ }^{54}$ H. Standing and A. M. R. Chowdhury, "Producing effective knowledge agents in a pluralistic environment: What future for community health workers?" Social Science and Medicine 66, no. 10 (2008): 2098.

${ }_{55}$ Rifkin, Paradigms Lost: Toward a new understanding of community participation in health programmes, 85.

${ }^{56}$ Walt, CHWs: Are National Programmes in Crisis?, 18.

${ }^{57}$ Jewkes and Murcott, Community representatives: Representing the 'community'?, 845.

${ }^{58}$ The under-five mortality rate: The indispensable gauge of child health, United Nations Children's Fund (UNICEF), 2008), http://www.unicef.org/sowc08/docs/sowc08 panels.pdf.
} 
$15.5 \%$ of CHWs were remunerated according to previous arrangements." 59 "Local communities and voluntary organizations generally assume that government ought to take responsibility for maintenance and staffing." ${ }^{60}$ CHWs largely failed to create selfgenerating, community processes to sustain health and development.

The goals of the empowerment model were too broad, unfocused, and lacked realistic mechanisms and resources to carry out systemic change. It was unrealistic to expect CHWs to lead their communities in prioritizing issues, develop plans to address those issues, and develop financial and management systems to carry out those functions. ${ }^{61}$ The type of community participation advocated in the empowerment model was too slow, undirected, and hard to measure. ${ }^{62}$

\subsection{Utilitarian Model}

In contrast to the empowerment model, those subscribing to the utilitarian model valued CHWs primarily for their role as health extension agents. Supporters of the utilitarian model promoted CHWs as a means to recruit local resources and offset the costs of providing community health services. ${ }^{63}$ CHWs offered a practical solution to the chronic and devastatingly huge health worker shortages and a means to do "rural

\footnotetext{
${ }^{59}$ Sauerborn, Nougtara, and Diesfeld, Low utilization of community health workers: Results from a household interview survey in Burkina Faso, 1170.

${ }^{60}$ Lenore Ralston, James Anderson, and Elizabeth Colson, Voluntary Efforts in Decentralized Management: Opportunities and Constraints in Rural Development, (Berkeley: Institute of International Studies, University of California, 1983), 42.

${ }_{61}^{6}$ John Hall and Richard Taylor, "Health for all beyond 2000: the demise of the Alma-Ata Declaration and primary health care in developing countries," Medical Journal of Australia 178 (2003): 18.

${ }^{62}$ J. E. Lawn et al., "Alma-Ata 30 years on: revolutionary, relevant, and time to revitalise," The Lancet 372 , no. 9642 (2008): 924.

${ }^{63}$ L. M. Morgan, "Community participation in health: Perpetual allure, persistent challenge," Health policy and planning 16, no. 3 (2001): 221.
} 
development on the cheap." ${ }^{, 64}$ Local individuals could be recruited and trained quickly and cheaply (in a matter of a few days or a few months) in various components of PHC. Recruited individuals would be expected to work voluntarily or with nominal remuneration from their communities, donors, or the government - substantially reducing the cost of training, recruiting, and employing nurses and other health officers to serve in poor, remote locations.

The utilitarian model also viewed CHWs as a means to increase the effectiveness of government and donor managed health interventions. Proponents of the utilitarian model propounded that as locally recruited health extension agents, CHWs would be effective at mobilizing community members to participate in various health interventions (for example, to attend immunization campaigns), disseminating information in a culturally sensitive way, gathering feedback about the programs and promoting local ownership. $^{6566}$

\subsubsection{Weaknesses of the Utilitarian Model}

While the expectations of the empowerment school were too idealistic, the application of community participation by proponents of the utilitarian model was often too superficial. In their effort to achieve greater impact at lower cost, those subscribing to the utilitarian model were criticized for perverting the intentions of community participation and comprehensive PHC by engaging CHWs and communities in a minimalistic way.

\footnotetext{
${ }^{64}$ Jewkes and Murcott, Community representatives: Representing the 'community'?, 845.

${ }^{65}$ Rifkin, Paradigms Lost: Toward a new understanding of community participation in health programmes, 79.

${ }^{66}$ Bracht and Tsouros, Principles and strategies of effective community participation, 204.
} 
Soon after Alma Ata, key policy-setters such as UNICEF and major donors began to shift away from broadly focused participatory approaches to target-driven campaigns managed by technical experts. UNICEF and the WHO advocated that progress could be accelerated by shifting efforts towards a selected number of targeted interventions based on epidemiological importance and technical affordability. ${ }^{67}$ This shift was based on the argument that high coverage of a few key, high-impact interventions such as growth monitoring, distribution of ORS packets, breastfeeding, and immunization (known as the GOBI strategy) would achieve greater impact in a shorter period of time. ${ }^{68} 69$

The top-down management of targeted interventions or 'selective PHC' was criticized for overshadowing the more complex mechanisms for promoting community participation. Rather than intimately involving communities in the planning, design and implementation of health programs, $\mathrm{CHWs}$ were engaged primarily for the purpose of 'convincing' or 'co-opting' community members to participate in initiatives such as immunization campaigns. $^{70}$ Health education also took a behaviouristic approach in line with the concept of selective primary health care, focusing on specific behaviours relating to specific target diseases prioritized by health professionals. ${ }^{71}$ In this environment of top-down management and lack of meaningful participation, compounded with poor

\footnotetext{
${ }^{67}$ Joyce Msuya, "Horizontal and Vertical Delivery of Health Services: What Are The Trade Offs?" World Bank (2004): $\underline{\mathrm{htp}}: / / \mathrm{www}-$ wds. worldbank.org/external/default/WDSContentServer/TW3P/IB/2003/10/15/000160016 2003101512512 9/additional/310436360_200502761000211.pdf.pdf., 2 .

${ }^{68}$ Hall and Taylor, Health for all beyond 2000: the demise of the Alma-Ata Declaration and primary health care in developing contries, 18.

${ }^{69}$ O. Solar and A. Irwin, "Social Determinants, Political Contexts and Civil Society Action: A historical Perspective on the Commission of Social Determinants of Health," Health Promotion Journal of Australia 17, no. 3 (2006): 181.

${ }^{70}$ Rifkin, Paradigms Lost: Toward a new understanding of community participation in health programmes, 81 .

${ }^{71}$ W. R. Brieger, "Health education to promote community involvement in the control of tropical diseases," Acta Tropica 61, no. 2 (1996): 95.
} 
support systems, CHWs became increasingly estranged from their community role. ${ }^{72}$ The disconnect between communities and CHWs was seen as contributing to the failure of CHW programs.

In the utilitarian model, CHWs represented a cheap substitute for building a comprehensive primary health system that required infrastructure, logistical support and investment in people and financing. While CHWs may cost less than other types of health workers, they still require investments in training, supervision, and other types of support. Inadequate training, lack of supervision, irregular availability of medicines and other supplies for CHWs, and hasty implementation are criticized for contributing to the low motivation, retention and effectiveness of $\mathrm{CHWs}^{73}$

While community participation lay at the foundation of PHC, there was little understanding of how to garner such participation or what level and intensity of community participation was required for a successful CHW program. ${ }^{74}$ Both empowerment and utilitarian schools "underestimated and oversimplified the complex concepts inherent in primary health care and have compromised and distorted its crucial principles, especially in the implementation of the community health workers strategy." 75 In the end, many programs fell short of inflated expectations. ${ }^{76}$ Unrealistic expectations of CHWs coupled with inadequate support systems led to low motivation and high attrition rates of CHWs. The global economic recession in the 1980s and the shift

\footnotetext{
${ }^{72}$ Walt, CHWs: Are National Programmes in Crisis?, 18.

${ }^{73}$ Rifkin, Paradigms Lost: Toward a new understanding of community participation in health programmes, 84.

${ }^{74} \mathrm{M}$. Rosato et al., "Community participation: lessons for maternal, newborn, and child health," The Lancet 372, no. 9642 (2008): 967.

${ }^{75}$ World Health Forum, 1984;5(4):303.

${ }^{76}$ Lehmann and Sanders, Community health workers: What do we know about them? The state of the evidence on programmes, activities, costs and impact on health outcomes of using community health workers, www.who.int/hrh/documents/community health workers_brief.pdf., v. Abbatt, Scaling Up Health and Education Workers: Community Health Workers - A Literature Review, 3.
} 
towards neoliberal economic policies with their belt-tightening social spending prescriptions effectively lead to the collapse of many large CHW that were already plagued by weaknesses. $^{77}$

\section{New Paradigms}

Lessons learned during the early years, however, have contributed to a strengthened, more realistic framework for CHWs. In contrast to the 1980 s and early 1990s when empowerment and target-oriented frames were seen in opposition, current discussions are rejecting this simplistic dichotomy and argue that "community participation and empowerment are necessary for the success of...programmes, whilst also acknowledging the need for expert opinion and theory to inform these programmes." 78 Participation is a dynamic interaction that requires "modification of both parties" views." 79 CHWs "must be rooted in the community, supported by ongoing access to needed and usable information and to significant commitment of organizational staff and material resources, and be given genuine support by health professionals and managers and by the political/administrative system." ${ }^{80}$ Although today CHWs are generally dismissed as community change agents, $\mathrm{CHWs}$ can help achieve concrete improvements in health when they have the right supports.

This more harmonious view of $\mathrm{PHC}$ and the role of community participation are helping to build stronger foundations for $\mathrm{CHW}$ programs. Today, our understanding of

\footnotetext{
${ }^{77}$ Standing and Chowdhury, Producing effective knowledge agents in a pluralistic environment: What future for community health workers?, 2098.

${ }^{78} \mathrm{~A}$. Braunack-Mayer and J. Louise, "The ethics of Community Empowerment: tensions in health promotion theory and practice." Promotion \& education 15, no. 3 (2008): 8.

${ }^{79}$ ibid., 8 .

${ }^{80}$ Zakus and Lysack, Revisiting Community Participation, 9.
} 
community participation and the role of CHWs within the larger context of the health system has matured. These conceptual adaptations can help anchor CHWs to a more supportive environment in which they can be effective. 


\section{CHAPTER 3: THE ROLE OF COMMUNITY HEALTH WORKERS AS PART OF HEALTH SYSTEMS}

Given the difficulties encountered in early $\mathrm{CHW}$ programs, the role of CHWs was re-conceptualized. Rather than looking at CHWs as a cheap substitute for professional health workers or as advocates for social change, CHWs were recast as a bridge "between the community and the formal health services...to increase both the effectiveness of curative and preventive services." This redefinition brings together the strengths of the empowerment and utilitarian models. It recognizes the importance of the CHW's link to the community while acknowledging the need to support $\mathrm{CHWs}$ as part of the larger health system. Given the focus on CHWs as bridges between communities and the health system and the current emphasis on health systems strengthening, this chapter examines the shift in donor engagement from vertical to horizontal program support to $\mathrm{PHC}$, the key components of health systems, and the role of CHWs within the health system context.

\section{Global Shifts in Health Assistance}

In the last few years, there has been a global shift towards horizontal programming and health systems strengthening. Horizontal programming is delivered through publically financed health systems, ${ }^{2}$ and thus forms part and parcel of routine

\footnotetext{
${ }^{1}$ Uta Lehmann and David Sanders, Community health workers: What do we know about them? The state of the evidence on programmes, activities, costs and impact on health outcomes of using community health workers, Anonymous , January 2007), www.who.int $/$ hrh/documents/community health_workers brief.pdf., 5.

${ }^{2}$ Joyce Msuya, "Horizontal and Vertical Delivery of Health Services: What Are The Trade Offs?" World Bank (2004): http://www-
} 
service delivery while vertical interventions are delivered through parallel structures managed by external agencies. ${ }^{3}$ Horizonal programming tends to emphasize "comprehensive care and a primary provider at the core, while vertical programs focus on preventing or treating individual diseases or working with specific populations." ${ }^{4}$

The Alma Ata declaration originally envisioned a comprehensive system of PHC - one that would be multisectoral in nature, encompassing clean water and sanitation, health education, and other sectors, as well as sound organizational and financial management of health services. ${ }^{5}$ Given the "daunting array of health demands and the limitations of both workers and finances," a more selective approach to PHC was put forward. ${ }^{6}$ Vertical approaches to PHC were "originally conceived as an interim strategy" to help accelerate the delivery of cost-effective interventions in the face of severe resource constraints and low government capacity to deliver health services. ${ }^{7}$ Vertical approaches were expected to be more efficient at delivering services and were expected to make it easier to manage and track results. ${ }^{8}$

In recent years, however, vertical programs have increasingly been criticized for creating "parallel chains of command and funding mechanisms, duplicated supervision and training schemes, and multiplied transaction costs" that produces health system

wds.worldbank.org/external/default/WDSContentServer/IW3P/IB/2003/10/15/000160016 2003101512512 9/additional/310436360 200502761000211.pdf.pdf., 2.

${ }^{3}$ ibid.2,

4 "Global View of Health Systems," Available from http://www.globalhealth.org/health_systems/global view/.

${ }^{5}$ ibid.

${ }^{6}$ J. E. Lawn et al., "Alma-Ata 30 years on: revolutionary, relevant, and time to revitalise," The Lancet 372 , no. 9642 (2008): 921.

${ }^{7}$ The World Health Organization, The World Health Report 2008: Primary Health Care Now More than Ever, The World Health Organization, 2008), 13.

${ }^{8}$ Lawn et al., Alma-Ata 30 years on: revolutionary, relevant, and time to revitalise, 921. 
fragmentation. ${ }^{9}$ Vertical programs concentrate resources in certain priority disease control programs, diverting resources away from more comprehensive health care that addresses a wide range of health needs across the population. ${ }^{10}$ Furthermore, many results achieved by vertical programs have been short-lived. ${ }^{11}$ Although vertical programming allows donors to bypass issues of corruption in government use of ODA funds, procurement delays, and other health system constraints, ${ }^{12}$ the duplication and system fragmentation caused by a burgeoning number of vertical programs has led to calls for a more integrated approach. ${ }^{13}$

Today, it is increasingly being recognized that the "structural problems of health systems - funding, payment and human resources" need to be addressed in order to create sustainable improvements in health. ${ }^{14} \mathrm{~A}$ "system's failure requires a system's solution. ${ }^{.15}$ Working through national systems, although more cumbersome and more risky, can help strengthen the health system in the long run and improve the country's capacity to deliver health services more broadly and equitably over time. Although most major funding for the MDGs remains focused on "selective, commodity-driven components," 16 the emergence of new frameworks, such as the International Health Partnership, are helping secure more support for a health systems approach. CHWs are increasingly being considered as part of, not as a substitute for, the formal health system.

\footnotetext{
${ }^{9}$ The World Health Organization, The World Health Report 2008: Primary Health Care Now More than Ever, 13.

${ }^{10}$ ibid., 13.

11 ibid., 13.

${ }^{12}$ O. Solar and A. Irwin, "Social Determinants, Political Contexts and Civil Society Action: A historical Perspective on the Commission of Social Determinants of Health," Health Promotion Journal of Australia 17 , no. 3 (2006): 181.

${ }^{13}$ The World Health Organization, The World Health Report 2008: Primary Health Care Now More than Ever, 13.

14 ibid., 13.

${ }^{15}$ ibid., xiii.

${ }^{16}$ Lawn et al., Alma-Ata 30 years on: revolutionary, relevant, and time to revitalise, 924.
} 


\section{Health System Components}

In order to analyze the role of CHWs within health systems, this section will first briefly examine the components of a health system. A health system can be defined as "the sum total of all the organizations, institutions and resources whose primary purpose is to improve health."17 The main objectives of a health system are to improve health outcomes, equity of access to services, patient satisfaction with health services, and costeffectiveness of service delivery.

The WHO and Marc Roberts, author of Getting Health Reform Right, present two helpful ways of looking at health systems. The WHO identifies six key building blocks of a health system: finances, health workforce, information, governance, medical products and technologies, and service delivery."18 The building blocks "provide a means of describing the attributes needed to establish and sustain health systems." 19 Marc Roberts identifies five 'control knobs' - financing, payment, organization, regulation, and behaviour - which can be adjusted by government to change the performance of the health system.

The following discussion will draw upon both of these frameworks and examine the areas in which CHWs have a direct impact on the health system. Since the role of CHWs has little relation to the control knob 'regulation' or the WHO building blocks of 'governance' and 'medical products and technologies,' these areas will not be examined.

\footnotetext{
17" What is a Health System, "World Health Organization, Available at http://www.who.int/features/qa/28/en/index.html

${ }^{18}$ Measuring Health Systems Strengthening and Trends: A Toolkit for Countries, World Health Organization, 2008. http://www. who.int/healthinfo/statistics/toolkit hss/EN_PDF Toolkit_HSS_Introduction.pdf., 3.

${ }^{19}$ Global Health Council, Global View of Health Systems, Available at http://www.globalhealth.org/health_systems/global_view/
} 


\subsection{Financing}

Emphasized by both the WHO and Roberts, financing refers to the "function of a health system concerned with the mobilization, accumulation, and allocation of money to cover the health needs of the people, individually and collectively, in the health system." 20 Financing "determines how much money is available, who bears the financial burden, who controls the funds, how risks are pooled, and whether health-care costs can be controlled." ${ }^{21}$ While funds can be raised through taxation (general revenue), social insurance, private insurance, direct payments by patients or community financing, directly or indirectly, all health funds (excluding foreign assistance) are directly or indirectly raised from citizens. ${ }^{22}$

\subsubsection{Challenges to Financing}

In poor countries where per capita income is very low and where most of the population is involved in subsistence agriculture or the informal economy, governments are inevitably less able to mobilize sufficient resources for health. Low population density compared to urban areas, poor transportation and electrical infrastructure make health service provision to remote, rural communities particularly costly and challenging. While community financing was once proposed as a partial solution to the problem of health financing for the poor, especially in rural communities, due to lack of earlier

\footnotetext{
${ }^{20}$ Measuring Health Systems Strengthening and Trends: A Toolkit for Countries, World Health Organization, 2008.

${ }^{21}$ Roberts et al., Getting Health Reform Right: A Guide to Improving Performance and Equity, 153.

${ }^{22}$ Ibid, 153.
} 
success, interest in community financing has waned. ${ }^{23}$ Serious equity concerns have arisen as a result of the skewed resource distributions in rural versus urban areas.

\subsubsection{CHW Role in Health Financing}

The cheaper costs associated with training and remunerating CHWs can help reduce the costs of providing basic health services. As health promoters that encourage individuals to adopt behaviours that promote improved health and reduce the likelihood of illness, $\mathrm{CHWs}$ can help reduce the cost of treating preventable illnesses. By helping to reduce costs, CHWs can help improve the cost-effectiveness of the health system. While the cost of a large scale CHW program can still be significant, ${ }^{24}$ employing CHWs represents a more financially feasible strategy in countries with a low capacity to generate funds.

\subsection{Human Resources for Health}

This category amalgamates the WHO category of health workforce, and the two control knobs - payment and organization - defined by Roberts. The health workforce is defined by the WHO as "all people engaged in actions whose primary intent is to enhance health. This includes clinical staff, such as physicians, nurses and dentists, as well as management and support staff - those who do not deliver services directly but are critical to the performance of health systems such as mangers, ambulance drivers and

\footnotetext{
${ }^{23}$ The under-five mortality rate: The indispensable gauge of child health, Anonymous United Nations Children's Fund (UNICEF), 2008), http://www.unicef.org/sowc08/docs/sowc08 panels.pdf.

${ }^{24}$ Lucy Gilson et al., "National Community Health Worker Programs: How Can They Be Strengthened?" Journal of public health policy 10, no. 4 (1989): 521.
} 
accountants." 25 The 2006 World Health Report estimates that there is a global shortage of 4.3 million health workers, with the greatest absolute shortage in Asia (notably Bangladesh, India and Indonesia) while the largest relative need exists in sub-Saharan Africa. ${ }^{26}$ An increase of approximately 1.5 million workers, ${ }^{27}$ almost $140 \%$, is necessary to meet the threshold level of 2.5 health care professionals (counting only doctors, nurses and midwives) per 1000 population. ${ }^{28}$ Roberts' emphasis on organization and payment emphasizes how the capacity of educational institutions, the type of training received, working conditions, and financial incentives affect the production and retention of health workers.

\subsubsection{Challenges to Scaling up the Health Workforce}

While report after report outlines the need to rapidly increase the production of health workers in order to rollout antiretroviral treatment, ${ }^{29}$ increase the access to skilled birth attendants, ${ }^{30}$ and many other key interventions, expanding the pool of health workers in many developing countries, and especially those in sub-Saharan Africa, is severely constrained by the scant number of medical schools: "Two-thirds of sub-Saharan African countries have only a single medical school."31

\footnotetext{
${ }^{25}$ Measuring Health Systems Strengthening and Trends: A Toolkit for Countries, World Health Organization, 2008.

${ }^{26}$ Nigel Crisp, Bience Gawanas, and Imogen Sharp, "Training the health workforce: scaling up, saving lives," The Lancet 371, no. 9613 (2008): 689-690.

${ }^{27}$ Nigel Crisp, Bience Gawanas, and Imogen Sharp, "Training the health workforce: scaling up, saving lives," The Lancet 371, no. 9613 (2008): 689.

${ }^{28}$ The World Health Report 2006, World Health Organization, 2006, 11.

${ }^{29}$ ibid., pl1.

${ }^{30}$ ibid., p11.

${ }^{31}$ C. Hongoro and B. McPake, "How to bridge the gap in human resources for health," Lancet 364, no. 9443 (2004): 1452
} 
The problem of low training capacity is compounded by the migration of health professionals to industrialized countries. Countries with "low per capita GDP may have net physician emigration rates exceeding $10 \%$ of stock, some being as high as $60 \%$ or more." 3233 In SSA, 10-40\% of all health care students find employment out of continent. ${ }^{34}$ Migration of doctors and nurses is worsening the already low health professional to population ratio.

Given the shortage of health professionals, few developing countries have effective human resource strategies to sufficiently staff public health facilities, particularly rural health clinics. Furthermore, there are insufficient incentives to entice health professionals to relocate to rural clinics. Most physicians in the public sector engage in supplementary private practice to boost their incomes. ${ }^{35}$ This type of income supplementation becomes difficult in rural areas. As a result, doctors are disinclined to relocate, and consequently, attend their rural posts erratically and irregularly and provide poorer quality services when they are there. ${ }^{36}$ Poorly equipped clinics, lower housing and school standards, erratic electricity supply and difficult transportation are additional drawbacks for physicians assigned to rural health centers. ${ }^{37}$ Although some countries such as Sri Lanka and Cuba have been comparatively successful in countering these general trends and extending rural health services, these countries are often considered

\footnotetext{
${ }^{32}$ A. Mejia, "Migration of physicians and nurses: A world wide picture," International journal of epidemiology 7, no. 3 (1978): 209.

${ }^{33}$ The under-five mortality rate: The indispensable gauge of child health, http://www.unicef.org/sowc08/docs/sowc08 panels.pdf.

${ }^{34}$ Crisp, Gawanas, and Sharp, Training the health workforce: scaling up, saving lives, 690 .

${ }^{35}$ Roberts et al., Getting Health Reform Right: A Guide to Improving Performance and Equity, 222.

${ }^{36}$ ibid., 176.

${ }^{37}$ ibid., 222.
} 
special cases - defined by their small size, relatively dense rural populations and ideological motivation in the public sector. ${ }^{38}$

\subsubsection{CHW Role in Strengthening the Health Workforce}

Rather than relying on a small pool of highly educated and highly skilled health professionals disinclined to work in rural communities, strategies to recruit and train a cadre of low level health workers to assume some basic responsibilities for delivering community health services offer clear advantages. While it takes years to certify a doctor or nurse, CHWs can be trained in a matter of a few weeks or months without requiring placement in a tertiary educational institution. By helping to deliver basic services which require less expertise, CHWs help manage the workload of professionally trained health staff by performing a triage function. CHWs are also less likely to immigrate because they have fewer transferable skills. ${ }^{39}$ Because of their lower levels of education, lower skills, and lower expectation of payment, $\mathrm{CHW}$ salaries cost much less to train and retain.

\subsubsection{Limitations of CHWs in Strengthening the Health Workforce}

Although CHWs can help expand the health workforce, they can simultaneously place extra burdens on the limited human resources that exist. CHWs require supervision, which in the case of government-sponsored programs, is often carried out by clinical staff at health centers. Individuals without previous supervisory experience

\footnotetext{
${ }^{38}$ ibid., 223.

${ }^{39}$ ibid. (Z4 2004 p223; 2004 p1453).
} 
require management training which requires resources and draws personnel away from their clinical responsibilities.

In terms of utility, CHWs are only trained to perform a limited number of basic tasks, thus they can not provide comprehensive or specialized care. ${ }^{40}$ Low utilization of CHWs can also diminish their contribution to the health workforce. Although CHWs are less likely to migrate to other countries, low retention and motivation has been a problem in many CHW programs. Like any other health professional, CHWs also require proper support and incentives to be effective in their posts.

\subsection{Health Information Systems}

According to the WHO, a health information system is used to inform decisionmaking and "has four key functions: data generation, compilation, analysis and synthesis, and communication and use." 41

\subsubsection{Challenges to Improving Information Systems}

Among the many challenges of improving health information systems, is the limited capacity to collect data. For example, UNICEF estimates that in Uganda only $3 \%$ of all births in the country are registered, and most deaths occur at home. ${ }^{42}$ Given the low capacity to collect data at the village level, many countries do not have a clear idea of

\footnotetext{
${ }^{40}$ Fred Abbatt, Scaling Up Health and Education Workers: Community Health Workers - A Literature Review, Anonymous UK Department for International Development (DFID), March 2005), 15.

${ }^{41}$ World Health Organization, Measuring Health Systems Strengthening and Trends: A Toolkit for Countries, http://www.who.int/healthinfo/statistics/toolkit hss/EN PDF Toolkit HSS Introduction.pdf. , 3.

2006 HCU Baseline Survey report, 63.
} 
morbidity and mortality in many communities, making it difficult to target interventions to areas most in need and track the effectiveness of interventions.

\subsubsection{The Strengths and Limitations of $\mathrm{CHWs}$ in Strengthening Information Systems}

CHWs have often been used to collect village level date. In Ghana, for example, CHWs are used in the surveillance of guinea worm and submit case detection reports to health centers. With over $90 \%$ of villages regularly submitting monthly reports, this method of surveillance is more cost effective and accurate than the previous system that relied on annual case searches conducted by external staff. ${ }^{43}$ Other studies, however, have noted that CHW record keeping has not always been consistently reliable. ${ }^{44}$

\subsection{Influencing Health Behaviours}

Although health education does not comprise one of the WHO building blocks, Roberts emphasizes the importance of encouraging health-seeking behaviours to health system performance, ${ }^{45}$ especially where deep social and economic inequities exist. ${ }^{46}$ It is widely recognized that improving the health of the rural poor relies not only upon increasing access to clinical health services, but also in enabling individuals to prevent sickness. Health education:

"comprises consciously constructed opportunities for learning involving some form of communication designed to improve health literacy, including improving knowledge, and developing life skills which are conducive to individual and community health. Health education is not

\footnotetext{
${ }^{43}$ Sandy Cairncross, Eka I. Braide, and Sam Z. Bugri, "Community participation in the eradication of guinea worm disease," Acta Tropica 61, no. 2 (1996): 125.

${ }_{44}$ Gill Walt, "CHWs: Are National Programmes in Crisis?" Health Policy and Planning 3, no. 1 (1988): 5.

${ }^{45}$ Roberts et al., Getting Health Reform Right: A Guide to Improving Performance and Equity, 281.

${ }^{46} \mathrm{R}$. Bodstein, "The complexity of the discussion on effectiveness and evidence in health promotion practices." Promotion \& education Suppl 1 (2007): 16.
} 
only concerned with the communication of information, but also with fostering the motivation, skills and confidence (self-efficacy) necessary to take action to improve health. Health education includes the communication of information concerning the underlying social, economic and environmental conditions impacting on health, as well as individual risk factors and risk behaviours, and use of the health care system. ${ }^{.47}$

Based on the epidemiological profile of diseases in developing countries, health promotion and prevention can play an important role in addressing high morbidity and mortality in developing countries. For example, "suboptimum breastfeeding, especially non-exclusive breastfeeding in the first 6 months of life, results in 1.4 million deaths and $10 \%$ of disease burden in children younger than 5 years" according to the Lancet. ${ }^{48}$ In Africa, the majority of child deaths are preventable. Africa accounts for "more than 9 out of 10 child deaths directly attributable to malaria, 9 out of 10 child deaths due to HIV/AIDS, 4 out of 10 child deaths due to diarrhoeal diseases. ${ }^{.49}$ Prevention is also key for quelling the raging HIV/AIDS epidemic that accounts for two million deaths each year, ${ }^{50}$ including $40 \%$ of all female deaths in Africa. ${ }^{51}$ Health education can also play an important role in increasing utilization of health services. ${ }^{52}$

\subsubsection{CHW Role in Health Promotion}

CHWs can be used as peer educators to facilitate health education. ${ }^{5354}$ When there are considerable socio-economic barriers to accessing services at health centers,

\footnotetext{
${ }^{47}$ Health Promotion Glossary, World Health Organization , 1998, 4.

${ }^{48}$ R. E. Black et al., "Maternal and child undernutrition: global and regional exposures and health consequences," The Lancet 371, no. 9608 (2008): 243-260.

${ }^{49}$ The Global Burden of Disease: 2004 Update, Anonymous World Health Organization, 2008), 26.

${ }^{50}$ AIDS Epidemic Update 2009, UNAIDS, http://www.unaids.org/en/KnowledgeCentre/HIVData/EpiUpdate/EpiUpdArchive/2009/default.asp, accessed Nov. 29, 2009, 18.

${ }^{51}$ ibid., 18.

${ }^{52}$ Roberts et al., Getting Health Reform Right: A Guide to Improving Performance and Equity, 300.

${ }^{53}$ ibid.,297.
} 
such as service fees, cost of medicines, distance to health center, and restrictions on women's mobility, health facilities are poor vehicles to deliver public health messages. ${ }^{55}$ CHWs, with their outreach services and intimate knowledge of their own communities and the barriers impeding behavioural changes, are often considered effective health promoters in such contexts. Nemcek and Sabatier state that "CHWs are indigenous, trusted, and respected members of the underserved community. They can act as a bridge between peers and health professionals." ${ }^{56} \mathrm{CHW}$ are often able to communicate messages more simply and clearly than health staff. For example, women in Oman who had received counseling on breastfeeding and complementary feeding "valued the volunteers ability to 'articulate health messages in a simple and informal manner easily understood by all' (in direct contrast to the difficulties found in communication with health staff). ${ }^{257}$ By helping to prevent illness, CHWs can help decrease patient load at local health centers by lessening the number of individuals requiring treatment. CHWs have also been valuable in promoting increased utilization of health services, such as improving immunization coverage. ${ }^{58}$

\subsubsection{Limitations of CHWs as Health Promoters}

Simply because CHWs are recruited from the community, does not mean that they will be adept at health education. Like any other skill, appropriate training and

\footnotetext{
${ }^{54}$ H. Standing and A. M. R. Chowdhury, "Producing effective knowledge agents in a pluralistic environment: What future for community health workers?" Social Science and Medicine 66, no. 10 (2008): 2105 .

${ }_{55}^{50}$ Roberts et al., Getting Health Reform Right: A Guide to Improving Performance and Equity, 293.

${ }^{56}$ Abbatt, Scaling Up Health and Education Workers: Community Health Workers - A Literature Review, 15.

${ }^{57}$ ibid., 10.

${ }^{58}$ Lehmann and Sanders, Community health workers: What do we know about them? The state of the evidence on programmes, activities, costs and impact on health outcomes of using community health workers, www.who.int/hrh/documents/community health_workers brief.pdf., 16.
} 
experience are required to hone communication skills. Furthermore, $\mathrm{CHWs}$ have sometimes struggled to fulfill their preventative roles. Indonesian CHWs or 'kaders' found conducting health education activities more difficult than providing routine health post activities such as providing vitamin A or ORS packets. ${ }^{59}$ While CHWs can help prevent disease and increase utilization of health services by providing clear and concise health education in communities with poor access to health information, it is well understood that dissemination of the message alone does not necessarily produce behavioural changes. $^{6061}$

\subsection{Service Delivery}

Service Delivery "is an immediate output of the inputs into the health system, such as workforce, procurement and supplies, and finance" and affects availability, affordability and acceptability of health services. ${ }^{62}$

\subsubsection{Challenges to Service Delivery}

Since service delivery is essentially the end product of a health system, any weakness in the system will hamper service delivery.

\footnotetext{
${ }^{59}$ T. Reis, "An Examination of the Performance and Motivation of Indonesian Village Health Volunteers." International Quarterly of Community Health Education 11, no. 1 (1990): 24.

${ }^{60}$ Roberts et al., Getting Health Reform Right: A Guide to Improving Performance and Equity, 204.

${ }^{61}$ G. S. Guldan, "Obstacles to community health promotion," Social Science and Medicine 43, no. 5 (1996): 689-691.

${ }^{62}$ World Health Organization, Measuring Health Systems Strengthening and Trends: A Toolkit for Countries
} 


\subsubsection{Strengths and Limitations of CHWs in Strengthening Service Delivery}

Among the three dimensions of service delivery which are availability, affordability and acceptability, CHWs are most likely to improve availability. By providing doorstep services in the community, CHWs can help improve access by reducing barriers such as travel time and cost required to receive health services at health facilities. By reaching those who would ordinarily not have access to basic services, CHWs can help improve equity.

While CHWs can increase the availability of some key health services, the number of services that CHWs can provide is limited. CHWs need to be able to refer patients to higher levels of care when needed. Furthermore, because CHW responsibilities are generally targeted towards the most common and pervasive determinants of poor health, they usually do not specifically target the needs of other vulnerable and marginalized groups such as sex workers, migrant workers, and people with disabilities. Thus, CHWs are not a panacea for health systems, but only one link in the system that needs to be functioning at many levels.

\section{Chapter Summary}

CHWs can contribute most directly to strengthening the health workforce, promoting healthy behaviours, improving service delivery, and improving the cost-effectiveness of the health system. In the face of weak health systems - limited financing, urban-biased health care, human resource shortages, unwillingness among health professionals to serve rural communities and the socio-economic barriers faced by the poor in accessing health services - CHWs represent one of the best options for scaling up the workforce in order to 
improve access and equity. CHWs are cheaper to train, require small remuneration, and are likely to remain in the communities where they work, and can help improve health literacy and utilization of health services.

The potential of CHWs to contribute to a stronger health system, however, needs to be considered in light of their limitations and in light of the demands they place on the very health system they are designed to strengthen. Limited areas of expertise and skill in providing curative and promotive services, low utilization, and poor motivation and retention limit the function and effectiveness of CHWs. While there has been a visible willingness by donors to support $\mathrm{CHW}$ programs as part of health system strengthening initiatives to scale up the health workforce, it is important to ensure that all aspects of the system are strengthened. CHWs represent only one aspect of the health system and depend on the functioning of the rest of the system. For example, weaknesses in procurement and distribution systems that hamper the timely receipt of medicines and supplies for CHWs will likely lower the effectiveness of CHWs. Similarly, poor financial management that results in delayed or irregular payment of CHWs is likely to have a negative effect on motivation, retention, and effectiveness. Thus, efforts to improve the effectiveness of CHWs and health systems strengthening go hand in hand. 


\section{CHAPTER 4: ASSESSING THE EFFECTIVENESS OF CHWS}

The previous chapter demonstrated that $\mathrm{CHWs}$ have an important role to play within health systems. There is a strong justification for employing CHWs given the health system weaknesses present in many developing countries. The rationale for employing CHWs, however, must be coupled with evidence of their impact. While Chapter 2 revealed serious weaknesses in $\mathrm{CHW}$ programs and disillusionment with their effectiveness, more recent studies provide new evidence that CHWs can improve utilization of health services, promote healthy behaviours, and decrease morbidity and mortality. Evidence of their success, however, should be considered in a balanced way that also takes into account difficulties in measurement, attribution, applicability to different contexts and publication biases.

\section{Evidence of CHW Effectiveness}

CHWs have been employed to treat and prevent a wide variety of illnesses. They are most often used to deliver maternal and child health interventions. In a review of 86 articles "discussing the use of specialized CHWs in developing countries, 30 focused on maternal and child health (including reproductive health and family planning), 19 on the treatment of TB, 9 on malaria control, 8 on ARIs, 7 on HIV/AIDS, 13 on other intervention areas." Other areas of intervention have included treatment of trachoma, river blindness, and guinea worm.

\footnotetext{
${ }^{11}$ Uta Lehmann and David Sanders, Community Health Workers: What do we Know about them? the State of the Evidence on Programmes, Activities, Costs and Impact on Health Outcomes of using Community Health Workers, January 2007), www.who.int/hrh/documents/community health workers brief.pdf, 12.
} 
Of all the areas of intervention, CHWs have been the most effective in managing childhood illness. Based on a Cochrane review of 43 studies, Lewin et al. concluded that CHWs "show promising benefits in promoting immunization uptake and improving outcomes for acute respiratory infections and malaria, when compared to usual care." ${ }^{2}$ In terms of child health, case management of pneumonia has "the strongest evidence of impact on mortality."3 While the study notes that CHWs have had a strong impact on child health outcomes, for other health issues, the "evidence is insufficient to justify recommendations for policy and practice." ${ }^{4}$

The table below provides a snapshot of some of the results that have been achieved by $\mathrm{CHW}$ programs in developing countries. While the research will shows the impact of CHWs in improving child health, the tables also highlight some key results in other areas. The table presents results related to the three measures of effectiveness used in this paper - utilization of health services, adoption of health-seeking behaviours, and impact on morbidity and mortality.

\footnotetext{
${ }^{2}$ Ibid., 15.

${ }^{3}$ Ibid., 15.

${ }^{4}$ Ibid., 15.
} 


\subsection{Table 1 - Snapshot of Effective Child Health Interventions}

\begin{tabular}{|c|c|c|}
\hline $\begin{array}{c}\text { Country/ } \\
\text { Implementing Agency }\end{array}$ & Date & Effectiveness \\
\hline 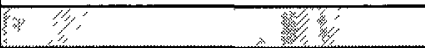 & All Caus & infant and Child Mortality \\
\hline Nepal & Multi-year & $\begin{array}{l}2003 \text { meta-analysis of nine studies utilizing CHWs } \\
\text { measured a } \mathbf{2 4 \%} \text { reduction in under- } 5 \text { mortality. }\end{array}$ \\
\hline India & $2004-2008$ & $\begin{array}{l}\text { A pilot health education program using locals to educate } \\
\text { villagers on safe new born care - regular, and close contact } \\
\text { between the mother and baby, breastfeeding, hygiene, and } \\
\text { prevention of hypothermia - halved the number of } \\
\text { newborn deaths in three years. }\end{array}$ \\
\hline Bangladesh & $2003-2005$ & $\begin{array}{l}34 \% \text { reduction over } 24 \text { months in neonatal mortality } \\
\text { attributed to the provision of a package of preventative and } \\
\text { curative care including antibiotic therapy by CHWs. }\end{array}$ \\
\hline \multicolumn{3}{|c|}{ 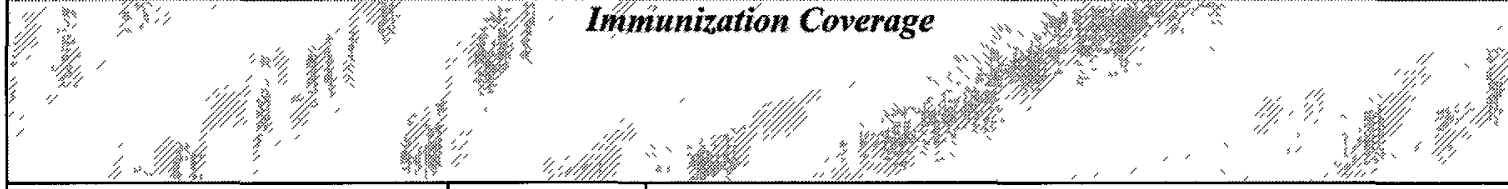 } \\
\hline Kenya & $\begin{array}{l}\text { Prior to } \\
1996^{8}\end{array}$ & $\begin{array}{l}\text { An outreach programme in Kenya helped push routine } \\
\text { immunization coverage upwards of } 90 \% \text { and decrease } \\
\text { child mortality. }\end{array}$ \\
\hline $\begin{array}{l}\text { Ghana, Planned Parenthood } \\
\text { Association of Ghana }\end{array}$ & $\begin{array}{l}\text { Prior to } \\
2008^{10}\end{array}$ & $\begin{array}{l}\text { Immunization coverage increased to } 74.7 \%-87.0 \% \text { in } \\
\text { its } 9 \text { project areas compared to } 30 \% \text { in surrounding } \\
\text { villages. }\end{array}$ \\
\hline 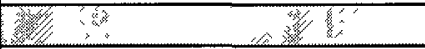 & 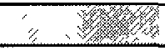 & 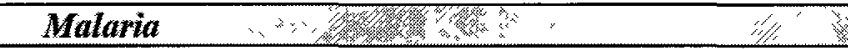 \\
\hline $\begin{array}{l}\text { Uganda, Cameroon and } \\
\text { Nigeria } \\
\text { Tropical Disease Research } \\
\text { (TDR) }\end{array}$ & $2005-2008$ & $\begin{array}{l}\text { Used established CHWs working under "the African } \\
\text { Programme for Onchocerciasis Control (APOC) to carry } \\
\text { out the distribution of Vitamin A, insecticide-treated } \\
\text { malaria nets, administration of antimalarials and } \\
\text { DOTs supervision for tuberculosis for a population of } \\
2.35 \text { million people. Under this program, "more than } \\
\text { twice as many children with fever received appropriate } \\
\text { antimalarial treatment" and "possession and utilization } \\
\text { of ITNs was two times higher in the study districts } \\
\text { compared to the three country average. }\end{array}$ \\
\hline
\end{tabular}

${ }^{5}$ T. Wardlaw and others, "Pneumonia: The Leading Killer of Children," Lancet 368, no. 9541 (2006), 1048. ${ }^{6}$ D. Kohn, "Community Involvement Saves Newborn Infants in India." Lancet 371, no. 9620 (2008): 1236. ${ }^{7}$ Bhutta, Z. A., and S. Soofi. "Community-Based Newborn Care: Are we there Yet?" The Lancet 372, no. 9644 (2008): 1125.

${ }^{8}$ This study was cited in the 1996 publication listed in footnote no. 10 of this page. Due to difficulties locating the original publication, the date of this study could not be located.

${ }^{9}$ S. A. Murray, "Learning from Primary Care in Developing Countries. Outreach Programme in Kenya was Based on Extensive Community Participation." BMJ (Clinical Research Ed.) 312, no. 7025 (1996): 250.

${ }^{10}$ This study was cited in the 2008 publication listed in footnote no. 12 of this page. Due to difficulties locating the original publication, the date of this study could not be located.

${ }^{11}$ Lehmann and Sanders, Community Health Workers: What do we Know about them? the State of the Evidence on Programmes, Activities, Costs and Impact on Health Outcomes of using Community Health Workers, www.who.int/hrh/documents/community health workers brief.pdf, 16.

${ }^{12}$ Special Programme for Research \& Training in Tropical Diseases (TDR), Community-Directed Interventions for Major Health Problems in Africa: A Multi-Country Study Final Report, 6. 


\begin{tabular}{|c|c|c|}
\hline $\begin{array}{l}\text { Democratic Republic of the } \\
\text { Congo }\end{array}$ & $1985-1987$ & $\begin{array}{l}\text { CHWs treated approximately } 65 \% \text { of community cases of } \\
\text { malaria which contributed to a } 50 \% \text { decline in malaria } \\
\text { morbidity compared to control areas. }\end{array}$ \\
\hline 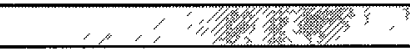 & Th & Pneumonia \\
\hline Nepal & $1995-2008$ & $\begin{array}{l}\text { Studies have shown that Nepalese CHWs are able to } \\
\text { identify over } 80 \% \text { of cases of pneumonia correctly. CHWs } \\
\text { treat } 56 \% \text { of expected pneumonia cases in } 42 \text { of } 75 \\
\text { districts, doubling the total number of cases treated. }\end{array}$ \\
\hline $3=2$ & .89 .91 & Dianthea \\
\hline Karachi, Pakistan & $2002-2003$ & $\begin{array}{l}\text { CHWs provided weekly education to households on proper } \\
\text { handwashing in the squatter camps in Karachi, Pakistan } \\
\text { and recorded a } 53 \% \text { lower incidence of diarrhea among } \\
\text { the } 25 \text { randomly assigned and } 11 \text { control neighbourhoods } \\
\text { ( } 906 \text { families including } 4700 \text { children). }{ }^{16}\end{array}$ \\
\hline $\mathscr{W} \mathbb{K}_{i}$ & $\sqrt{5}$ & Breastfeeding \\
\hline $\begin{array}{c}\text { Brazil } \\
\text { Programa Agente } \\
\text { Comunitário de Sáude }\end{array}$ & $\begin{array}{l}1987-1994 \\
1993-1997\end{array}$ & $\begin{array}{l}\text { CHWs increased the average length of breastfeeding } \\
\text { from } 4 \text { to } 7 \text { months and decreased the proportion of all } \\
\text { children never breast-fed from } 14 \% \text { to } 6 \%(1987-1994) \text {. } \\
\text { Increased the prevalence of exclusive breastfeeding of } \\
\text { children 0-4 months from } 34 \% \text { to } 47 \% \text { (1993-1997). }{ }^{17}\end{array}$ \\
\hline
\end{tabular}

\subsection{Table 2 - Snapshot of Effective CHW Interventions}

\begin{tabular}{|c|c|c|}
\hline $\begin{array}{c}\text { Country/ } \\
\text { Implementing Agency }\end{array}$ & Date & Effectiveness \\
\hline 怒 & 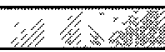 & Trachoma \\
\hline Ghana & 1996 & $\begin{array}{l}\text { CHW decision to treat trachoma was correct in } 83 \% \text { of } \\
\text { households and the dose of azithromycin was accurate in } \\
\text { more than } 98 \% \text { of cases... adverse reactions were } \\
\text { infrequent."18 }\end{array}$ \\
\hline 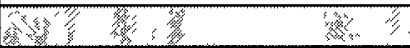 & & TVAADS and TB \\
\hline $\begin{array}{l}\text { Bangladesh } \\
\text { BRAC }\end{array}$ & $1996-1997$ & $\begin{array}{l}\text { The treatment success rate using DOTS by CHWs in } \\
\text { the BRAC area was } 83.3 \% \text { versus } 82.7 \% \text { in the } \\
\text { government area that did not use CHWs. }{ }^{19}\end{array}$ \\
\hline
\end{tabular}

${ }^{13}$ Lehmann and Sanders, Community Health Workers: What do we Know about them? the State of the Evidence on Programmes, Activities, Costs and Impact on Health Outcomes of using Community Health Workers, www. who.int/hrh/documents/community health workers brief.pdf, 13.

${ }^{14}$ Delacollette, C., P. Van Der Stuyft, and K. Molima. "Using Community Health Workers for Malaria Control: Experience in Zaire." Bulletin of the World Health Organization 74, no. 4 (1996): 427.

${ }^{15} \mathrm{P}$. Dawson and others, "From Research to National Expansion: 20 Years' Experience of CommunityBased Management of Childhood Pneumonia in Nepal," Bulletin of the World Health Organization 86, no. 5 (2008): 339.343 (accessed 7 November 2009)., 340.

${ }^{16}$ S. P. Luby and others, "Effect of Handwashing on Child Health: A Randomised Controlled Trial," Lancet 366, no. 9481 (2005): 225.

${ }^{17}$ E. C. Svitone and others, "Primary Health Care Lessons from the Northeast of Brazil: The Agentes De Saude Program," Revista Panamericana De Salud Publica/Pan American Journal of Public Health 7, no. 5 (2000): 296.

${ }^{18}$ Fred Abbatt, Scaling Up Health and Education Workers: Community Health Workers - A Literature Review, March 2005), 7.

${ }^{19}$ Ibid., 11. 


\begin{tabular}{|c|c|c|}
\hline $\begin{array}{c}\text { Kibera slum, Nairobi } \\
\text { Kenya }\end{array}$ & $\begin{array}{l}\text { Prior to } \\
2008^{20}\end{array}$ & $\begin{array}{l}\text { CHWs working with patients and families to support } \\
\text { compliance have achieved over } 90 \% \text { adherence to DOTS } \\
\text { for TB and } 92 \% \text { adherence to anti-retroviral } \\
\text { treatment. }\end{array}$ \\
\hline$x^{3}+3 x$ & & 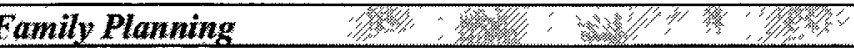 \\
\hline $\begin{array}{c}\text { Uganda } \\
\text { Save the Children }\end{array}$ & 2007 & $\begin{array}{l}\text { In a pilot program, } 20 \text { CHWs recruited } 562 \text { clients to } \\
\text { receive Depo Provera (injectible contraceptive) } \\
\text { compared to } 383 \text { by nurses and midwives in } 10 \text { health } \\
\text { centers. CHW "clients were just as likely to receive their } \\
\text { second injection." } 22\end{array}$ \\
\hline "W & 2 & River Blindness \\
\hline Sub-Saharan Africa & 2005 & $\begin{array}{l}\text { In } 2005 \text { CHWs distributed } 98 \text { million ivermectin tablets } \\
\text { in } 95000 \text { communities in } 16 \text { sub-Saharan countries, } \\
\text { covering over } 50 \text { million people. In randomly sampled } \\
\text { study communities, ivermectin treatment coverage was } \\
\mathbf{6 3 . 8 \%} \text {. }^{23}\end{array}$ \\
\hline 8 & & \multirow{2}{*}{ In Ghana, CHWs detect $87 \%$ of guinea worm cases. ${ }^{25}$} \\
\hline Ghana & $\begin{array}{l}\text { Prior to } \\
1996^{24}\end{array}$ & \\
\hline
\end{tabular}

Utilizing CHWs to deliver high impact child interventions has helped put Nepal - one of only 5 countries - on the path towards meeting the fourth MDG on child health. ${ }^{26}$ Thailand's applauded dedication to PHC and use of CHWs has helped place Thailand at "the top of the list of 30 low-income countries making rapid progress for child mortality reduction." "To date, the largest and most successful programme" 28 is the national

\footnotetext{
${ }^{20}$ This study was cited in the 2008 publication listed in footnote no. 21 of this page. Due to difficulties locating the original publication, the date of this study could not be located.

${ }^{21}$ Community Health Workers in Africa. IDS Health and Development Information, Institute of Development Studies. February 22, 2008. www.eldis.org/go/topics/resource.../health.../health.../february2008.

${ }^{22}$ John Stanback, Anthony Mbonyeb and Martha Bekiitac, "Contraceptive Injections by Community Health Workers in Uganda: A Nonrandomized Community Trial," Bulletin of the World Health Organization 85, no. $10(2007), 770$.

${ }^{23}$ Community-Directed Interventions for Major Health Problems in Africa: A Multi-Country Study Final Report, $2008,56$.

${ }^{24}$ This study was cited in the 2008 publication listed in footnote no. 25 of this page. Due to difficulties locating the original publication, the date of this study could not be located.

${ }^{25}$ Sandy Cairncross, Eka I. Braide and Sam Z. Bugri, "Community Participation in the Eradication of Guinea Worm Disease," Acta Tropica 61, no. 2 (4, 1996), 125.

${ }^{26}$ Dawson and others, From Research to National Expansion: 20 Years' Experience of Community-Based Management of Childhood Pneumonia in Nepal, 340.

${ }^{27} \mathrm{~J}$. Walley and others, "Primary Health Care: Making Alma-Ata a Reality," The Lancet 372, no. 9642 (2008), 1002.
} 
Brazilian Family Health Programme, which has substantially increased the prevalence of exclusive breastfeeding and decreased infant mortality by $32 \%$ in 5 years. ${ }^{29}$ Both discrete projects and national programmes are demonstrating that CHWs are contributing to remarkable improvements in child survival.

\section{The Challenges of Measuring CHW Effectiveness}

Measuring effectiveness has been hampered by problems of endogeneity - the embeddedness of CHWs within the health system and within the social, political, and economic context. In many cases, it is difficult to distinguish to what extent CHWs have contributed to the improved health outcomes occurring in areas where CHWs have been trained. While the literature provides many examples of successful programs where CHWs have been involved, "the reports often do not isolate the contribution made specifically by CHWs." ${ }^{30}$ While Thailand and Brazil both employ extensive CHW programs, these two countries have also heavily invested in improving access to facilitybased PHC services. Though promotion of early and exclusive breastfeeding is one of the most effective ways to improve child survival, ${ }^{31}$ it is unclear to what extent improved breastfeeding practices promoted by CHWs have contributed to the $32 \%$ reduction in infant mortality in Brazil.

In general the impact of CHWs on morbidity and mortality has been difficult to assess. For example, "CHWs may have roles that only have an indirect impact on health"

${ }^{28}$ Lehmann and Sanders, Community Health Workers: What do we Know about them? the State of the Evidence on Progranmes, Activities, Costs and Impact on Health Outcomes of using Community Health Workers, www.who.int/hrh/documents/community_health_workers brief.pdf, 26.

${ }^{29}$ Ibid., 8.

${ }^{31}$ R. E. Black and others, "Maternal and Child Undernutrition: Global and Regional Exposures and Health Consequences," The Lancet 371, no. 9608 (2008), 243. 
such as providing health education or encouraging the use of health services. ${ }^{32}$ Although CHWs "can implement effective interventions, they do not always consistently provide services likely to have substantial health impact. ${ }^{233}$ In Sri Lanka, for example, where most of the volunteers' tasks were educational, it has been difficult to measure their effectiveness. ${ }^{34}$ As a result, studies using health outcomes as a measure of effectiveness have often been limited to a few very specific, targeted interventions. ${ }^{35}$ It is much more difficult to locate studies identifying the impact of a package of $\mathrm{CHW}$-delivered interventions. Furthermore, because multiple agencies often operate programs in the same area, it is sometimes challenging to attribute improved health outcomes to a particular intervention. ${ }^{36}$ These measurement problems are further compounded by the fact that in many programs, especially older ones like in Sri Lanka, baseline studies were never conducted. ${ }^{37}$

\subsection{Publication Biases}

While there is clearly an extensive list of studies that can be drawn upon to demonstrate the potential of CHWS, the extent to which these successful cases are

${ }^{32}$ Community Health Workers in Africa. IDS Health and Development Information, Institute of Development Studies. February 22, 2008, http://www.dfidhealthrc.org/publications/health service delivery/05HRScalingUp03.pdf, 9. ${ }^{33}$ Lehmann and Sanders, Community Health Workers: What do we Know about them? the State of the Evidence on Programmes, Activities, Costs and Impact on Health Outcomes of using Community Health Workers, www. who.int/hrh/documents/community health workers brief.pdf, $\mathrm{v}$.

${ }^{34}$ G. Walt, M. Perera and K. Heggenhougen, "Are Large-Scale Volunteer Community Health Worker Programmes Feasible? the Case of Sri Lanka," Social Science and Medicine 29, no. 5 (1989), 603.

${ }^{35}$ R. Sauerborn, A. Nougtara and H. J. Diesfeld, "Low Utilization of Community Health Workers: Results from a Household Interview Survey in Burkina Faso," Social Science and Medicine 29, no. 10 (1989), 1163.

${ }^{36}$ Victora, Cesar, Robert Black, and Jennifer Bryceb. "Evaluating Large-Scale Programmes in Child Survival." Bulletin of the World Health Organization 87, no. 0 (2009): 1.

${ }^{37}$ Walt, Perera and Heggenhougen, Are Large-Scale Volunteer Community Health Worker Programmes Feasible? the Case of Sri Lanka, 603. 
representative of the general experience is somewhat unknown and indeterminable at present. $^{38}$

While there have been an increasing number of meta-analyses synthesizing the experience of a broad range of programs, these reviews tend to highlight the positive results. The lack of a comprehensive database listing the results of the bulk of CHW programs and the dearth of publications on underperforming programs makes it difficult to assess the proportion of projects with insignificant or negative outcomes. Ideally, some sort of internationally-managed database that would identify the location, specific CHW roles, and impact achieved would be extremely useful. But in the absence of such a database, we must rely on surveys of academic journals, organizational databases, and published grey literature.

Among the programs reviewed for this paper, there were few clear examples of program failure among programs implemented post 1990. The National Programme for Family Planning and Primary Health Care implemented in 1994 in Pakistan trains salaried, female CHWs called Lady Health Workers in a wide number of primary health care services. They are trained to diagnose pneumonia and treat fever presumptively, alongside distribution of contraceptive pills, condoms, paracetamol tablets, ORS sachets, choroquine for malaria and cotrimoxizole for respiratory infections. However, they have not contributed significantly to decreases in child mortality. ${ }^{39}$

Unusually, there was a single study from Navrongo, Ghana reporting negative health outcomes where CHWs were involved. A four-arm, community-randomized,

\footnotetext{
${ }^{38}$ Lehmann and Sanders, Community Health Workers: What do we Know about them? the State of the Evidence on Programmes, Activities, Costs and Impact on Health Outcomes of using Community Health Workers, www.who.int/hrh/documents/community health_workers brief.pdf, 3 .

${ }^{39}$ A. Haines and others, "Achieving Child Survival Goals: Potential Contribution of Community Health Workers," Lancet 369, no. 9579 (2007), 2123.
} 
controlled trial conducted between 1993-2000 concluded that in villages where primarily male CHWs were used, under 5 mortality increased by $14 \%$, whereas it decreased by the same proportion in villages where Ministry of Health community nurses were employed. ${ }^{40}$ Surprisingly, there has been a dearth of critical debate surrounding these negative results. A search of Google Scholar, Pub Med and Scopus did not reveal any critical commentary on the findings. The authors surmise that "the presence of health volunteers, especially in the absence of nurses in the village, may divert health-seeking behavior away from the more skilled medical care available in the sub-district clinics." ${ }^{241}$ They conjecture that health volunteers are inappropriately administering paracetamol to children with acute respiratory infections and diarrheal diseases - two of the leading causes of death - when they should have been referring these children to clinics. ${ }^{42}$

It is very hard to pinpoint the source of the poor performance. While the researchers conjecture that inappropriate diagnosis and treatment by CHWs is to blame, it might be equally likely that reliance on a cadre of primarily male volunteers had a detrimental effect. Experience from BRAC programs in Bangladesh revealed that low CHW utilization was largely due to the lack of comfort women had receiving services from male CHWs. ${ }^{43}$ Furthermore, the article does not provide any insight into retention rates among the volunteers and community health nurses.

\footnotetext{
${ }^{40}$ B. W. Pence and others, "The Effect of Community Nurses and Health Volunteers on Child Mortality: The Navrongo Community Health and Family Planning Project," Scandinavian Journal of Public Health 35 , no. 6 (2007), 599-608 (accessed 6 November 2009), 7.

${ }^{41}$ Ibid., 406.

${ }^{42}$ Ibid., 33.

${ }^{43}$ H. Standing and A. M. R. Chowdhury, "Producing Effective Knowledge Agents in a Pluralistic Environment: What Future for Community Health Workers?" Social Science and Medicine 66, no. 10 (2008), 2096-2107 (accessed 12 November 2009), 2011.
} 


\subsection{Transferability of Results}

The Navrongo study also highlights the difficulty of exporting 'effective' program designs to other contexts. The study points out that the Navrongo program drew upon the program design in Matlab Bangladesh which reduced neonatal, infant, and child mortality by $17 \%, 9 \%$, and child $30 \%$ respectively. ${ }^{44}$ "Differences in volunteer training, their specific responsibilities, or their coordination with medical personnel may underlie the differences in the Matlab and Navrongo experiences. ${ }^{245}$ International comparison is quite difficult due to differences in technical aspects such as quality of training, but also due to social and cultural differences such as the status of CHWs. ${ }^{46}$ The facilitating environment needed for success can be very different between and even within countries. $^{47}$

\section{Chapter Summary}

Despite the limitations of assessing CHW impact, "there is robust evidence that CHWs can undertake actions that lead to improved health outcomes, especially, but not exclusively, in the field of child health. ${ }^{48}$ As the number and size of CHW programs continue to grow, understanding the factors that inhibit or enhance CHW effectiveness is important for ensuring productive investments in health.

\footnotetext{
${ }^{44}$ Pence, B. W., P. Nyarko, J. F. Phillips, and C. Debpuur. "The Effect of Community Nurses and Health Volunteers on Child Mortality: The Navrongo Community Health and Family Planning Project." Scandinavian journal of public health 35, no. 6 (2007): 606.

${ }^{45}$ Pence and others, The Effect of Community Nurses and Health Volunteers on Child Mortality: The Navrongo Community Health and Family Planning Project, 599-608, 606.

${ }^{46}$ Sauerborn, Nougtara and Diesfeld, Low Utilization of Community Health Workers: Results from a Household Interview Survey in Burkina Faso, 1163.

${ }^{47}$ L. M. Morgan, "Community Participation in Health: Perpetual Allure, Persistent Challenge," Health Policy and Planning 16, no. 3 (2001), 225.

${ }^{48}$ Lehmann and Sanders, Community Health Workers: What do we Know about them? the State of the Evidence on Programmes, Activities, Costs and Impact on Health Outcomes of using Community Health Workers, www. who.int/hrh/documents/community health_workers brief.pdf, v.
} 


\section{CHAPTER 5: PROBLEMS OF LOW MOTIVATION AND RETENTION}

Although recent evidence demonstrates that CHWs are effective in increasing utilization of health services, promoting healthy behaviours and improving health outcomes, poor motivation and retention of CHWs have been identified as critical factors hampering effectiveness. The literature has documented serious difficulties in retaining CHWs. ${ }^{1}$ Studies conducted in the 1980 s found attrition rates of $30 \%$ over nine months in Senegal ${ }^{2}$ and $50 \%$ over two years in Nigeria ${ }^{3}$ and Papua New Guinea. ${ }^{4}$ Low motivation and high attrition were also documented in Burkina Faso. ${ }^{5}$ Gill Walt cites high drop-out rates and inadequate motivation across large-scale, national programs in Indonesia, Thailand and Sri Lanka as major impediments hampering program effectiveness and viability. ${ }^{6}$ In Indonesia, drop out rates in the first year and a half after training were as high as $70 \%$ in some regions. ${ }^{7}$ Low activity levels and high drop out rates of CHWs in these countries have led some to question the utility of $\mathrm{CHWs} .^{8}$

\footnotetext{
${ }^{1}$ Uta Lehmann and David Sanders, Community health workers: What do we know about them? The state of the evidence on programmes, activities, costs and impact on health outcomes of using community health workers, January 2007, www. who.int/hrh/documents/community health workers brief.pdf, 14. ${ }^{2}$ Karabi Bhattacharyya et al., Community Health Worker Incentives and Disincentives: How They Affect Motivation, Retention, and Sustainability, Anonymous Basic Support for Institutionalizing Child Survival Project (BASICS II) published for the United States Agency for International Development, Oct. 2001), 2.

${ }^{3}$ ibid., 2.

${ }^{4} \mathrm{~J}$. S. Moir et al., "The role of voluntary village aides in the control of malaria by presumptive treatment of fever. 1. Selection, training and practice." Papua and New Guinea medical journal 28, no. 4 (1985): 262.

${ }^{5}$ R. Sauerborn, A. Nougtara, and H. J. Diesfeld, "Low utilization of community health workers: Results from a household interview survey in Burkina Faso," Social Science and Medicine 29, no. 10 (1989): 1170.

${ }^{6}$ G. Walt, M. Perera, and K. Heggenhougen, "Are large-scale volunteer community health worker programmes feasible? The case of Sri Lanka," Social Science and Medicine 29, no. 5 (1989): 599-608., 599.

${ }^{7}$ T. Reis, "An Examination of the Performance and Motivation of Indonesian Village Health Volunteers." International Quarterly of Community Health Education 11, no. 1 (1990): 19-27., 21.

${ }^{8}$ Walt, Perera, and Heggenhougen, Are large-scale volunteer community health worker programmes feasible? The case of Sri Lanka, 599-608., 606.
} 
More recent studies continue to highlight the problems of poor motivation and retention. In his 1994 paper, Curtail questions the effectiveness of Nepalese CHWs in the face of low motivation and high drop-out rates. ${ }^{9}$ According to the African Medical and Research Foundation (AMREF), one-third of CHWs in project regions dropped out. ${ }^{10}$ In clear recognition of the ongoing issues of poor retention and motivation, in 2001 USAID commissioned a group of prominent academics, Karabi Bhattacharyya, Peter Winch, Karen LeBan, and Marie Tien, to produce an analysis of the issue. Their report entitled "Community Health Worker Incentives and Disincentives: How They Affect Motivation, Retention, and Sustainability" opens with "One of the most frustrating elements of many CHW programs is their high attrition rate." The study notes that attrition rates as high as $77 \%$ have been recorded in $\mathrm{CHW}$ programs. ${ }^{11}$ Improving retention and motivation is important as USAID, along with other donors and governments, continue to make large investments in CHW programs.

\section{Impact of Low Retention and Motivation}

Low retention and motivation pose serious problems for program effectiveness and viability. When high numbers of CHWs drop-out, it disrupts program continuity and undercuts capacity building. ${ }^{12}$ CHWs build skills and knowledge over time which can help them become more effective in diagnosing illness and engaging community

\footnotetext{
${ }^{9}$ F. Curtale et al., "Improving skills and utilization of community health volunteers in Nepal," Social Science and Medicine 40, no. 8 (1995): 1117-1125., 1123.

${ }^{10}$ IDS Health and Development Information, Institute of Development Studies, Community health workers in Africa, Anonymous, February 22, 2008)

${ }^{11}$ Bhattacharyya et al., Community Health Worker Incentives and Disincentives: How They Affect Motivation, Retention, and Sustainability, 2.

12 ibid., 2.
} 
members in a constructive manner. ${ }^{13}$ The trust and rapport built between the $\mathrm{CHW}$ and community members is lost when the CHW resigns. ${ }^{14}$ Where CHWs make referrals to health centers or help mobilize communities for immunization days, the link between communities and the health system is weakened by the CHW's resignation. Furthermore, efforts to promote behavioural change rely on repeated contact and repetition of messages and trust with the community; ${ }^{15}$ thus, CHWs who drop-out break this chain of information required for health promotion. Human resources have been described as the 'heart of the health system.' ${ }^{16}$ The delivery of services depends on the availability of trained individuals to deliver them. When CHWs drop out, they create gaps in essential service delivery. A study by Khan et al concludes that poor retention of CHWs "decreased achievement of targets in Bangladesh." Very high attrition rates also make it "difficult to keep track of volunteers and to judge their usefulness." the USAID report state, "The very effectiveness of CHW work usually depends on retention." 19

Ultimately, the program cannot be sustained if $\mathrm{CHWs}$ cannot be retained. However, merely retaining a $\mathrm{CHW}$ who rarely carries out his/her activities will assuredly

\footnotetext{
${ }^{13} \mathrm{~S}$. Shrestha, "A conceptual model for empowerment of the female community health volunteers in Nepal," Education for Health 16, no. 3 (2003): 323.

${ }^{14}$ H. Standing and A. M. R. Chowdhury, "Producing effective knowledge agents in a pluralistic environment: What future for community health workers?" Social Science and Medicine 66, no. 10 (2008): 2105.

${ }^{15} \mathrm{~S}$. Gennaro et al., "Health promotion and risk reduction in Malawi, Africa, village women." Journal of obstetric, gynecologic, and neonatal mursing : JOGNN / NAACOG 30, no. 2 (2001): 225.

${ }^{16} \mathrm{C}$. Hongoro and B. McPake, "How to bridge the gap in human resources for health," Lancet 364, no. 9443 (2004): 1451.

${ }^{17}$ Lehmann and Sanders, Community health workers: What do we know about them? The state of the evidence on programmes, activities, costs and impact on health outcomes of using community health workers, www.who.inthrh/documents/community health workers brief.pdf, 15 .

${ }^{18}$ ibid., 14 .

${ }^{19}$ Bhattacharyya et al., Community Health Worker Incentives and Disincentives: How They Affect Motivation, Retention, and Sustainability, 2.
} 
dampen program impact. Beyond retention, CHWs must be motivated to carry out their responsibilities. Improving motivation goes hand in hand with improving retention.

Although the primary purpose of CHWs is to improve health outcomes, they have also been prioritized because of their cost-effectiveness. High attrition rates represent a significant lost investment in training and recruitment costs. ${ }^{20}$ Training represents a significant proportion of CHW program outlays and is time intensive activity for health staff and/or project management to deliver. Frequent re-training creates rising costs for the program. $^{2122}$ In Bangladesh, BRAC estimated that each CHW who dropped out cost the program $\$ 24$ US in 1994 amounts. $^{23}$ Although it can be cheaper to use volunteer, unpaid CHWs (Walt estimates that CHW salaries can account for up to $90 \%$ of program $\operatorname{costs}^{24}$ ) very high attrition rates among volunteers can negate what is saved on salaries. ${ }^{25}$

\subsection{Factors Relating to Low Motivation and Retention}

Widespread problems of poor motivation and retention and low utilization and impact, coupled with the global economic recession in the 1980 s, led many policy makers to turn away from CHW programs. ${ }^{26}$ However, some programs sought to strengthen CHW programs rather than abandon them. ${ }^{27}$ They made changes such as adapting

\footnotetext{
${ }^{20}$ ibid., 2.

${ }^{21}$ Lucy Gilson et al., "National Community Health Worker Programs: How Can They Be Strengthened?" Journal of public health policy 10, no. 4 (1989): 521.

${ }^{22}$ Lehmann and Sanders, Community health workers: What do we know about them? The state of the evidence on programmes, activities, costs and impact on health outcomes of using community health workers, www.who.int/hrh/documents/community health workers brief.pdf, 14 .

${ }^{23}$ ibid., 14.

${ }^{24}$ Gilson et al., National Community Health Worker Programs: How Can They Be Strengthened?, $518-$ $532 ., 521$.

${ }^{25}$ Lehmann and Sanders, Community health workers: What do we know about them? The state of the evidence on programmes, activities, costs and impact on health outcomes of using community health workers, www.who.int/hrh/documents/community health_workers_brief.pdf., 14 .

${ }^{26}$ ibid., 5 .

${ }^{27}$ ibid., 5.
} 
learning methodologies, providing more opportunities for refresher training, and increased engagement with supervisors and the community. In response to the high attrition rate, AMREF instituted a "modest, cost-effective, support package ${ }^{28 \text { " which has }}$ decreased CHW drop out to $1-2 \%$ compared to $33 \%$ in unsupported districts. ${ }^{29}$ Frustrated with the performance of its community male paramedics in the early 1980s, BRAC switched to training female CHWs who were more effective at reaching the poor, especially poor women. ${ }^{30}$

Accumulated lessons learned from many programs across the years, are providing a better understanding of the factors that influence effectiveness. Following the publication of the World Health Report 2006 which identified CHW-related research as a priority, the WHO commissioned Uta Lehman and David Sanders ${ }^{31}$ to review evidence for their effectiveness. Lehman and Sanders conclude that while there are still many gaps in our understanding of program effectiveness, it is clear that community participation, recruitment and selection, training, supervision and support, and compensation need to be addressed in all programs. ${ }^{32}$ These same elements are identified in the report "Community Health Worker Incentives and Disincentives: How They Affect Motivation, Retention, and Sustainability" commissioned for USAID. ${ }^{33}$

\footnotetext{
${ }^{28}$ Unfortunately, the contents of the support package were not detailed in the article nor elaborated on the AMREF website.

${ }^{29}$ Community health workers in Africa, IDS Health and Development Information, Institute of Development Studies, 2008.

${ }^{30}$ Standing and Chowdhury, Producing effective knowledge agents in a pluralistic environment: What future for community health workers? 2011.

${ }_{31}$ Professors from School of Public Health at the University of Western Cape in South Africa

${ }^{32}$ Lehmann and Sanders, Community health workers: What do we know about them? The state of the evidence on programmes, activities, costs and impact on health outcomes of using community health workers, www.who.int/hrh/documents/community health_workers brief.pdf., vi.

${ }^{33}$ Bhattacharyya et al., Community Healih Worker Incentives and Disincentives: How They Affect Motivation, Retention, and Sustainability, iii.
} 
The following sections examine the current body of knowledge on how each of the six factors - recruitment, selection criteria, training, supervision, compensation, and community support - contribute to retention and motivation. Each section outlines the evidence, challenges, and knowledge gaps related to improving motivation and retention for the six identified elements. The knowledge gaps identified in the literature serve as the basis for the case study conducted with the Healthy Child Uganda project.

\section{Community Participation in Recruitment}

There is almost unanimous consent that CHWs should be chosen from the communities they will serve and by the members of those communities. ${ }^{34}$ Lack of broad community participation in recruitment has been associated with high levels of attrition and low motivation. While local leaders are often seen as representatives of the community, giving them sole discretion to appoint CHWs can isolate CHWs from the community with which they are supposed to be working closely. Local leaders often enlist relatives, friends, or other people of status who are neither particularly well-suited nor committed to the role of a CHW, leading to high attrition and/or low motivation. ${ }^{35} \mathrm{~A}$ 1989 survey by UNICEF found that $45 \%$ of CHWs surveyed were related to the local chief or other political representatives. ${ }^{36}$ In Tanzania, CHWs who were enlisted by local leaders were negatively associated with the government. ${ }^{37}$

\footnotetext{
${ }^{34}$ Lehmann and Sanders, Community health workers: What do we know about them? The state of the evidence on programmes, activities, costs and impact on health outcomes of using community health workers, www.who.inthrh/documents/community health_workers brief.pdf, 17.

${ }_{35}^{35}$ Gennaro et al., Health promotion and risk reduction in Malawi, Africa, village women., 294.

${ }^{36}$ Bhattacharyya et al., Community Health Worker Incentives and Disincentives: How They Affect Motivation, Retention, and Sustainability, 27.

${ }^{37} \mathrm{M}$. Lynch et al., "Azithromycin treatment coverage in Tanzanian children using community volunteers," Ophthalmic epidemiology 10, no. 3 (2003): 173.
} 
Although it is difficult to isolate the degree to which retention rates are attributable to democratic, community-wide participation in $\mathrm{CHW}$ recruitment, the evidence of a strong correlation between the two is growing. Preliminary indications of the relationship began to emerge in early programs such as Sri Lanka where investigations revealed that the majority of volunteers had been recruited by health staff contrary to the original intention of recruiting via community selection ${ }^{38}$ or in Indonesia where volunteers known as 'kaders' were appointed by village heads. Both countries have noted chronic problems with high retention. ${ }^{39}$

A CHW program in Senegal plagued by attrition rates of $60 \%$ over two years in the first phase of the project, modified its selection process from one in which a small group of all male community leaders selected the CHWs to a system involving in-depth, community-wide discussions. ${ }^{40}$ In the succeeding five years, the project recorded few drop outs. "Official community recognition of their roles and the moral encouragement from their communities" were attributed to this remarkable improvement. ${ }^{42}$

Many other projects also attest to the importance of widespread community participation in recruitment. A 1987 report from a Kenyan project which made a conscientious effort to assemble the whole village and explain the purpose of the program through a number of preparatory meetings prior to selection, documented an extremely

\footnotetext{
${ }^{38}$ Walt, Perera, and Heggenhougen, Are large-scale volunteer community health worker programmes feasible? The case of Sri Lanka, 602.

${ }_{39}$ ibid., 599.

${ }^{40}$ Bhattacharyya et al., Community Health Worker Incentives and Disincentives: How They Affect Motivation, Retention, and Sustainability, 26.

${ }^{41}$ ibid., 26.

${ }^{42}$ ibid., 26.
} 
high retention rate with only 4 volunteers of 126 resigning over 4 years. ${ }^{43} 44$ BRAC, one of the most reputable NGOs implementing CHW programs has discovered through its experience that community recruitment is one of the three most important factors contributing to a successful program. ${ }^{45}$ BRAC's focus on creating community ownership through community selection, has helped contribute to the low $3.2 \%$ drop-out of CHWs throughout the 1990s. ${ }^{46}$ Of those that did drop out 'inappropriate selection' was one of the main causes. ${ }^{47}$

\subsection{Challenges}

Although there is widespread recognition that the 'community' should have substantive involvement in the recruitment of CHWs, there is a tendency to oversimplify the concepts of community and participation. ${ }^{48}$ Communities are not homogenous, benign entities. ${ }^{49}$ Individual prejudices, stereotypes, gender roles and position in the social hierarchy bias the selection of $\mathrm{CHWs}$, as well as whom the $\mathrm{CHW}$ chooses to serve. ${ }^{50}$ It is difficult for outsiders to fully understand the internal social dynamics of a community. ${ }^{51}$ While it has become increasingly clear that community involvement in recruitment needs to be broadened beyond the involvement of local leaders to include

${ }^{43}$ D. C. O. Kaseje, H. C. Spencer, and E. K. N. Sempebwa, "Characteristics and functions of community health workers in Saradidi, Kenya," Annals of Tropical Medicine and Parasitology 81, no. SUPPL. 1 (1987): 64.

${ }^{44}$ Geoff Watts, "Bangladesh group has trained 30000 community health workers," British Medical Journal 329 , no. Nov. 13 (2004): 1124.

${ }^{46}$ Standing and Chowdhury, Producing effective knowledge agents in a phuralistic environment: What future for community health workers?, 2102.

${ }_{47}$ ibid., 2102.

${ }^{48}$ David Zakus and Catherine Lysack, "Revisiting Community Participation," Health Policy and Planning 13, no. I (1988): 4.

${ }^{49}$ R. Jewkes and A. Murcott, "Community representatives: Representing the 'community?" Social Science and Medicine 46, no. 7 (1998): 843.

${ }^{50}$ Zakus and Lysack, Revisiting Community Participation, 7.

${ }^{51}$ ibid., 9. 
women and other groups, achieving a 'representative' process is incredibly difficult. The most marginalized and powerless groups, who are perhaps the most in need of $\mathrm{CHW}$ services, are least likely to be substantively involved. ${ }^{52}$

Organizing representative recruitment processes involves a lot more time and resources than simply requesting health staff or local leaders to designate a CHW. As a result, large-scale programs have a tendency to skirt these time and resource intensive processes. ${ }^{53}$ Furthermore, if communities do not fully understand the role of $\mathrm{CHWs},{ }^{54}$ their input into CHW recruitment will be of less value. Despite all the shortcomings of the processes of 'participation' and 'representation', engaging with communities as intimately as possible, in as representative a manner as possible, can help improve retention and motivation.

\subsection{Knowledge Gaps}

Since the era of the Alma Ata Declaration, community participation has been associated with the ideals of empowerment and community ownership. ${ }^{55}$ Yet many theoretical concepts associated with PHC have not translated well in practice. For example, CHWs were conceived as community change agents in the literature, but in reality, CHWs and communities did not consider themselves as such. Today, the concept of community participation in recruitment is associated with higher retention and motivation of CHWs. However, little is known about how CHWs perceive and value

\footnotetext{
${ }^{52}$ Bhattacharyya et al., Community Health Worker Incentives and Disincentives: How They Affect Motivation, Retention, and Sustainability, 25.

${ }^{53}$ Walt, Perera, and Heggenhougen, Are large-scale volunteer community health worker programmes feasible? The case of Sri Lanka, 602.

${ }_{54}$ Bhattacharyya et al., Community Health Worker Incentives and Disincentives: How They Affect Motivation, Retention, and Sustainability, 26.

${ }^{55} \mathrm{~K}$. J. Kelly and H. Van Vlaenderen, "Dynamics of participation in a community health project," Social Science and Medicine 42, no. 9 (1996): 1235.
} 
such participation. In order to examine why community participation in recruitment contributes to improved retention and motivation, the case study from the Healthy Child Uganda project tested what selection mechanisms project $\mathrm{CHWs}$ considered the most appropriate and why.

\section{Selection Criteria}

CHWs are not uniform inputs; particular capabilities and traits make certain individuals more effective, and thus more likely to be motivated and stay on the job. "From the qualitative data, it is clear that sheer personality, capability, and enthusiasm play a major role." The Bhattacharyya review echoes this view: "The characteristics of the CHWs are usually far more important for their ability to function effectively than their external incentives." "When given the opportunity, communities are often able to develop the criteria that ensure CHWs stay on the job." 58

Because retention and motivation are associated with the personality and individual characteristics of CHWs, it is surprising that such little attention has been paid to this key area. Programs often include marital status, education, age, and gender as criteria for selection, ${ }^{59}$ yet the characteristics of $\mathrm{CHWs}$ have rarely been rigorously evaluated. In fact, a 1999 literature review conducted by Janet O'Connor et. al revealed no "quantitative evaluations of individual level factors related to volunteer performance in Africa. ${ }^{260}$ However, two examples were found while conducting this review.

\footnotetext{
${ }^{56}$ Walt, Perera, and Heggenhougen, Are large-scale volunteer community health worker programmes feasible? The case of Sri Lanka, 604.

${ }_{57}$ Bhattacharyya et al., Community Health Worker Incentives and Disincentives: How They Affect Motivation, Retention, and Sustainability, 11.

${ }^{58}$ ibid., 26.

${ }^{59}$ J. O'Connor et al., "Characteristics of effective Village Treatment Assistants: The Kongwa Trachoma Project," Ophthalmic epidemiology 6, no. 4 (1999): 263.

${ }^{60}$ ibid., 263.
} 
Studies of individual characteristics in Latin America found no significant difference between literate and illiterate Volunteer Collaborators in Guatemala's malaria control program, nor any difference in performance among primary health care workers of varying age, marital status, sex and education. ${ }^{61}$ Similarly, age was not associated with effectiveness in Kenya. ${ }^{62}$ And in Ghana, illiterate CHWs were as reliable as literate ones in reporting cases of guinea worm. ${ }^{63}$ Determining the criteria that are and are not important to motivation, retention, and effectiveness is important. For example, if literacy is not a criteria, more women are able to be involved. ${ }^{64}$

Counter to the experience in Guatemala, marital status and gender does appear to play a role in some programs. Married women in Mauritania were found to perform better than men $^{65}$ while unmarried women in Tanzania were associated with poor performance ${ }^{66}$ Male CHWs in India ${ }^{67}$ and male paramedics in Bangladesh ${ }^{68}$ were underutilized by women. As a result, BRAC changed their model in the early 1980s and began training an exclusive cadre of women CHWs ${ }^{69}$ While BRAC mentions that poor women who have few opportunities to receive paid employment may be more willing to work for small sums of money, ${ }^{70}$ there is a paucity of evidence on how gender influences retention and motivation.

\footnotetext{
${ }^{61}$ ibid., 263.

${ }^{62}$ Kaseje, Spencer, and Sempebwa, Characteristics and functions of community health workers in Saradidi, Kenya, 64. .

${ }^{63}$ Sandy Cairncross, Eka I. Braide, and Sam Z. Bugri, "Community participation in the eradication of guinea worm disease," Acta Tropica 61, no. 2 (1996): 123. .

${ }_{64}$ ibid., 123.

${ }^{65}$ O'Connor et al., Characteristics of effective Village Treatment Assistants: The Kongwa Trachoma Project, 263.

${ }^{66}$ ibid., 262.

${ }^{67}$ Gill Walt, "CHWs: Are National Programmes in Crisis?" Health Policy and Planning 3, no. 1 (1988): 18.

${ }^{68}$ Standing and Chowdhury, Producing effective knowledge agents in a pluralistic environment: What future for community health workers?, 2011.

${ }^{69}$ ibid., 2011.

${ }^{70}$ ibid., 2104.
} 
In general, studies on individual characteristics have tended to focus on performance broadly, without specifying how particular individual characteristics impact retention and motivation. The review by Bhattacharyya et al provided the only examples that related directly to retention and motivation. Bhattacharyya et al conclude that "community members are often much more aware of the characteristics that will ensure CHW retention." ${ }^{271}$ They base their statement on the following two examples. When asked what criterion the program should use to select CHWs, local communities in Ethiopia indicated that $\mathrm{CHWs}$ should be married (to be more permanent in the community) and not have an addiction to the herbal stimulant, chat. $^{72}$ And in Guatemala, communities indicated that CHWs should be chosen based on demonstrated commitment to the community. ${ }^{73}$ While it is logical to assume that these types of criteria would enhance retention and motivation, further research in this area should be conducted.

\section{1 Challenges}

Given the varied roles and contexts in which CHWs work, the types of characteristics that are most suitable are likely to differ considerably across projects and countries. However, based on this cursory evidence, it does appear that there may be some general patterns. Marital status, for example, was mentioned in several cases. As mentioned in the previous section on recruitment, if communities do not understand the role of the CHW well, they may not necessarily produce the most effective selection criteria. While it is easier to survey the community members on their input once they are

\footnotetext{
${ }^{71}$ Bhattacharyya et al., Community Health Worker Incentives and Disincentives: How They Affect Motivation, Retention, and Sustainability, 26.

72 ibid., 26.

${ }^{73}$ ibid., 26.
} 
familiar with the CHW program, it is more useful to establish such criteria prior to the initial selection of CHWs.

\subsection{Knowledge Gaps}

The few studies that have been conducted tend to focus on how individual characteristics relate to effectiveness broadly rather than motivation and retention more specifically. Furthermore, I could not find any studies that sought the opinion of CHWs on what characteristics are most important to retention and motivation. It is likely that CHWs would have considerable insight into this question. Thus, the case study with the Healthy Child Uganda project specifically examines in what way CHWs perceive age, gender, parental status, local council membership, and level of education to be important.

\section{Training}

\subsection{Training in Treatment Versus Prevention}

CHWs who are trained exclusively in preventative and health promotive tasks have been associated with higher rates of attrition. A number of articles by Walt, Standing, Curtale, and others contend that an exclusively preventative role creates a disconnect between the demand for curative services sought by the community and the preventative health education role with which the CHW has been tasked. This gap in expectations diminishes the community's and the CHWs perceived value of the role of the CHW. ${ }^{74}$ In Nepal, CHWs expressed "frustration that, contrary to the expectation of future for community health workers?, 2096. Curtale et al., Improving skills and utilization of community 
their fellow villagers, they were not really able to treat illnesses when they returned home after their 'health' training." ${ }^{75}$ A study was therefore conducted to test if adding curative services would increase community utilization of services and CHW motivation. The study found that $92 \%$ of mothers made contact with the $\mathrm{CHW}$ at least once in a 12 -month period compared to just $24 \%$ in the control group providing preventative services. ${ }^{76}$ In communities where CHWs provided supplementary curative services, community attendance and participation at CHW-organized events increased during the study period. $^{77}$

\subsection{Training Pedagogy}

Inadequate and inappropriate training has repeatedly been linked to low confidence in volunteers and subsequent high turn-over. ${ }^{78}$ In Burkina Faso, training was so inadequate that many CHWs did not even understand the purpose of their role. ${ }^{79}$ Training methods in early programs that were "too theoretical, too classroom-based and too complicated" were not well-received by CHWs. ${ }^{80}$ As a result of these criticisms, many programs have moved away from didactic training methods towards more participatory methodologies that develop skills for use in the community. ${ }^{81}$ Guatemala for example adopted Indonesia's model for training 'kaders' which uses tools such as role

health volunteers in Nepal, 1117 ; Walt, CHWs: Are National Programmes in Crisis?, 11 ; Curtale et al., Improving skills and utilization of community health volunteers in Nepal, 1118.

${ }^{75}$ ibid., 1118.

${ }^{76}$ ibid., 1119.

${ }^{77}$ ibid., 1122.

${ }^{78}$ P. Biggs-Jarrel, "Village Health Volunteers: Key Issues Facing Agencies in Malawi," Malawi Medical Journal 8, no. 2 (1992), 69.

${ }^{79}$ Sauerborn, Nougtara, and Diesfeld, Low utilization of community health workers: Results from a household interview survey in Burkina Faso, 1169.

${ }^{80}$ Gilson et al., National Community Health Worker Programs: How Can They Be Strengthened?, 524.

${ }^{81}$ Bhattacharyya et al, Community Health Worker Incentives and Disincentives: How They Affect Motivation, Retention, and Sustainability, 23. 
play to practice counseling and visual cue cards for practicing diagnostic algorithms. ${ }^{82}$ Since "learning skills is one of the main reasons CHWs volunteer," 83 adapting training pedagogy to suit the needs of CHWs can help improve motivation and effectiveness.

\subsection{Refresher Training}

Providing regular opportunities for refresher training has been strongly linked to motivation and retention. Continuous training also provides opportunities for $\mathrm{CHWs}$ to reinforce their skills and increase confidence in their abilities. "Skills do not develop at once. They develop gradually as a result of repeated supervised practice of skills followed by feedback from the supervisor." 84 These reasons are echoed by BRAC which considers refresher training important in order to build and retain knowledge, to provide a venue for supportive dialogue between CHWs, to maintain regular contact with the program/health system, and "most importantly, it gives CHWs the motivation to continue the work." ${ }^{" 85}$ In Nepal, adding three days of refresher training and curative tasks helped improve knowledge on the assigned health topics, utilization of $\mathrm{CHWs}$ by villagers, and reduced drop-out rates. The study estimates that "less than three additional training days provided regularly to the $\mathrm{CHWs}$ every year, will result in improved quality of service with consequent increased utilization." 86

J. E. Bailey, "Effectiveness of an Indonesian model for rapid training of Guatemalan health workers in diarrhea case management," Journal of community health 21, no. 4 (1996): 277.

${ }^{83}$ Bhattacharyya et al., Community Health Worker Incentives and Disincentives: How They Affect Motivation, Retention, and Sustainability, 22.

${ }^{84}$ Shrestha, A conceptual model for empowerment of the female community health volunteers in Nepal, 318-327.323.

${ }^{85}$ Standing and Chowdhury, Producing effective knowledge agents in a pluralistic environment: What future for community health workers?, 2101.

${ }^{86}$ Curtale et al., Improving skills and utilization of community health volunteers in Nepal, 1123. 
Where there are few opportunities for further education, CHWs often value training as an opportunity for personal development. ${ }^{87}$ In a 1987 study in Kenya, 'training' emerged as the strongest reason for continuing work as a $\mathrm{CHW}^{88}$ In Kenya "continuous training provided enough motivation for the village health helpers to continue working even without financial support and in Guatemala where the La Leche League mothers continued to provide services to the community four years after funding ended. "89

\subsection{Challenges}

On the one hand, training CHWs in the treatment of diseases can help increase motivation; on the other hand, erratic drug supplies can also cause communities to lose faith in CHWs and bypass their services. ${ }^{90}$ In some cases, CHWs simply stopped working after the first stock of supplies were distributed. ${ }^{91}$ Deciding whether or not CHWs should perform curative roles should depend partly on the capacity of the health system to procure and distribute drugs in a timely fashion. ${ }^{92}$ Furthermore, when drugs are made available, CHWs tend to focus on treatment only and "perform few promotive or preventative tasks." ${ }^{93}$ More training on the development of preventative and promotive skills may help overcome this trade-off and achieve a more balanced role. ${ }^{94}$

\footnotetext{
${ }^{87}$ Bhattacharyya et al, Community Health Worker Incentives and Disincentives: How They Affect Motivation, Retention, and Sustainability, 21.

${ }^{88}$ Kaseje, Spencer, and Sempebwa, Characteristics and functions of community health workers in Saradidi, Kenya, 63.

${ }^{89}$ Bhattacharyya et al., Community Health Worker Incentives and Disincentives: How They Affect Motivation, Retention, and Sustainability, 23.

${ }^{90}$ Curtale et al., Improving skills and utilization of community health volunteers in Nepal, 1124.

${ }^{91}$ ibid., 1118.

${ }^{92}$ Gennaro et al., Health promotion and risk reduction in Malawi, Africa, village women., 309.

${ }^{93}$ Gilson et al., National Community Health Worker Programs: How Can They Be Strengthened?, 527.

${ }^{94}$ ibid., 530.
} 
While it is well understood that CHWs find it easier to understand and develop skills when participatory training methodologies are used, the individuals who are providing this training must necessarily be well-versed in these same methods. In national programs where nurses or other public employees are used to train CHWs but have little experience with participatory learning methodologies, training of the trainers might be required. ${ }^{95}$ Such training would likely add to program costs and lengthen the preparation time.

\subsection{Knowledge Gaps}

The value that CHWs place on personal development and its impact on motivation and retention is generally under-emphasized. Most studies tend to focus on how training in prevention versus treatment and training methods relate to effectiveness. The Uganda case study examines the extent to which project CHWs are motivated by training and the reasons it is highly valued.

\section{Supervision}

Appropriate and ongoing opportunities for training must be complemented with adequate supervision to monitor performance and support morale. Weak support and supervision was "the one persistent weakness mentioned in all studies of CHWs" reviewed by Walt in $1989 .^{96}$ Many reports attribute low morale and low retention to the sense of isolation and abandonment that CHWs experience as a result of weak and poorly

\footnotetext{
${ }^{95}$ Roemer, M. I. "Priority for Primary Health Care: Its Development and Problems." Health policy and planning I, no. I (1986): 64.

${ }_{96}$ Walt, Perera, and Heggenhougen, Are large-scale volunteer community health worker programmes feasible? The case of Sri Lanka, 606 . .
} 
developed supervisory relationships. ${ }^{97}$ Ongoing contact with supervisors provides CHWs with a chance to discuss problems and reinforce training through one-on-one mentoring. CHWs associate strong links with $\mathrm{MoH}$ health staff with increased credibility, legitimacy, and prestige in their communities. ${ }^{98}$ In Sri Lanka, strong links to supervisors and the health system helped improve status and credibility of the CHWs. ${ }^{99}$ In Tanzania, the CHW program "has shown that optimal functioning depended primarily on visible support from higher levels..."100 An early study by Parlato and Favin measured two to three times lower attrition rates in Guatemalan CHWs that were supervised compared to those that were not. ${ }^{101}$ Direct supervision by BRAC program administrators during field visits is a key aspect of their program design. ${ }^{102}$

The inclusion of MoH health staff at CHW training can also help to build relationships and forge stronger bonds between $\mathrm{CHWs}$, their supervisors, and the health system. In Nepal joint training sessions in which $\mathrm{CHWs}$ and supervisors were trained together led to more frequent field supervision by the health staff. ${ }^{103}$ Monthly meetings between Bolivian CHWs, health care providers, and community meetings to discuss community-collected health data and develop action plans has resulted in increased community awareness, support, and positive attitudes for the work of the $\mathrm{CHW}{ }^{104}$

\footnotetext{
${ }^{97}$ Roemer, M. I. "Priority for Primary Health Care: Its Development and Problems." Health policy and planning 1, no. 1 (1986): 64. Curtale et al., Improving skills and utilization of community health volunteers in Nepal, 1123.

${ }^{98}$ Walt, Perera, and Heggenhougen, Are large-scale volunteer community health worker programmes feasible? The case of Sri Lanka, 604.

${ }^{99}$ ibid., 604.

${ }^{100}$ Curtale et al., Improving skills and utilization of community health volunteers in Nepal, 1124.

${ }^{101}$ Bhattacharyya et al., Community Health Worker Incentives and Disincentives: How They Affect Motivation, Retention, and Sustainability, 19.

${ }^{102}$ Standing and Chowdhury, Producing effective knowledge agents in a phuralistic environment: What future for community health workers?, 2100.

${ }^{103}$ Curtale et al., Improving skills and utilization of community health volunteers in Nepal, 1123.

${ }^{104}$ Bhattacharyya et al., Community Health Worker Incentives and Disincentives: How They Affect Motivation, Retention, and Sustainability, 21.
} 


\subsection{Challenges to Intensifying Supervision}

Despite the clear importance of supervision on retention and motivation, there are many challenges to intensifying the level of supervision. The cost of supervision can "represent $40 \%$ of the total cost of a CHW." ${ }^{105}$ Increasing the frequency of contact between CHWs and supervisors is hampered by "poor roads, insufficient and expensive transport, inadequate vehicle repair, and poor supplies of fuel."106 When there is no financial incentive to attend to supervisory duties, supervisors may have little motivation to monitor CHWs. ${ }^{107}$ Emerging technologies, such as the use of cell phones to communicate, send data, and make patient referrals, may help strengthen connections between CHWs, supervisors and the health system. While communications technology is becoming increasingly more affordable, such technology would still add significant costs.

\subsection{Knowledge Gaps}

In an effort to ground $\mathrm{CHW}$ programs more firmly in health systems, the literature places a strong emphasis on supervision. While improving supervision is key to improving motivation, retention, and effectiveness, ${ }^{108}$ less research has been dedicated to investigating complementary support mechanisms. In my opinion, investigation of complementary support systems should be driven not only from a cost-effective

\footnotetext{
${ }^{105}$ Gilson et al., National Community Health Worker Programs: How Can They Be Strengthened?, 521. ${ }^{106}$ P. A. Haggerty et al., "Community-based hygiene education to reduce diarrhoeal disease in rural Zaire: Impact of the intervention on diarrhoeal morbidity," International journal of epidemiology 23, no. 5 (1994): 1058

${ }^{107}$ Gilson et al., National Community Health Worker Programs: How' Can They Be Strengthened?, 528. ${ }^{108}$ Gennaro et al., Health promotion and risk reduction in Malawi, Africa, village women., 294. Gilson et al., National Community Health Worker Programs: How Can They Be Strengthened?, 528.
} 
standpoint, but also to more firmly ground CHWs in community networks that can support them.

Although not heavily emphasized in the literature, peer support appears to be an important avenue for improving retention and motivation. According to the Bhattacharyya et al "findings from Colombia, Mozambique, Nepal and Uganda show that peer support is as important to CHW performance as supervisory feedback." ${ }^{109}$ Peer support can be generated by opportunities to meet with other CHWs, through refresher training and formation of CHW associations. ${ }^{110}$ The Healthy Child Uganda case study tests how peer interactions contribute to retention and motivation.

\section{Compensation}

\subsection{Volunteerism}

As early as the late 1980 s, volunteer programs have been associated with higher rates of attrition. ${ }^{111}$ Walt argued that unremunerated CHWs will be difficult to retain except under rare conditions - notably where a strong tradition of volunteerism, usually founded on religion, exists, and in environments where revolutionary restructuring of society creates the drivers for community cooperation. He argues that the predominance of Buddhist traditions in Thailand, Sri Lanka and Burma ${ }^{112}$ that promotes volunteerism and the community orientation that arose under communist revolutionary governments in Mozambique, Burma, and China have made large-scale volunteer health programs

\footnotetext{
${ }^{109}$ Bhattacharyya et al., Community Health Worker Incentives and Disincentives: How They Affect Motivation, Retention, and Sustainability, 23.

${ }^{110}$ ibid., $\mathrm{x}$.

${ }^{111}$ Walt, Perera, and Heggenhougen, Are large-scale volunteer community health worker programmes feasible? The case of Sri Lanka, 600.

${ }_{112}$ ibid., 600.
} 
possible in these countries. ${ }^{113}$ However, even these countries have experienced

difficulties retaining CHWs. In Sri Lanka, most CHWs volunteered their services in hope that their volunteer position would lead to paid employment. ${ }^{114}$ Mozambican CHWs who "had been happy to volunteer under socialism," are now demanding payment as the country shifts towards a capitalist economic system. ${ }^{115}$ In their recent report, Lehmann and Sanders conclude that there "exists virtually no evidence that volunteerism can be sustained for long periods."116

\subsection{Payment}

It is widely held that CHWs "expect and require an income." 117 When a project by the Christian Reformed Church in Nigeria introduced cash incentives, retention increased, though average retention was still only 3.25 years for men and 1.5 years for women. ${ }^{118}$ BRAC considers the ability of $\mathrm{CHWs}$ to earn an income extremely important for motivation and retention. ${ }^{119}$ Their volunteers are provided with a small loan to create a revolving fund to purchase drugs which are sold at a profit. The sale of medicines and other products allows CHWs to compete against other informal providers and helps give them legitimacy. ${ }^{120}$ For Bangladeshi women, especially rural women, who have very few

\footnotetext{
${ }^{113}$ ibid., 606. Bhattacharyya et al., Community Health Worker Incentives and Disincentives: How They Affect Motivation, Retention, and Sustainability, 6. Walt, CHWs: Are National Programmes in Crisis? 12. ${ }^{114}$ ibid., 3.

${ }^{115}$ Bhattacharyya et al., Community Health Worker Incentives and Disincentives: How They Affect Motivation, Retention, and Sustainability, 6.

${ }^{116}$ Lehmann and Sanders, Community health workers: What do we know about them? The state of the evidence on programmes, activities, costs and impact on health outcomes of using community health workers, www.who.int/hrh/documents/community health_workers_brief.pdf, vi.

117 ibid., vi.

${ }^{118}$ Bhattacharyya et al., Community Health Worker Incentives and Disincentives: How They Affect Motivation, Retention, and Sustainability, 15.

${ }^{119}$ Standing and Chowdhury, Producing effective knowledge agents in a phralistic environment: What future for community health workers? 2103.

120 ibid., 2103.
} 
opportunities to earn even a small amount of money, even three dollars a month can help sustain motivation.

\subsection{Non-monetary incentives}

In addition to or in lieu of a salary, some programs have provided payments inkind, travel allowances, gifts and preferential treatment. T-shirts for identification, bags, umbrellas or raincoats, and gifts of grain, sugar, soap or other household items are all considered perks of the position and can help substitute for low salaries. ${ }^{121}$ Awarding CHWs preferential access to micro-credit, literacy classes, or rapid treatment at health clinics, as already done in some countries, rewards CHWs while keeping costs down. ${ }^{122}$ While it is assumed that these types of non-monetary incentives contribute to improved motivation, there is very little evidence that directly associates types of incentives to improved retention. The review by Bhattacharyya et al. found only a single example of an organization using a behavioural model to plan $\mathrm{CHW}$ incentives and track attrition rates. $^{123}$

While all CHWs would like to be paid, there are other forms of motivation that do not derive from money. BRAC notes that other non-financial forms of motivation must complement income-generating sales. ${ }^{124}$ In other studies, witnessing observable declines in morbidity and mortality; ${ }^{125}$ a sense of personal accomplishment and fulfillment; and

\footnotetext{
${ }^{121}$ Bhattacharyya et al., Community Health Worker Incentives and Disincentives: How They Affect Motivation, Retention, and Sustainability, 20.

122 ibid., 20.

123 ibid., 31.

${ }^{124}$ Standing and Chowdhury, Producing effective knowledge agents in a phralistic environment: What future for community health workers? 2101.

${ }_{125}$ Caimcross, Braide, and Bugri, Community participation in the eradication of guinea worm disease, $121-$ 136.; Bhattacharyya et al., Community Health Worker Incentives and Disincentives: How They Affect Motivation, Retention, and Sustainability, 21.
} 
service to the community were rated as the strongest motivators. ${ }^{126}$ Finding creative ways to recognize and validate the work of CHWs can help satisfy other dimensions of motivation.

\subsection{Challenges to Remuneration}

Remunerating CHWs creates its own set of problems. Delayed or irregular payment has been noted as a major deterrent. " ${ }^{127}$ "Low salaries that are considered an insufficient living wage are also associated with high drop-out rates. ${ }^{128}$ Furthermore, initial payment usually leads to future calls for increases. ${ }^{129}$ Discrepancies between salaries of CHWs, health center staff and locals employed by other NGOS can also create tensions and lead to job dissatisfaction. ${ }^{130}$ In 1985 in Jamaica where CHWs lobbied for government salaries, they became more closely linked to the health center, but their availability in the community diminished. ${ }^{131}$ When associated with profits that are the 'incentive' for the CHW, few of these schemes have been successful or achieved any level of scale." 132 It is also important to make sure that various forms of in kind payment are provided in a transparent way that will not perceived as a bribe. Furthermore, nonmonetary incentives, when given in excess, can have the opposite effect and act as a

\footnotetext{
${ }^{126}$ Walt, Perera, and Heggenhougen, Are large-scale volunteer community health worker programmes feasible? The case of Sri Lanka, 602.

${ }_{127}$ Bhattacharyya et al., Community Health Worker Incentives and Disincentives: How They Affect Motivation, Retention, and Sustainability, 16.

${ }^{128}$ H. H. Gray and J. Ciroma, "Reducing attrition among village health workers in rural Nigeria," Socioeconomic planning sciences 22, no. 1 (1988): 39-43.

${ }^{129}$ Bhattacharyya et al., Community Health Worker Incentives and Disincentives: How They Affect Motivation, Retention, and Sustainability, $\mathrm{x}$.

${ }^{130}$ ibid., 16.

${ }^{131}$ World Bank, World Development Report 1993: Investing in Health, Oxford University Press, http://files.dcp2.org/pdf/WorldDevelopmentReport1993.pdf, 156.

${ }^{132}$ Bhattacharyya et al., Community Health Worker Incentives and Disincentives: How They Affect Motivation, Retention, and Sustainability, 15.
} 
demotivating influence in the long-term. ${ }^{133}$ There is a danger that "treating health workers as if their motivations were wholly financial might undermine whatever produces the ethos of public service... and reforms that do not take this factor into account will undermine the development of the public mission itself." ${ }^{\prime 134}$

\subsection{Knowledge Gaps}

Failure to motivate and retain volunteers has triggered a relatively one-sided call for remuneration of CHWs while the counter-call for research and exploration into innovative ways to motivate CHWs has not been driven forward with the same momentum. On the whole, volunteerism in developing countries is poorly understood. Much of the literature on volunteerism originates from industrialized countries where volunteers donate their time from a secure financial base. ${ }^{135}$ Little is understood about why the poor in developing countries choose to volunteer. CHW programs often disproportionately rely on women volunteers - individuals who are already burdened with household and family duties. ${ }^{136}$ In Malawi, the ministry of health surmises that respect and prestige are insufficient motivators, but they note that the lack of systematic evaluation of volunteer motivations in Malawi prevents them from drawing any strong conclusions. ${ }^{137}$ The case study from Healthy Child Uganda helps fill this knowledge gap by examining what other factors motivate project CHWs given their nominal compensation. Better understanding of overlapping motivations - monetary and nonmonetary - can help improve retention and motivation and keep costs down.

\footnotetext{
${ }^{133}$ ibid., 17.

${ }^{134}$ Hongoro and McPake, How to bridge the gap in human resources for health, 1455.

${ }^{135}$ Walt, CHWs: Are National Programmes in Crisis?, 3.

${ }^{136}$ Zakus and Lysack, Revisiting Community Participation, 7.

${ }^{137}$ Biggs-Jarrel, Village Health Volunteers: Key Issues Facing Agencies in Malawi, 67.
} 


\section{Community Support}

As community health workers, CHWs must be rooted in the community. ${ }^{138}$ Lack of perceived community support by CHWs has been a major cause of low motivation and high attrition among CHWs. In many programs "the potential of the CHW has not been realized because of a poor relationship with the community." "32 percent of the nonworking village health workers surveyed left their posts because of a lack of community support." ${ }^{140}$ In Burkina Faso, lack of community support was attributed to the low motivation and high attrition rate of $\mathrm{CHWs}{ }^{141}$

The success of a "community based health agent lies in the fact that there are forms of trust and legitimacy in health care services which do not derive from the professionalisation model but are much more firmly embedded in local social relations, and such agents, where successful, embody this." ${ }^{142}$ Reinforcing the primacy of community involvement, "a study in Colombia found that the community had more influence on the CHWs than the health system, contrary to widely held assumptions. If the community...is the primary reference group for CHWs, then feedback from the community has a significant influence on motivation and performance."143

A number of studies point to the fact that community appreciation and/or community respect for their work are among the strongest motivations. In Indonesia,

\footnotetext{
${ }^{138}$ Zakus and Lysack, Revisiting Community Participation, 9.

${ }^{139}$ Bhattacharyya et al., Community Health Worker Incentives and Disincentives: How They Affect Motivation, Refention, and Sustainability, 25.

140 ibid., 25.

${ }^{141}$ Sauerborn, Nougtara, and Diesfeld, Low utilization of community health workers: Results from a household interview survey in Burkina Faso, 1170.

${ }^{142}$ Standing and Chowdhury, Producing effective knowledge agents in a pluralistic environment: What future for community health workers?, 2105.

${ }^{143}$ Bhattacharyya et al., Community Health Worker Incentives and Disincentives: How They Affect Motivation, Refention, and Sustainability, 20.
} 
'compliments from the community' ${ }^{144}$ and in Columbia 'having influence in the community $^{145}$ and in Ghana, recognition for helping to eliminate a hated scourge ${ }^{146}$ were identified as important motivators. Praising $\mathrm{CHWs}$ over the radio for their hard work has shown to increase utilization of CHWs and retention in Indonesia. ${ }^{147}$ Finding creative ways to recognize and validate the work of CHWs can help improve motivation and retention.

\subsection{Challenges}

The concept of community ownership and participation has been poorly conceived and difficult to operationalize in practice. Community ownership is not automatic. In the past, over idealistic expectations that CHWs - in their role as change agents - would be able to singlehandedly mobilize communities to support their activities led to problems of high attrition. Similarly, programs which bypassed substantive community involvement in an effort to increase efficiency also experienced similar problems of low motivation. CHWs were perceived as part of the health system or donor employees, not community representatives. Today, there is a general consensus that community participation in recruitment can serve as a practical means to improve community ownership. Although our understanding has developed, there is still a lack of understanding how to garner community ownership and what level and intensity of

\footnotetext{
${ }^{144}$ Reis, An Examination of the Performance and Motivation of Indonesian Village Health Volunteers., 25.

${ }^{145}$ Bhattacharyya et al., Community Health Worker Incentives and Disincentives: How They Affect Motivation, Retention, and Sustainability, 28.

${ }^{146}$ Caimcross, Braide, and Bugri, Community participation in the eradication of guinea worm disease, 129.

${ }^{147}$ Bhattacharyya et al., Community Health Worker Incentives and Disincentives: How They Affect Motivation, Retention, and Sustainability, 19.
} 
community participation is required. ${ }^{148}$ Generating community ownership is a slow, bottom-up process that is variable and hard to measure. ${ }^{149}$

\subsection{Knowledge Gaps}

The primacy of the relationship between CHWs and the community is often overlooked. Given the complexity and failures in understanding community relationship building, programs are looking to financial remuneration as an easier, more practical means of improving motivation and retention. The Healthy Child Uganda case study tests how community selection, respect in the community and community demand for services weigh in relation to other motivators.

\section{Chapter Summary}

Problems associated with lack of community participation in recruitment, limited understanding of selection criteria, inadequate training and supervision, low compensation and community support are linked to high attrition rates and low motivation. Based on the literature review, I constructed the following diagram to present the key determinants of motivation, retention, and effectiveness.

\footnotetext{
${ }^{148}$ M. Rosato et al., "Community participation: lessons for maternal, newborn, and child health," The Lancet 372, no. 9642 (2008): 967.

${ }^{149}$ J. E. Lawn et al., "Alma-Ata 30 years on: revolutionary, relevant, and time to revitalise," The Lancet 372, no. 9642 (2008): 924.
} 


\subsection{Diagram 1 - Determinants of Motivation, Retention, and Effectiveness}

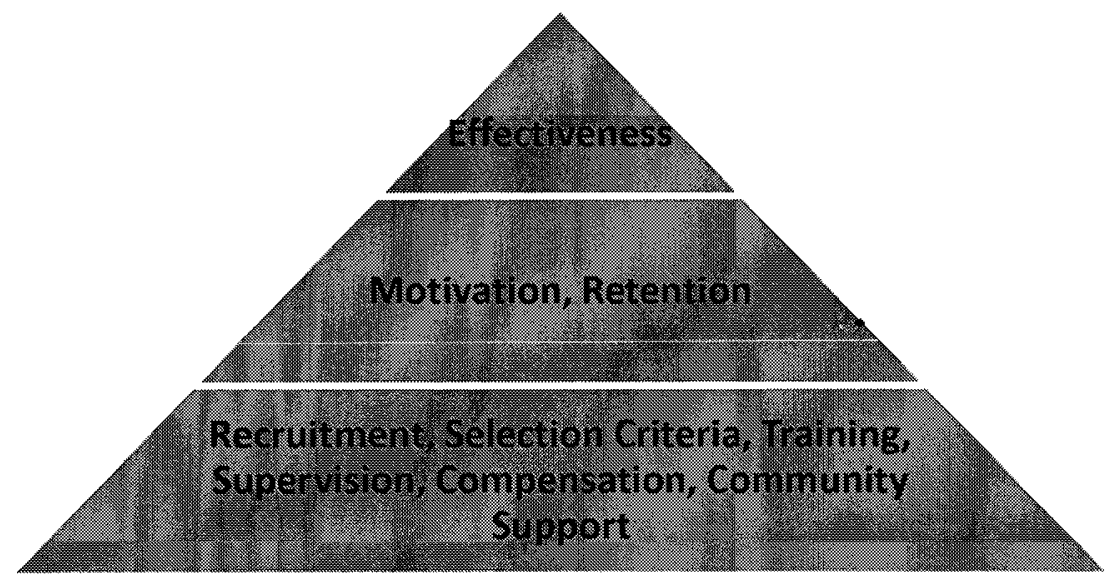

While there are undoubtedly other factors that contribute to motivation and retention, the components identified appear to play a strong role. Based on the six elements identified in the literature review - recruitment, selection criteria, training, supervision, compensation, and community support - I developed the following hypotheses and exploratory questions. Community participation in recruitment is important to motivation and retention because it helps generate community support and reduce selection bias. I also explored whether $\mathrm{CHWs}$ feel that community participation in recruitment is important to their motivation and continued service. I hypothesized that marital status and gender, but not age or education, affect $\mathrm{CHW}$ effectiveness and explored what other characteristics may also have an effect? I also hypothesized that training contributes strongly to motivation, retention and effectiveness because it gives CHWs confidence and skills that their communities value. I tested whether peer and community support contribute to the retention and motivation of CHWs. Finally, I hypothesized that $\mathrm{CHWs}$ are more motivated by financial compensation than an ethos of community service. 
Although the literature has identified elements that influence retention and motivation, there are still large knowledge gaps surrounding how to best reduce attrition rates. ${ }^{150}$ To help elucidate better understanding of the determinants of retention and motivation and help fill the gaps that emerged in the literature review, I tested how the nine hypotheses and two exploratory questions based on the six key elements influence retention, motivation, and effectiveness in the Healthy Child Uganda project.

${ }^{150}$ Bhattacharyya et al., Community Health Worker Incentives and Disincentives: How They Affect Motivation, Retention, and Sustainability, xii. 


\section{CHAPTER 6: CASE STUDY: HEALTHY CHILD UGANDA PROJECT}

The literature review identified that $\mathrm{CHWs}$ can effectively perform basic health services to improve utilization of health services, health behaviours and health outcomes. However, the effectiveness of $\mathrm{CHW}$ programs requires that a number of supportive elements be in place, namely appropriate recruitment, selection, training, supervision, compensation, and community support. These elements contribute not only to the traditional measures of effectiveness, but also to the retention and motivation of CHWs. While there is a growing body of knowledge about how these six components contribute to retention, motivation, and effectiveness, key knowledge gaps remain.

I conducted a case study to test the nine hypotheses and three exploratory questions pertaining to the six program components. Based on the absence of studies, I examined CHW views on community participation in recruitment and the influence of personal characteristics and attributes on retention, motivation and effectiveness. Diverging from the traditional focus on supervisory support systems, I tested the role of peer and community support on motivation and retention. Lastly, I tested the strength of various motivators in a project that uses volunteer CHWs to carry out primarily health promotion activities.

This study confirms that each of the six elements have an important influence on retention, motivation, and effectiveness. While many of the results confirmed the hypotheses, the findings also shed light on some new dimensions. The findings suggest that level of education, local council membership, marital status, parental status and gender may be linked to retention, motivation, and effectiveness. Contrary to most findings in the literature, project CHWs demonstrated a willingness to carry out 
preventative and promotive health activities on a primarily voluntary basis. This suggests that it is possible to stimulate community demand for preventative and promotive services and that $\mathrm{CHWs}$ can be highly motivated by non-monetary drivers. These findings have particular relevance given the current focus on compensation and curative activities. Thus, the results of this study help reinforce and strengthen existing evidence in the literature while helping to expand on less well-understood areas that can inform program implementation as increasing levels of health assistance are directed towards CHW programs.

\section{Suitability of Case Study Location}

Although the location of the case study was selected purposively rather than randomly, the Healthy Child Uganda (HCU) project, nevertheless, provides a good location to test the hypotheses. As a region, Africa has among the worst health indicators in the world and the most severe health worker shortages. ${ }^{1}$ Consequently, many donors have begun making large investments in CHW programs in Africa. ${ }^{2}$ Despite the current focus on Africa, there are comparatively fewer CHW studies that have been conducted in Africa compared to Asia.

The 2006 World Health Report estimates that there is a global shortage of approximately 4.3 million health workers, including1 .5 million needed for Africa alone. ${ }^{3}$ "Of the 20 countries with the lowest physician to population ratios, African countries

\footnotetext{
${ }^{1}$ The Global Burden of Disease: 2004 Update, Anonymous World Health Organization, 2008), 16-17. 2 "The Catalytic Initiative to Save a Million Lives," in Canadian International Development Agency (CIDA) [database online]. Sept. 9, 2009Available from $\underline{\text { tttp://www.acdi-cida.gc.ca/acdi-cida/acdi- }}$ cida.nsf/eng/NAD-1249841-JLG.

${ }^{3}$ Nigel Crisp, Bience Gawanas, and Imogen Sharp, "Training the health workforce: scaling up, saving lives," The Lancet 371, no. 9613 (2008): 689-690.
} 
claim all but two spots. In Tanzania, Ethiopia, [and] Sudan... there are 2, 3, [and] 22 physicians respectively per 100,000 people." 4 Expanding the pool of health workers in Africa is severely constrained by the scant number of medical schools ("two-thirds of sub-Saharan African countries have only a single medical school). ${ }^{5}$ The migration of health workers further exacerbates the health worker crisis. Ten to forty percent of all health care students in sub-Saharan Africa find employment out of continent. ${ }^{6}$ Meanwhile the HIV/AIDS epidemic continues to place a growing burden on health systems. $^{7}$

Secondly, focusing on a child health project is particularly pertinent given the astoundingly high rate of child mortality in Sub-Saharan Africa. According to global statistics, "the death rate per 1000 children aged $0-4$ years in the African Region is almost double that of the region with the next highest rate." 8 The rate is 88 per 1000 in developing countries, ${ }^{9} 120$ per 1000 in the poorest of these countries, ${ }^{10}$ and shockingly 172 per 1000 in sub-Saharan Africa. ${ }^{11}$ In absolute numbers, over half of all child deaths occur in Africa. ${ }^{12}$ The WHO Africa Region accounts for "more than 9 out of 10 child deaths directly attributable to malaria, 9 out of 10 child deaths due to HIV/AIDS, 4 out of

\footnotetext{
${ }^{4} \mathrm{~W}$. Burdick, "Challenges and issues in health professions education in Africa," Medical teacher 29, no. 910 (2007): 883.

${ }^{5}$ C. Hongoro and B. McPake, "How to bridge the gap in human resources for health," Lancet 364, no. 9443 (2004): 1452.

${ }^{6}$ Crisp, Gawanas, and Sharp, Training the health workforce: scaling up, saving lives, 690.

${ }^{7}$ Uta Lehmann and David Sanders, Community health workers: What do we know about them? The state of the evidence on progranmes, activities, costs and impact on health outcomes of using community health workers, Anonymous , January 2007), www. who.int/hrh/documents/community health workers brief.pdf., 13.

${ }^{8}$ The Global Burden of Disease: 2004 Update, 26.

${ }^{9} \mathrm{C}$. G. Victora et al., "Applying an equity lens to child health and mortality: More of the same is not enough," Lancet 362, no. 9379 (2003): 234.

${ }^{10}$ ibid., 234.

${ }^{11}$ Department for International Development (Dfid), Millennium Development Goal 4, 2009), http://www.dfid.gov.uk/Global-Issues/Millennium-Development-Goals/4-Reduce-child-mortalitv/. http://www.dfid.gov.uk/mdg/childmortalityfactsheet.asp).

${ }^{12}$ ibid.
} 
10 child deaths due to diarrhoeal diseases and 5 out of 10 child deaths due to pneumonia." While an estimated $80 \%$ of African children die at home without seeing a health care provider, it is estimated that nearly two-thirds of childhood deaths could be prevented through universal coverage of a few basic interventions, combined with clean water and sanitation. ${ }^{13}$ Effective $\mathrm{CHW}$ programs could go a long way to reducing the disproportionately high child mortality in the region.

Thirdly, Uganda in particular is a good case study. According to the WHO, the country has a doctor-patient ratio of less than $1: 24,000^{14}$ and in 2005 placed $14^{\text {th }}$ among countries with the highest child mortality. The government has recently begun to accelerate the roll-out of village health teams which include CHWs as part of the government's national health strategy. ${ }^{15}$ "CHWs carry out health education during home visits to members of the community and at community gatherings and distribute antimalarials, vitamin A, condoms, albendazole - a drug used for de-worming - and oral rehydration solution for use in cases of diarrhea." 16 Over the next few years, an increasing part of the country will be covered by village health teams. Thus the HCU case study can help provide recommendations that are directly applicable to the context of Uganda.

And lastly, because the factors that influence motivation, retention, and effectiveness are not fully understood, examining a CHW project that has been able to successfully retain its volunteers can help provide insight into under-investigated dimensions. Since the case study was selected based on the dependent variable of high

\footnotetext{
${ }^{13}$ ibid.

${ }^{14}$ Kyalimpa, Joshua. "UGANDA: Village Health Teams: First Draft of a Solution." IPS News. http://ipsnews.net/news.asp?idnews $=46414$ )

${ }^{15} \mathrm{http}: / /$ www.ugandavillageproject.org/what-we-do/healthy-villages/village-health-teams/

${ }^{16} \mathrm{http} / / / \mathrm{www} . u g a n d a v i l l a g e p r o j e c t . o r g / w h a t-w e-d o / h e a l t h y-v i l l a g e s / v i l l a g e-h e a l t h-t e a m s /$
} 
retention, it cannot test whether volunteerism or a primarily preventative role contributes to lower or higher retention; however, the case study, does nevertheless, shed understanding on what motivates CHWs in primarily volunteer programs serving a preventative role. The findings can help policymakers as they try to find a balanced role for compensation and prevention in program design.

\section{Background: Healthy Child Uganda Project}

Healthy Child Uganda (HCU) is a child survival project conceptualized and implemented by Ugandans with Canadian support ${ }^{17}$. In 2003, the Mbarara University of Science and Technology (MUST) in Uganda and Bushenyi and Mbarara District Health Services (DHS) partnered with the University of Calgary (UofC), Dalhousie University, and the Canadian Paediatric Society to implement this project. Since then, the project has received a number of awards for its accomplishments and community-oriented strategy. ${ }^{18}$ Since 2003, HCU has trained 379 CHWs in 175 villages serving a population of approximately 95,000 people. $^{19}$ The project reaches approximately 16,000 Uganda children under five annually.

\footnotetext{
${ }^{17}$ Funding from the Canadian International Development Agency $(\$ 75,000$ between 2003-2005) and the Association of Universities and Colleges of Canada (AUCC) (\$1M between 2005-2010) and private Canadian donors.

${ }^{18}$ I@MAK, National Innovation Award from Makerere University, Kampala (2006); Outreach and Community Relations Award from The Association of Commonwealth Universities (2007); National 'Best Practice' awards from The Civil Society Capacity Building Programme of Uganda (2008); Project Director and Dean of Medicine at Mbarara University of Science and Technology, Jerome Kabakyenga was awarded a Teasdale-CortiGlobal Health Leadership Award from Canada's Global Health Research Initiative (2009).

${ }^{19} 2006$ HCU Baseline Survey report, 20
} 


\subsection{Causes of Childhood Death in HCU Project Areas}

HCU works in poor, rural communities in southwestern Uganda where "most families support themselves through subsistence farming. Many lack clean drinking water, proper hygiene, and adequate nutrition. With limited infrastructure, transportation and communication tools, travel to health facilities is extremely challenging. Health facilities suffer from shortages of staff, medications and materials to adequately treat the many sick children they see. ${ }^{.20}$ Based on 1123 household surveys, $80 \%$ of mothers reported that their youngest child had been sick in the previous 2 weeks: "Diarrhoea was the most commonly cited illness, affecting $43 \%$ of children. Malaria/fever was reported in $32 \%$ and $15 \%$ had fast breathing/difficult breathing, suggestive of an Acute Respiratory Illness (ARI) ...8.5\% of children reportedly 'passed worms' in stool or vomit." ${ }^{21}$ According to the survey, the most common causes of childhood deaths in these two districts are malaria, pneumonia, diarrhea, measles and meningitis. ${ }^{22}$ Twentytwo percent of children younger than 24 months demonstrated moderate or severe malnutrition based on weight for age. ${ }^{23}$ A country-wide estimate conducted by UNICEF in 2005 measured under-five child mortality at $137 / 1000$ live births. ${ }^{24}$

\subsection{The Role of CHWs in the HCU project}

HCU trains CHWs to serve as health educators and promoters by performing community health talks and home visits. Training is conducted using a participatory

\footnotetext{
${ }^{21} 2006$ HCU Baseline Survey report, 64.

222006 HCU Baseline Survey report, 16.

${ }^{23} 2006$ HCU Baseline Survey report, 44.

${ }^{24} 2006$ HCU Baseline Survey report, 16.
} 
methodology and is based on the topics outlined in the WHO/UNICEF Integrated Management of Childhood Illness (IMCI) strategy. Initial training spans five days and is followed by monthly refresher sessions with a supervisor from the health center. Topics cover immunization, nutrition, breastfeeding, weaning, hygiene and sanitation, HIV/AIDS, malaria, newborn care, antenatal care, and family planning. Training in health promotion is grounded in a broader focus on community development and emphasizes the development of leadership and community facilitation skills. Other duties include organizing National Child Health Days (biannual outreach campaigns), performing growth monitoring, assisting with home-management of diarrhea using homebased oral rehydration salts (ORS), distributing free malaria nets, referring children with severe dangers signs to health centers, and record-keeping.

\subsection{HCU Project Design and Implementation}

Project guidelines stipulate that CHWs should be selected in a representative and transparent manner by their own communities in a process facilitated by project management and health center staff. The local council leader is made responsible for setting the day of the selection and mobilizing community members to attend. HCU management and health center staff then orient community members about the project goals and responsibilities of CHWs. Following the introduction, those in attendance are asked to select two individuals, one of whom must be a woman, to be trained by HCU. The individual selected should be a parent and be able to read and write in the local language. 
CHWs are integrated into the district health systems via the direct supervision of CHWs by health center staff. CHWs do not receive a salary but are provided 1500 Shillings (approximately \$1US per month as a transportation allowance to the monthly meeting. (Most CHWs, however, save the money and simply walk to the meeting location). Other incentives include a t-shirt for identification, certificates, participation in project competitions, and more recently, some financial support for income-generating activities.

\subsection{Table 3 - CHW Demographics and Activities}

\begin{tabular}{|c|c|c|c|c|}
\hline \multicolumn{3}{|c|}{$\begin{array}{l}\text { CHW Demographics (April 2009) } \\
\text { (sample size n-177) }\end{array}$} & $\begin{array}{l}\text { CMW Activities }(2008) \\
(1=350)\end{array}$ & \multirow{2}{*}{$\frac{\sqrt{3}}{\text { Avg. } 40}$} \\
\hline Female & $68 \%$ & & $\begin{array}{l}\text { \# children under } 5 \text { covered per } \\
\text { CHW }\end{array}$ & \\
\hline $\begin{array}{l}\text { Schooling: } \\
\text { Primary 4-6 } \\
\text { Senior 1-3 } \\
\text { Senior 4-6 }\end{array}$ & $\begin{array}{l}62 \% \\
20 \% \\
15 \%\end{array}$ & 3 & $\begin{array}{l}\text { Annual: } \\
\text { Home visits } \\
\text { Referrals }\end{array}$ & $\begin{array}{l}43,500 \\
2,800\end{array}$ \\
\hline Mean Age & 35 & 络 & New small businesses & 80 \\
\hline Avg. \# children & 4.8 & & Livestock projects & 100 \\
\hline Avg. \# children under 5 & 2.1 & & Savings/loan groups & 450 \\
\hline Child under 5 & $94 \%$ & & $\begin{array}{l}\text { CHW groups with constitutions \& } \\
\text { registered as community-based } \\
\text { organizations (CBOs) }\end{array}$ & $100 \%$ \\
\hline
\end{tabular}

\subsection{Retention}

According to $\mathrm{HCU}$ project registries, $\mathrm{HCU}$ has trained a total of $379 \mathrm{CHWs}$ since 2003 , approximately $69 \%$ of whom are women. Excluding those who have died or changed residence (usually following divorce), approximately $95 \%$ and $96 \%$ of the volunteers trained in 2004 and post-2006 respectively are still in active service.

\footnotetext{
${ }^{25}$ Data obtained directly from the Healthy Child Uganda project
} 
Retention among female CHWs is higher than that of male CHWs. Overall, the project considers $\mathrm{CHW}$ retention rate to be high.

\subsubsection{HCU Retention Rates}

\begin{tabular}{|c|c|c|}
\hline * Reason for Resignation & $\begin{array}{l}\text { Number of Resigned } \\
\text { CHW's to Date across all } \\
\text { project areas }\end{array}$ & $\begin{array}{l}\text { Núnber of Resignied } \\
\text { Cliws from } 9 \text { orignal } \\
\text { project areas only }(2004)\end{array}$ \\
\hline Changed residence & 6 & 4 \\
\hline Too busy & 5 & 4 \\
\hline Health & 4 & 0 \\
\hline Business & 3 & 0 \\
\hline Death & 2 & 1 \\
\hline Fired & 1 & 1 \\
\hline Further education & 1 & 1 \\
\hline Unknown & $\frac{1}{1}$ & 0 \\
\hline Total: & $23 / 379$ & $11 / 117$ \\
\hline Retention & $94 \%$ & $94 \%$ \\
\hline
\end{tabular}

\subsection{Retention of CHWS by Gender}

\begin{tabular}{|l|c|c|c|}
\hline & $\begin{array}{c}\text { Total Traited } \\
\text { Since 2004 }\end{array}$ & $\begin{array}{c}\text { Number Resigied } \\
\text { (by Gender) }\end{array}$ & $\begin{array}{c}\text { Retention Rate } \\
\text { (by Gender) }\end{array}$ \\
\hline Females & 260 & 11 & $96 \%$ \\
\hline Males & 119 & 12 & $90 \%$ \\
\hline Total & 379 & 23 & - \\
\hline
\end{tabular}

\subsection{Project Impact on Child Mortality}

Calculating HCU's impact on child mortality has been extremely challenging.

UNICEF notes that measuring child mortality is extremely difficult; in 2005 only about $4 \%$ of births in the country were registered, and most deaths occur at home ${ }^{26}$ According to $\mathrm{CHW}$ reports recording the number of monthly births and deaths of children under five, HCU calculated a 35\% decline in child morality between May 2006 and April 2009

\footnotetext{
${ }^{26}$ http://plan-international.org/birthregistration/resources/country-case-studies/uganda
} 
across its nine original communities. ${ }^{27}$ In order to verify the accuracy of the CHW reporting, $\mathrm{HCU}$ conducted an audit earlier this year. From information obtained in the audit, the number of deaths reported by CHWs closely resembled the numbers reported via household surveys. However, there were significant differences between the number of births reported. Thus, HCU concludes that the number of childhood deaths has declined significantly over time, but cannot conclusively report on mortality. National data for this region is not available.

\section{Results}

This study tested how the six elements - community participation in recruitment, selection criteria, training, supervision, compensation, and community support - affect retention, motivation, and effectiveness. The results of the study are separated into two chapters. The first focuses on recruitment and selection criteria, while the second focuses on the four remaining elements.

The results of this chapter demonstrate that community participation in recruitment is widely supported by CHWs. CHWs support community participation in recruitment as a mechanism to improve candidate selection and generate community support. Marital status, gender, local council membership, level of education, cooperative nature, and concern for healthy communities represent potential areas that may impact retention, motivation, and effectiveness. Policy makers would be wise to invest time and resources to promote community participation in recruitment and should pay closer attention to selection criteria in order to improve retention, motivation, and effectiveness of CHWs.

\footnotetext{
${ }^{27}$ Includes only 9 out of 18 districts where the project was first implemented in 2003.
} 


\section{Recruitment}

Hypothesis 1: Community participation in recruitment is important to motivation and retention because it helps generate community support for the work of the CHW and reduces selection bias.

Given the high retention among project CHWs, the case study tested to what extent representative, participatory recruitment processes were used. Three main measures were used to gauge the level of participation and representation: the percentage of CHWs who recall being selected by the community; total percentage of the village present; and, the percentage of village women present. A fourth measure - type of democratic selection mechanism used - explored how villagers were engaged in the process.

\subsection{Key Results}

Among the $46 \mathrm{CHWs}$ surveyed, $87 \%$ were selected in a community election. Eighty-nine percent recall at least half of the community being present on selection day and $87 \%$ estimate that women comprised at least half of those in attendance. Thus, gender representativeness and overall levels of participation appear to be quite high.

Democratic mechanisms used by communities to select CHWs include: allowing each side of the village to choose one $\mathrm{CHW}$; allowing individuals to nominate him/herself for consideration; accepting only third party nominations; nominating two individuals (without opposition) and confirming them by consensus, and choosing from among several candidates. Sixty-five percent (26/38) of CHWs who were elected by their community specifically mentioned that at least three individuals stood for election. 
Voting was typically carried out by show of hands or by standing behind the candidate of their choice. In one case, candidates were required to deliver a speech outlining his/her suitability. Six CHWs were selected in an irregular fashion in which either local council leaders were uniquely responsible for choosing the CHWs or the community was requested to choose a CHW from among a small group of individuals on the women's council or local council. This represents an aberration from project policy.

\subsection{Additional Results}

When asked whether the community encountered any problems on selection day, only three respondents indicated so. In one case, a belief that CHWs would benefit financially from the project led to competition and quarrels among individuals eager to be selected. In another case, the community pushed for two women CHWs rather than following the project preference of selecting a male and female CHW. The third did not elaborate on the problem.

One CHW was forced to resign when a conflict between her, her sister-in-law, who was the other $\mathrm{CHW}$, and the local council chairman developed:

"My fellow CHW reported me to the chairman and stopped me from working without my consent. It was really a family rather than a work issue. The CHW who was my colleague was my sister in law and had taken my child as her housemaid. So when I complained about my child, she decided to report me to the local council chairman. The chairman who had developed a relationship with my sister in law decided to dismiss me. Since the CHW selection was not done by the community, I did not have any community to support me against the chairman."

Six of eight local council members indicated that community elections are important for creating community-wide awareness about the program and identification with the 
volunteer responsible for working with them. Similarly, five of seven members resigned after indicating that community election was the preferred means of recruitment.

\subsection{Discussion of Results}

Based on participant recall, gender representativeness and overall levels of participation appear to be quite high. While these measures do not probe the extent to which villagers felt comfortable voicing their opinions, the level of debate, or whether certain minority groups were excluded from the process, the measures, nevertheless, demonstrate that meaningful efforts to engender community participation took place. These results support the hypothesis that programs with high CHW retention tend to actively seek community engagement in $\mathrm{CHW}$ recruitment. In addition to community participation, HCU key informants perceive that a clear understanding of the roles, responsibilities, and level of compensation during the recruitment process is important for reducing disaffection and subsequent resignation by over-expectant CHWs.

The case where the CHW was forced to resign due to interpersonal conflicts, suggests that broad community support rendered as a result of community selection can help guard against favoritism by Local Councils and arbitrary dismissal. Representative community selection processes, although never perfect, represent a mechanism to reduce biases and generate more wide-spread support for the CHW.

Further exploration into how the different models of selection (self-selection followed by community confirmation, voting among multiple candidates or other selection mechanisms) contribute to higher or lower levels of retention and motivation would be useful. 


\section{Recruitment - Part II}

Exploratory Question 1: Do CHWs feel that community participation in recruitment contributes to their motivation and continued service?

The theoretical benefits of community participation in health and development (empowerment, ownership, culturally appropriate design) have been propounded since Alma Ata. However, few studies have sought the views of CHWs on the importance of community participation. In my literature review, I did not find any studies which investigated whether CHWs support community participation in recruitment and for what reasons.

From among the four options presented - selection by local council, health center staff, community election, or other means - community election was almost universally preferred by CHWs as the most favourable means of CHW recruitment (43/46). Notably, the number of CHWs preferring community election, is greater than the number of CHWs who were appointed by local councils.

\subsection{Key Results}

In explaining the rationale behind their choice, currently-serving CHWs identified two main benefits of community selection. Firstly, community members have intimate knowledge of their neighbours, and therefore, are best placed to determine who among them would be most suitable to perform the role of CHW (29/43). In contrast, three CHWs suggested responsibility for recruitment should lie primarily with the local council 
because the local council was perceived to be more impartial and respected in the community.

Secondly, since CHWs are community representatives whose role is to serve the community, community members should have the right to select the CHW (12/43): "The people have the power to vote for a $\mathrm{CHW}$ since they want someone ... who is willing to serve them and not somebody chosen by other people." Similarly, "because this person is going to lead these people, they have the right to vote for this person." And thirdly, community selection promotes community ownership for the performance of the CHW (5/43): "the people know what they want and can always blame themselves in case their choice is bad."

\subsection{Discussion of Results}

While this study cannot determine causation, the widespread CHW perception that communities as a whole are better able to recruit suitable individuals, and by extension retain CHWs, supports the hypothesis that community participation in recruitment is associated with higher retention. The nearly universal support for community participation in recruitment via community elections demonstrates that CHWs perceive real benefits from community engagement; community participation is not just a theoretical construct in the literature, but one with practical application. The results demonstrate that $\mathrm{CHWs}$ have a clear appreciation of the intended benefits of community participation and consider the practical application of community participation essential for strong candidate selection and community ownership. 
The emphasis on CHWs as representatives or agents of the community is somewhat surprising. The self-portrayal of CHWs as community agents or representatives seems to imply a middle-ground between the empowerment and utilitarian models in which CHWs are more than just health extension workers, but not necessarily change agents for restructuring systemic power relations. Their self-portrayal parallels the current view that CHWs are a bridge between communities and the health system.

As donors push forward with large-scale CHW programs to achieve 'quick wins' against MDG indicators, I think there is a danger that their 'bridging' role can be overlooked - that CHWs will be portrayed simply as health extension agents who diagnose and treat illness like any other health worker. The emphasis on community service suggests that programs should be diligent in ensuring that program design incorporates elements that strengthen bonds with the community. Community participation in recruitment may have a considerable impact on motivation and retention.

\section{Selection}

Hypothesis 2: Marital status affects retention and effectiveness because unmarried individuals are more likely to leave the community.

Hypothesis 3: Gender affects CHW effectiveness because women are more comfortable approaching female CHWs.

Hypothesis 4: Age and education do not influence effectiveness. 
Despite the fact that personal attributes and individual characteristics are undoubtedly an important determinant of an individual's acceptability in the community, their skills and capabilities, and their enthusiasm for serving the community, there has been a dearth of studies exploring individual characteristics and CHW motivation, retention, and effectiveness. Programs often have a set of criteria that individuals must meet in order to be eligible for recruitment. However, little is known about how such criteria enhances or inhibits retention, motivation, and effectiveness.

In the questionnaire, $\mathrm{CHWs}$ were asked to imagine a scenario in which they were the only $\mathrm{CHW}$ working in their village. (Depending on the size of the village, HCU asks each village to select either two or three CHWs.) The survey asked CHWs, if they could choose a CHW with whom to partner, what characteristics and qualities should that individual possess? For each of the following questions, CHWs were first asked to select an answer among the multiple-choice options provided. Following their answer, CHWs were asked to explain the rationale for their choice. While I recognize that CHWs may be likely to choose attributes that resemble themselves, CHWs are also likely to have considerable insight into what characteristics and qualities make a CHW more effective, more likely to stay on the job, and more motivated to carry out their work. Thus, this area of the study serves as a useful preliminary investigation into which selection criteria deserve further consideration and examination. 


\subsection{Marital Status}

One study suggested that married individuals are more likely to remain in their positions as CHW because they are more permanent in the community. ${ }^{28}$ Two studies associated marital status with performance but did not detail the rationale for this link. ${ }^{29}$

\subsubsection{Key Results}

There was nearly unanimous agreement that the CHW should be married (93\%) or have at least been married in the past (7\%). CHWs stated that a married person has more respect in the community (17/43). Secondly, the respondents indicated that married individuals are more entrenched in their communities and less likely to move to another town, especially upon marriage (15/43). Most importantly, CHWs expressed that in order to educate others, one must have experience raising children and be able to exemplify what one teaches (20/43): "Married people always have homes and children and it's from this situation that the ideas of this project are embraced."

\subsubsection{Discussion of Results}

These findings support the preliminary link that marital status is linked to retention and effectiveness. It seems likely that in many traditional societies, marriage would convey greater respect, and thus, help augment the influence and effectiveness of the CHW. Giving preference to married individuals could be an easy way to improve retention and effectiveness and should be further investigated to see if the relationship

\footnotetext{
${ }^{28}$ Karabi Bhattacharyya et al., Community Health Worker Incentives and Disincentives: How They Affect Motivation, Retention, and Sustainability, Anonymous Basic Support for Institutionalizing Child Survival Project (BASICS II) published for the United States Agency for International Development, Oct. 2001), 26. ${ }^{29}$ J. O'Connor et al., "Characteristics of effective Village Treatment Assistants: The Kongwa Trachoma Project," Ophthalmic epidemiology 6, no. 4 (1999): 263.
} 
holds across different contexts. Further exploration could have significant implications for programs like those in Sri Lanka which have traditionally relied upon the young, unmarried individuals to serve as CHWs. ${ }^{30}$

Interestingly, the importance of CHWs as role models is a theme that repeatedly emerges throughout this section on personal characteristics. These findings reinforce the view that behaviour modification strategies must consider more than just the information itself; they need to emphasize how the information is conveyed. It also reinforces the view that $\mathrm{CHWs}$ are not merely health extension workers who diagnose and treat illness; they are community representatives, and as such, should embody the teachings that they espouse. While recruiting individuals who are motivated to help their communities may help produce better role models, it is hard to outline exactly how to create effective community role models.

\subsection{Gender}

Experience from India ${ }^{31}$ and Bangladesh ${ }^{32}$ suggests that gender may be associated with effectiveness.

\subsubsection{Key Results}

Seventy-four percent of CHWs supported the pairing of male and female CHWs. Respondents indicated that male CHWS can serve as role models to increase

\footnotetext{
${ }^{30}$ G. Walt, M. Perera, and K. Heggenhougen, "Are large-scale volunteer community health worker programmes feasible? The case of Sri Lanka," Social Science and Medicine 29, no. 5 (1989): 602. ${ }^{31}$ Gill Walt, "CHWs: Are National Programmes in Crisis?" Health Policy and Planning 3, no. 1 (1988): 11. ${ }^{32}$ H. Standing and A. M. R. Chowdhury, "Producing effective knowledge agents in a pluralistic environment: What future for community health workers?" Social Science and Medicine 66, no. 10 (2008): 2011.
} 
acceptability and involvement of men in health matters (17/34): "Some men are hard to convince on family issues and they also tend to minimize some women making teaching hard. But if a man is also a CHW, he can talk to his fellow man and influence him to change and be involved in the family health affairs." CHWs also contended that gender balance in CHWs would help promote a shift away from the traditional belief that health is only a woman's issue (9/34): "Because it shows that we both have responsibilities of taking care of children's lives and both are capable and hence making it not appear like a bias on one sex or the other."

Others felt that broaching certain topics was easier to do between members of the same sex (12/34): "It's easy and comfortable for same sex to talk together. For example, when checking for bed nets, it necessitates entering someone's bedroom and this can be done woman to woman. In case you find a group of men in the trading centres, it's easy for a fellow man to approach and teach them. So it's necessary for the CHWs to be moving together depending on who they meet."

A minority of 7 respondents believed that women exclusively should be CHWs because they have a greater understanding of and commitment to issues that affect young children: "Women work better than men when it comes to family and health care. They can't miss meetings of health and development compared to male CHWs."

\subsubsection{Discussion of Results}

This study contributes to the small body of evidence that gender may indeed influence CHW effectiveness. Whereas all-male $\mathrm{CHW}$ contingents have sometimes been ineffective at reaching women, all female cadres of CHWs may also be less effective in 
promoting parallel changes in the practices and behaviours of men. Making men and women equal partners in promoting health may help accelerate positive behavioural changes and habits. If men are reticent to change, it may limit the ability of women to make positive health changes. Thus, while it is reasonable to accept that men should be engaged, there has been very little investigation into how to best do so. For example, in areas where association between men and women is not condoned, how can both men and women be reached?

Furthermore, there is the question whether men are equally willing to work as CHWs? The minority of respondents indicated that women are more committed to child and health issues, suggesting that motivation could be related to gender. It is also unclear how gender affects retention. According to the HCU registry, retention is slightly higher for women than for men - $94 \%$ versus $90 \%$ - but qualitative answers from CHWs did not suggest a link between gender and retention. The BRAC project in Bangladesh, however, suggests that women who have few opportunities to earn an income may be more willing to work as CHWs. ${ }^{33}$ If increasing evidence establishes that better gender balance among CHWs improves effectiveness, then compensation may have to be higher to retain male CHWs. At the present time, however, there is no evidence in which to base such policy decisions. The importance of this dual dynamic of engaging both sexes warrants further study.

\footnotetext{
${ }^{33}$ ibid., 2103.
} 


\subsection{Level of Education}

The few studies which mentioned education did not associate schooling with retention, motivation or effectiveness. ${ }^{34} 35$

\subsubsection{Key Results}

Ninety-three percent of respondents indicated that CHWs should have at least four years of primary school education in order to be able to read, write, and fill out reports in the local language. Interestingly, CHWs also mentioned that those with lower levels of education - primary as opposed to secondary - were more willing to volunteer $(8 / 43)$. Those with higher education were more likely to spend time outside the village and had less of a community orientation: An individual "may still have the spirit of people of the village compared to a person with $\mathrm{S} 1-\mathrm{S} 6 /$ University who will have less time to even visit his own village" and "those who study higher than this are less interested because they have other jobs and are never around much for the community."

\subsubsection{Discussion of Results}

In contrast to previous findings, the results of this study suggest that education may be associated with retention and motivation. Those with higher levels of education and formal employment may be less community-oriented and have less time to spend on community health activities, negatively influencing retention, motivation, and effectiveness. While it may be more expedient for programs to work with individuals

\footnotetext{
${ }^{34}$ Sandy Cairncross, Eka I. Braide, and Sam Z. Bugri, "Community participation in the eradication of guinea worm disease," Acta Tropica 61, no. 2 (1996): 123.

${ }_{35}^{35}$ D. C. O. Kaseje, H. C. Spencer, and E. K. N. Sempebwa, "Characteristics and functions of community health workers in Saradidi, Kenya," Annals of Tropical Medicine and Parasitology 81, no. SUPPL. 1 (1987): 64 .
} 
who are conversant in an international language and who have higher levels of literacy, conducting training in the local language and using pictorial charts and forms can allow less literate individuals (particularly women and the poor) to serve as $\mathrm{CHWs}^{36}$ The findings did not indicate whether those with higher or lower levels of education are more likely to equitably serve all segments of the population, covering both poor and wealthier households within a village and whether those with higher or lower education are better received by villagers. This is an additional dimension that could be explored.

\subsection{Age}

In the literature review age was not associated with retention, motivation, or effectiveness.

\subsubsection{Key Results}

Responses regarding the most appropriate age range varied considerably. The most common response supported an age range of $25-35$ years old (36\%). Individuals in this range were likely to be parents with children under 5 years old, energetic yet possessing a degree of maturity and respect in their community.

\subsubsection{Discussion of Results}

These findings are consistent with the study in the literature review from Kenya which suggested that maturity and community acceptance are more important than age. ${ }^{37}$ While younger individuals are less stable in the community, older people, on the other

\footnotetext{
${ }^{36}$ Cairncross, Braide, and Bugri, Comminity participation in the eradication of guinea worm disease, 123.

${ }^{37}$ Kaseje, Spencer, and Sempebwa, Characteristics and functions of community health workers in Saradidi, Kenya, 64.
} 
hand, may find it tiresome to travel the long distances required to perform home visits and attend CHW meetings. Aside from these two ends of the spectrum, retention, motivation, and effectiveness were not strongly associated with age.

\section{Selection Criteria - Part II}

Exploratory Question 2: What personal characteristics and attributes do CHWs associate with effectiveness and long-term service?

When employers hire individuals, they carefully consider the suitability of the individual's personality along with their skill set. It seems somewhat odd that $\mathrm{CHW}$ programs have not paid attention to the individual level characteristics of their team members. While the literature suggests that a few characteristics, such as gender and marital status, may be associated with retention and effectiveness, overall there have been very few reviews on personal attributes and characteristics. In light of the large knowledge gap, this study examined whether a number of additional characteristics including parental status, membership on the local council, and what personal qualities are associated with retention, motivation, or effectiveness in a child health program.

\subsection{Parental Status}

All CHWs interviewed unanimously concurred that CHWs should be parents; $80 \%$ of which believe CHWs should have a child under 5 years old. Since the project specifically targets children under 5 , respondents believed CHWs should have firsthand knowledge of the issues that affect children (14/37). More importantly than familiarity with common health issues affecting children, CHWs should have children so that they 
may adopt the behaviours and practices they espouse within their own families (27/37). CHWs believe they serve as important role models in their communities: "If someone talks of weaning, one should have practical knowledge about this topic. If one doesn't have a child below this age, however, her advice remains a story" and so "she/he can start with his own children and know how to deal with others."

\subsubsection{Discussion of Results}

CHWs consider practicing what one preaches paramount to fostering community receptiveness and uptake of health education. These findings on parental status parallel the results from the section on marital status and the emphasis on acting as a role model. While it is not clear how best to provide health education and how to recruit individuals willing to serve as community role models, tailoring recruitment processes, selection criteria, and training pedagogy to this aim may help improve retention, motivation, and effectiveness.

\subsection{Local Council Membership}

Seventy percent of respondents believed CHWs should not be members of the local council, primarily due to the difficulties of adequately fulfilling the responsibilities of both posts simultaneously (25/28): "Both jobs need commitment and attention every time duty calls. If the two clash at the same time, it's very difficult to choose or attend to both. One will over shadow the other." One respondent suggested that local council leaders have a higher expectation of payment and so may prioritize paid engagements over CHW volunteer responsibilities. 
Another respondent suggested that a local council member simultaneously serving as CHW might use his position of power to intimidate community members into complying with the health advice rather than using positive persuasion. Conversely a minority of individuals supported local council representatives taking on the dual role of $\mathrm{CHW}$, precisely because of their ability to influence community members.

Three individuals believed CHWs should ideally be independent from the local council but have experience working with the local council in order to promote a stronger framework for development through better cooperation and coordination among the two groups.

\subsubsection{Discussion of Results}

These preliminary results suggest that membership on the local council may be negatively associated with effectiveness as local council members may struggle to complete the responsibilities of both roles. Their position of power may also be used to negatively co-opt cooperation by villagers which runs counter to the tenets of positive self-empowerment and health promotion. Certainly there are local council members who would be extremely committed and effective CHWs - in fact there are a number of local council members doubling as CHWs in the HCU project, although the exact number is not known - but, on the whole, this survey found that local council members are generally not considered the most appropriate choice of CHW.

However, engaging local councils in other ways is likely to improve project effectiveness. Local councils serve as useful entry points to the community. Key Informants indicate that local council support is extremely helpful for mobilizing the 
community for selection day and generating a supportive environment for the project. CHWs and Key Informants note that local council support during periodic home visits and health talks can help bolster the credibility and influence of CHWs, thus improving their effectiveness and motivation. CHWs also complain that resistance and belittlement by local councils diminish their motivation and effectiveness in the community; thus, bringing LCs on side is clearly important to program effectiveness. The results from this section combined with those from the section on community participation in recruitment suggest that finding a balanced way to engage local councils - enlisting their support for recruitment and $\mathrm{CHW}$ activities, but not allowing them to dominate the selection processes or intimidate villagers - may enhance program effectiveness. Building cooperative relationships with local councils, however, will require a substantial time investment by the program management.

\subsection{Personal Qualities}

Respondents were asked which two of the following seven characteristics are most important for a CHW to possess: Cooperates well with others; Sociable and easy to talk to; A good role model in the community; Willing to volunteer; Hardworking; Has previous experience as a community leader, such as a retired teacher, church leader, burial group leader, leader of the women's group, etc..; and Cares deeply for children. The multiple choice options were developed from informal discussions with CHWs. 


\subsubsection{Key Results:}

"Cooperates with others" $(65 \%)$ and "cares deeply for children" $(61 \%)$ were the most popular answers. In the following open-ended question, CHWs were asked "What other qualities should a CHW have?" The majority indicated that the CHW should exemplify the behaviours that they espouse (31/46). They should also be nonjudgmental, confidential, trustworthy, and approachable (12/46): "Should be easy to approach and stand to be advised from every age group and capacity. She should be willing to visit all homes and help everyone without discrimination."

\subsubsection{Discussion of Results}

The results suggest that programs ought to pay attention to the attributes of CHWs as their personal qualities may affect their effectiveness. It is reasonable that CHWs who are cooperative, who are able to work well with individuals across the community, will be able to more effectively reach a larger segment of the population. Here again, the importance of serving as a role model is highlighted. The emphasis on a cooperative nature and acting as a role model further reinforces the primacy of the CHW's relationship with the community.

Although the emphasis on 'cares deeply for children' relates specifically to child health programs, the need to find individuals who care deeply about health in the community applies to all $\mathrm{CHW}$ programs. It stands to reason that individuals who are concerned about community health will be more motivated to carry out their responsibilities. Most CHWs are lowly paid; thus, compensation is unlikely to be a sufficient motivator. Using community participation in recruitment to help locate 
individuals who work well with others and who are committed to improving health may help improve retention, motivation, and effectiveness.

\section{Chapter Summary}

Promoting broad community participation in recruitment and shaping selection criteria can help build community support for the $\mathrm{CHW}$ while simultaneously locating a cadre of individuals who have the personal characteristics and attributes to work effectively for improved health. While it is impossible to create a universal set of selection criteria, some guidelines such as marital status or cooperative nature are likely to be applicable in a wide variety of contexts. Establishing a few key criteria relevant to the particular context may help improve retention and effectiveness. Furthermore, while community participation in recruitment can help reduce biases in selection, they are still political processes in which certain groups or individuals are likely to be more dominant. Improving recruitment and selection is not a panacea for retention and motivation, but close attention to these aspects of program design can help limit the entrance of poorly suited and less committed individuals. The topic of selection criteria clearly merits further investigation. 


\section{CHAPTER 7: TESTING THE IMPORTANCE OF TRAINING, SUPERVISION, COMPENSATION, AND COMMUNITY SUPPORT ON RETENTION, MOTIVATION, AND EFFECTIVENESS}

CHW programs have gained popularity, in part, because they are presented as a lower-cost option for scaling up primary health care. In order to keep costs down, most programs do not pay CHWs a living wage and many pay virtually nothing at all. Thus, the success of CHW programs hinges on the willingness of individuals to carry out the assigned roles in spite of low compensation. Despite the reliance on partial volunteerism, CHW motivation is poorly understood in developing countries. While the literature review identified six areas of importance (community participation in recruitment, selection criteria, training, supervision, compensation, and community support), we do not have a clear picture of how various, overlapping motivations weigh against each other. Thus, it is not clear which of the determinants of motivation and retention should be prioritized by policy makers as they strive to improve program effectiveness.

The previous chapter examined the role of community participation in recruitment and selection criteria in the Healthy Child Uganda project. This chapter examines the influence of training, peer support (as complement to supervision), compensation, and community support on retention, motivation, and effectiveness. HCU provides an interesting case study to test the strength of different motivators. The project trains volunteers in primarily preventative tasks, yet has succeeded in maintaining high retention rates. This runs contrary to general findings in the literature that emphasize the importance of remuneration and curative roles. An investigation into the motivations of project CHWs can provide insight for other programs as they try to find a balanced role 
between curative and preventative tasks and monetary and non-monetary determinants of motivation.

Overall, the case study provides reinforcing evidence that training, peer support, and community support are important to motivation and retention. However, compensation played a much weaker role. In terms of ranking, 'improved child health' and 'training and education' emerged as the strongest motivators for working as a CHW. The relative weight and reasons attached to the importance of each of the four elements can help guide policy makers as they consider how to best invest their money to strengthen $\mathrm{CHW}$ programs.

\section{Motivation Ranking Results}

To determine the centrality of a number of potential motivators, a community tool called matrix ranking was used to allow CHWs to easily weigh one motivator against another. ${ }^{1}$ The options presented were enumerated by CHWs in a small preliminary study conducted previously by the project and through informal brainstorming sessions with CHWs. As such, the options presented approximate the six areas (recruitment, selection, training, supervision, compensation, and community support), but do not correspond exactly.

When asked what factors motivated respondents to initially accept the position of CHW, the 6 options provided were ranked in the following order $^{2}$ :

1. To gain knowledge about health problems: $4.13 / 5$

2. To help your community: $4.07 / 5$

3. To help your own children: $2.89 / 5$

\footnotetext{
${ }^{1}$ Refer to Appendix 3 for a more detailed explanation of matrix ranking.

${ }^{2}$ Given the 6 options presented, the highest score possible is 5 . A score of 5 indicates that all CHWs ranked that answer over all other options.
} 
\begin{tabular}{|l|}
\hline 4. Because the community selected/appointed you: $2.02 / 5$ \\
\hline 5. To increase your respect and influence in the community: $1.26 / 5$ \\
\hline 6 . Expectation of payment: $0.54 / 5$ \\
\hline
\end{tabular}

In a subsequent question designed to investigate whether motivation among

CHWs may have changed over time, nearly identical answers to the question about initial motivation were recorded. The reasons that motivate CHWs to continue volunteering are provided below:

\begin{tabular}{|l|}
\hline 1. Improved child health in my village: $5.72 / 6^{3}$ \\
\hline 2. Education and training: $4.50 / 6$ \\
\hline 3. Community members ask me for health advice or assistance: $4.22 / 6$ \\
\hline 4. Friendship with other CHWs: $2.39 / 6$ \\
\hline 5. Income-generating projects and cash rounds: $2.02 / 6$ \\
\hline 6. Respect by people in community: $1.39 / 6$ \\
\hline 7. Monthly payment of 3000 Shillings: $0.43 / 6$ \\
\hline
\end{tabular}

In both matrix ranking questions, reasons related to community health and education received the highest scores. Community demand for CHW services also rated strongly. These responses are the only ones which received a score of more than four. A more detailed discussion of the results and implications of the findings are provided in the succeeding sections. The results of the matrix ranking questions will be substantiated with qualitative answers from the Phase I and II questionnaires. ${ }^{4}$

Although the wording of the first question pertains more closely to motivation (why did you accept the position) and the second question to retention (why do you continue to volunteer), the distinction between motivation and retention is somewhat nebulous; as such, I will generally not distinguish between motivation and retention in my discussion of the results.

\footnotetext{
${ }^{3}$ Given the 7 options presented, the highest score possible is 6 . A score of 6 indicates that all CHWs ranked that answer over all other options.

${ }^{4}$ After performing a preliminary review of the results from the Phase I questionnaire, a second Phase II questionnaire composed of entirely open-ended questions was administered to help strengthen understanding of the results in the first questionnaire and elicit additional information.
} 


\section{Training}

\section{Hypothesis 5:}

Training contributes strongly to motivation retention, and effectiveness because it gives CHWs confidence in their skills.

\section{Hypothesis 6:}

CHWs are not motivated to deliver preventative and promotive health activities because of low community demand.

This section investigates how project $\mathrm{CHWs}$ who are trained primarily in preventative roles using interactive, participatory training methods value the training they receive. As described previously, project CHWs are trained almost exclusively in health promotion and identification of danger signs. They are trained to identify illness and refer individuals to health centers rather than prescribe or administer treatment with the exception of preparation of oral rehydration solution for diarrhea.

\subsection{Key Results}

'To gain knowledge about health problems' emerged as the strongest reason to accept a role as a CHW and 'education and training' ranked second among reasons for continued service in the two matrix questions. Respondents' answers in Phase $2^{5}$ parallel the matrix ranking findings. When asked in an open-ended question why they volunteer their time without being paid, 11 of 12 respondents mentioned that after receiving training, they became aware of how their education could help their own children and the children of the community: "When I got this education especially about how to feed the

\footnotetext{
${ }^{5}$ The Phase II questionnaire was composed of entirely open-ended questions designed to expand upon responses received in the Phase I questionnaire. The Phase II questionnaire was administered to 12 CHWs.
} 
children, pregnant mothers and their care, how to eat body building foods, I realised this would greatly change my family and the whole community at large."

The desire for knowledge is also evident in the use of the terms 'ignorant' and 'backward.' "Because my community was backward and I decided to volunteer to prevent sickness in our children" and "I was ignorant about many things which were bringing about sickness in my family...." Similarly, when asked what they enjoy about being a $\mathrm{CHW}$, fifty percent mentioned training, learning, and dispelling ignorance in the community: "I get more sensitized. For example, the re-fresher courses they give us, keep opening our eyes" / "I have learnt a lot from being a CHW though we are not paid" / "To fight illiteracy among parents as far as their children are concerned."

Demand for $\mathrm{CHW}$ advice or assistance emerged as the third strongest motivator in the matrix ranking question. It was one of only three motivators to receive a score greater than 4. Thus, training has provided CHWs with skills and knowledge that are valued by community members. Training has also provided $\mathrm{CHWs}$ with skills that are transferable to other areas of community life. Three individuals mentioned that training has helped them improve their communication skills which are applicable to other situations. : "I have improved my communication skills and with these some women groups ask me to go and address some functions and meetings."

\subsection{Discussion of Results}

While these results clearly demonstrate that training is one of the strongest motivators for project $\mathrm{CHWs}$, the results do not confirm the two hypotheses. I initially hypothesized that training contributes strongly to motivation, retention, and effectiveness 
because it gives CHWs confidence in their skills. However, the results more strongly show that project CHWs value training because it gives them an opportunity to learn, an opportunity to gain awareness about the determinants of poor health. This makes sense given the programs' focus on prevention and referral rather than treatment. But it also makes sense that in areas where there are few opportunities for further education, CHWs may be highly motivated by opportunities to receive training. Programs should capitalize on this interest as a practical way to improve motivation and retention.

Secondly, I hypothesized that CHWs are not motivated to deliver preventative and promotive health activities; yet, in this case study, CHWs appear highly motivated by community demand for the health education that they provide. Demand for CHW advice or assistance emerged as the third strongest motivator in the matrix ranking question. Although community demand for curative services may be higher than that for preventative and promotive services, these findings suggest that it is possible to stimulate community demand for health education. In order to be effective health promoters, CHWs need simultaneous training in communication and leadership skills. Thus, training pedagogy that emphasizes the development of community-relevant skills is likely to play an important role.

The clear prioritization of training as one of the strongest motivators suggests that investing in opportunities for continuous training may reap large payoffs in terms of retention, motivation, and effectiveness. Further investigation into whether initial or refresher training has a stronger influence on motivation and effectiveness could help inform program design. 


\section{Peer Support - A Complementary Role to Supervision}

Hypothesis 7: Peer interactions between CHWs contributes to the retention and motivation of CHWs.

In my literature review, supervision was identified as one of the key components that contributes to retention, motivation, and effectiveness. While conducting my review, I also came across a study by Bhattacharyya et al "findings that concluded that peer support is as important to CHW performance as supervisory feedback." ${ }^{.6}$ On the whole, however, I found very little research investigating the role of peer interactions. Given this evidence gap, I tested whether friendship among VHVs is a strong or weak contributer to motivation and retention.

\subsection{Key Results}

In terms of ranking, friendship with other CHWs placed a modest fourth among the seven key motivators identified. In response to the Phase II question "What do you like about being a CHW?" one quarter (3/12) of the respondents stated that they enjoyed being a part of a network of CHWs for friendship and support: "I get to know my fellow CHWs and our relationship grows since we learn from each other and support each other in various situations." In the section on personal benefits, $2 / 12 \mathrm{CHWs}$ highlighted the importance of learning from other $\mathrm{CHWs}$ including through peer exchanges to other parishes (districts): "Through field visits, I have been able to visit various families in different parishes and learn more from these families like planting seeds of different plants."

\footnotetext{
${ }^{6}$ Karabi Bhattacharyya and others, Community Health Worker Incentives and Disincentives: How they Affect Motivation, Retention, and Sustainability, Oct. 2001), 23.
} 


\subsection{Discussion of Results}

Friendship and peer support appear to play a relevant auxiliary support function. The stronger ranking accorded to 'friendship with other CHWs' than 'respect by community members' demonstrates that peer relationships are an important form of motivation. Pairing CHWs together or providing opportunities for CHWs from the same district to meet with each other during refresher training, may represent simple ways for programs to improve retention and motivation without adding much cost. Supporting the development of peer support networks may also help ground CHWs more firmly in community networks, and by extension, help embed CHWs in their communities.

\section{Compensation}

Hypothesis 8: CHWs are more strongly motivated by compensation than an ethos of community service.

In the past, the debate between whether $\mathrm{CHWs}$ should be paid or not paralleled the divide between the empowerment and utilitarian models. The former presenting CHWs as community representatives, the latter tending to view CHWs as health extension workers. Today's literature suggests that volunteer $\mathrm{CHW}$ programs are linked to higher rates of attrition and that as individuals living in poverty, CHWs ought to be paid. $^{7}$

In contrast to these claims, this study tested what factors are responsible for the high rate of retention given the low financial compensation provided to HCU CHWs.

\footnotetext{
${ }^{7}$ Uta Lehmann and David Sanders, Community Health Workers: What do we Know about them? the State of the Evidence on Programmes, Activities, Costs and Impact on Health Outcomes of using Community Health Workers, January 2007), www.who.int/hrh/documents/community health workers_brief.pdf, 24.
} 
HCU considers its $\mathrm{CHWs}$ volunteers since they receive a nominal 1500 shillings a month (approximately one dollar) as a travel allowance to the monthly group meeting. CHWs usually retain this money rather than spending it on transportation.

\subsection{Key Results}

In the first motivation ranking question, 'to help your community' ranked a close second while in the second question, 'improved child health' was far and away the strongest determinant for continued volunteer service. In contrast, "expectation of payment' as a reason to begin training as a CHW and payment of ' 3000 shillings monthly' in the second question both ranked at the very bottom. Involvement in incomegenerating projects and community savings groups ranked fifth out of seven.

\subsubsection{Improved Child Health}

In the Phase 2 interviews, when asked "how has the community benefitted from being part of the HCU program," all 12 respondents gave concrete examples of community-wide adoption of new practices:

"Almost every home, if not all, have vegetable gardens. This has greatly improved the health of our children. Neighbouring villages which are not part of Healthy Child Uganda want similar training. Their children almost die daily."

"Diseases that were erupting from untidiness like diarrhea have greatly decreased because people now know the effect of dumping waste in compounds and banana plantations - that it can cause diseases if children play in such an environment. Our children are healthy through eating well and playing in a safe environment." 


\subsubsection{Non-Monetary Forms of Compensation}

In order to elicit other types of non-monetary benefits, the Phase II questionnaire asked respondents to detail how their family has benefited and how they have personally benefited from being a CHW. Two individuals mentioned that they use the 3000 shillings from the monthly travel allowance to purchase a bar of soap for their family. In terms of personal benefit, three individuals mentioned preferential treatment received at the health center (3/12). Only one person mentioned that the personal benefits were insufficient.

Other intangible benefits were also enumerated. Five of twelve mentioned that their children are healthier and/or suffer less from illness. Three individuals mentioned that they have been able to gain support from their husbands for improving child health: "I have also gained respect in my own home my husband now respects me more because I am more sensitized." Similarly, "I have no proper words to explain how my family has benefited. At first my husband was against it, but after pushing immunisation, proper feeding, etc... my children are healthy... we are among the role models in our community. From sensitisation about family planning, my husband and I agreed to use it so that we may be able to manage a small family and live happily."

\subsubsection{Deterrents to Volunteerism}

In Phase $1,28 \%$ of CHWs admitted knowing at least one $\mathrm{CHW}$ who they consider insufficiently active. Of the thirteen participants who conjectured why these individuals might be insufficiently engaged, reasons relating to insufficient pay was the most common response. Similarly, a Phase 2 question posed "What do you dislike about being 
a CHW?" four of twelve respondents mentioned lack of transportation, rain boots and umbrellas, especially during the rainy season and no lunch provided during monthly meetings. Belittling remarks by community members $(2 / 12)$ is also unappreciated. Almost half (5/12), however, gave no complaint at all.

Among the ten CHWs who resigned (for reasons other than death, sickness, or relocation), seven $^{8}$ were interviewed. Of the options listed, 5 out of 7 respondents said the main reason for resignation was 'too busy'.

\subsection{Discussion of Results}

The results of this study run counter to my hypothesis which contended that financial incentives would play a stronger role in motivation than community service. Based on the motivation ranking results, CHWs were clearly motivated by a desire to help their communities and by improvements in child health. As with most surveys, responses were likely influenced by a propensity to reply in a manner favourable to the project/interviewer. While there may have been a tendency to over-emphasize improved child health in the community as the primary motivation, powerful examples of healthy changes in their families and communities quoted in Phase 2 of the research support the findings of the motivation rankings.

Recognizing that CHWs who receive very little compensation are unlikely to prioritize payment as a key motivator, the results, nonetheless, demonstrate that CHWs can be motivated by other drivers than expectation of payment. While all individuals would like to be compensated for the work they do, there are other forms of motivation

\footnotetext{
${ }^{8}$ Four others were unavailable due to: working outside the village, attending to child in hospital, attending a funeral, and husband's refusal to allow his wife to be interviewed. Three interviews were cancelled due to time constraints.
} 
that do not derive from money. In previous questions, desire to help one's community/improved health, pursuit of knowledge/education, and community demand/recognition for CHWs have heavily contributed to the motivation and retention of CHWs. Counter to widespread opinion, this study demonstrates that there is a willingness among the poor to volunteer. The findings also demonstrate that CHWs can be motivated by observable changes in child health. Having CHWs track activities and results, such as immunization coverage, presence of malaria nets in homes, number of children who have gained weight, deaths and births, can help concretize CHW achievements and contribute to their motivation.

While project CHWs have shown a willingness to volunteer, they would nevertheless prefer to receive greater material support. They complained about minimal payment and not being supplied with umbrellas and bicycles. CHWs suspect that lack of payment is the main reason for low engagement by less active CHWs. More meaningful payment and provision of equipment and job-related materials may help increase motivation. In more urban areas or areas where there is more opportunity for paid employment, compensation may play a more prominent role.

Payment alone, however, will likely be an insufficient solution to the problem of low motivation. Like any other worker, CHWs are unlikely to be motivated solely by financial remuneration. Paying CHWs does not necessarily mean that they will be motivated to carry out home visits, organize health promotion activities, and perform other responsibilities on their own initiative. Since many CHWs are largely unmonitored on a day to day basis, CHWs, must also be motivated self-starters. Since their motivation also depends on whether they believe they are making a difference or not, 
programs may need to establish a monitoring and reporting system to track results. While switching from volunteer to paid CHWs is an alluringly simple solution to the problems of low retention and motivation, policy makers should consider the multiple determinants of motivation and retention as they decide how to allocated money within CHW programs.

\section{Community Support}

Hypothesis 9: Community participation in recruitment, community appreciation for services, and community respect for $\mathrm{CHWs}$ are forms of community support that contribute to $\mathrm{CHW}$ retention and motivation.

As demonstrated in the literature review, the CHW's relationship with the community is a strong determinant of motivation and retention. This study tested how various forms of community support (community recruitment, community demand for services, and community respect) influence motivation among project $\mathrm{CHWs}$. While there are certainly other means to measure community support, the measures chosen have been identified in the literature and by project CHWs in informal discussions.

\section{1 Key Results}

\subsubsection{Community Recruitment}

In the first matrix ranking question investigating the initial motivators for beginning service as a CHW, "Because the community selected you" ranked a modest $4^{\text {th }}$ out of 6 with a score of $2.02 / 5$. In an open-ended question, 8 of 46 respondents indicated that they 
accepted the position of CHW because the community entrusted them with the role:

"People trusted me enough to work for them up to the point of electing me...I got motivated."

\subsubsection{Community Demand for Services}

'Community members ask me for health advice or assistance' received a very strong third place ranking, receiving almost double the score of the fourth option (4.22/6). As mentioned previously, in the Phase 2 interviews, when asked "how has the community benefitted from being part of the HCU program," all 12 respondents gave concrete examples of community-wide adoption of new practices: “...Now almost every parent has an idea of how children should be catered for." Similarly, 24 of $35 \mathrm{CHWs}$ indicated that community uptake of $\mathrm{CHW}$ teachings has motivated them to become increasingly active in their communities: "When I go to teach my village members, they welcome me and practice what I teach them about their children and good feeding."

\subsubsection{Community Respect}

In the first matrix question 'To gain increased respect' placed $5^{\text {th }}$ among the reasons for beginning work as a $\mathrm{CHW}$. In the succeeding question investigating motivations for continued service, 'respect by people in community' continued to rank a low (6th out of 7). However, respect was a prominent theme in the Phase II responses. When asked how they have personally benefitted from being a CHW, 5 of 12 respondents mentioned that they are now more respected in the community because of the education that they provide: "I have gained respect among my friends since we are taught things 
that help our lives" and "I am very much considered as the adviser." Another CHW states that:

"When I put my blue T-shirt uniform on in my village, I gain respect and when I advise people to do something, they do it in time and they are very happy. This has greatly changed my image and how people treasure what I teach."

"I am liked by people because of what I am doing for them. So they give me respect. Now I have skills and knowledge about leadership and how to look after children."

\subsection{Discussion of Results}

The high ranking of 'Community members ask for health advice or assistance' attests to the importance of the community as a core reference point for CHW motivation and confirms my hypothesis. Increased financial remuneration is not necessarily a replacement for community validation. These findings would be strengthened by exploring why CHWs were well-received by community members given the lack of emphasis on curative tasks. For example, what role did the training methodology and community participation in recruitment play in equipping CHWs with appropriate skills and generating community receptiveness?

The discrepancy between the low rank accorded to 'increased respect' in the matrix ranking in contrast to the emphasis received in Phase II is perhaps due to the nuanced way in which CHWs perceive and relate to the concept of respect. While it appears that project CHWs are not motivated to volunteer in order to gain increased respect in terms of raised social status, they are motivated by the respect shown for their work. If the role of the $\mathrm{CHW}$ is not valued and validated by the community, the $\mathrm{CHW}$ will not likely be motivated to carry out his/her responsibilities. Finding innovative ways 
to publically display appreciation, such as through community radio broadcasts as done in Indonesia, would likely contribute strongly to improved retention and motivation. ${ }^{9}$ The literature pointed out that there is almost no precedent for communities being involved in the evaluation process. Community involvement in evaluation represents another potential area of investigation and avenue for increasing community support. ${ }^{10}$

\section{Additional Results - Level of Engagement}

The forty-six respondents in Phase 1 were asked to estimate the average number of hours spent on health-related activities in a week and the average number of house visits conducted in a month.

- $50 \%$ reported spending 10 or more hours on health-related activities per weak - The most common response (28\%) was 'greater than 10 hours' per week.

-With reference to the lower range, $32 \%$ reported working 5 hours or less per week.

- $58 \%$ reported visiting more than 20 homes per month.

- The most common response (43\%) was 'more than 25 ' homes per month.

- With reference to the lower range, $9 \%$ estimate that they conduct 15 or fewer visits monthly

In the succeeding question, participants were asked to compare their current workload with their original workload after their initial recruitment:

- $76 \%$ said they are 'more active' now than before

- $11 \%$ 'less active'

- $13 \%$ do approximately the same amount of work as before

The reasons provided for increased engagement closely mirror the findings from the matrix ranking questions. Based on the open-ended responses, community uptake and

\footnotetext{
${ }^{9}$ Bhattacharyya and others, Community Health Worker Incentives and Disincentives: How they Affect Motivation, Retention, and Sustainability, 19.

${ }^{10}$ Reid, M., Courtright, P., "How do we Sustain Village Health Volunteers?" Malawi Medical Journal 9 , no. 2 (1993), 8 .
} 
embracement of teachings attributing to improved health has played the strongest role in boosting morale (24/35): "In our village child mortality was very high, but after we got involved through the project, now it has decreased very much. We have fought and advocated for cleanliness. We are appreciated by our community and this boosts our morale." Increased awareness, knowledge and skills acquired through refresher training, and peer exchanges have also contributed to increased engagement (11/35): "This is because I gained awareness, my eyes were opened. I was excited to apply what I learnt in my community. There are many changes that are a good in my community like lower child mortality, less diseases, immunisation, good nutrition among children and many other things."

Despite the increased involvement of the majority, a number of factors have contributed to CHWs'decreased engagement. Two CHWs reported lower activity levels due to diminished demand for $\mathrm{CHW}$ advice because the community has already been sensitized (2/4): "This is because I sensitised my area and there has been much development, hence I only supervise." Lack of appreciation by community members and low pay $(2 / 4)$ were also mentioned.

Despite the difficulties encountered - low pay, walking long distances to conduct home visits, lack of umbrellas and bicycles - the vast majority of project CHWs have demonstrated that they are committed to working for improved child health in their community. For the majority, their engagement is not only remaining steady, but intensifying over time. How long $\mathrm{CHWs}$ should serve and what mechanisms should be used to replace and train new CHWs needs to be considered as programs mature over time. 


\section{Chapter Summary}

Based on the results training, peer support, compensation, and community support all appear to influence motivation and retention; however, project CHWs seem to be most strongly motivated by improved child health, education and training, and community demand for advice and assistance. Material incentives, such as receipt of monthly payment and income-generating projects ranked among the lowest motivators. Counter to most findings in the literature, project CHWs demonstrated a willingness to carry out preventative and promotive health activities on a primarily voluntary basis. Certainly, past conceptions of CHWs as altruistic, community-oriented, non-profit seeking individuals is flawed and overly idealistic. However, I also think that it is important not to swing the pendulum too far in the opposite direction and overstate the role of compensation as a solution to poor motivation and retention.

The results suggest that payment should not be considered a simple, singlefaceted solution to the problems of low motivation and retention. Even if CHWs are paid, policy makers should pay close attention to the non-financial drivers that motivate CHWs. The heavy emphasis on training and education suggests that investments in opportunities for continuous training may produce large payoffs in terms of retention, motivation, and effectiveness. Similarly, investing money in time-intensive recruitment processes can help locate individuals who are interested not only in earning an income, but also genuinely interested in helping their communities, which in turn, may help improve retention and motivation. Supporting peer exchanges, assigning CHWs into groups or pairs to carry out their work, and providing other opportunities for CHWs to 
work together formally and informally may help build a supportive environment for CHWs. Policy makers should consider the multiple dimensions of motivation when determining how to best allocate money within CHW programs. Perhaps one of the greatest challenges will be applying lessons learned to large-scale programs. The larger the program, the more difficult it is to create a supportive environment for CHWs that includes genuine community participation, participatory learning, and strong supervisory and peer support networks. 


\section{CHAPTER 8: CONCLUSION}

Global commitment to the health MDGs and health system strengthening has sparked renewed interest in primary health care and community health workers. Noting the increased global investments in CHW programs, this paper examined historical experiences with $\mathrm{CHW}$ programs, the role of CHWs within health systems, and ways to improve the effectiveness of CHW programs. Chronic problems of poor retention and motivation emerged as critical to effectiveness, and thus, served as the basis for the case study with the Healthy Child Uganda project. The findings of the primary and secondary research can help inform program design and guide implementation in order to improve effectiveness as countries and donors invest in the scale-up of CHW programs.

Lessons learned since Alma Ata have contributed to a strengthened, more realistic framework to situate CHWs. Today, $\mathrm{CHWs}$ are no longer conceived as change agents for community empowerment, but as bridges between the community and the health system. As such, they must be supported by both the health system and the community in order to be effective.

From the literature, it is clear that CHWs can play a vital role in filling service gaps and linking communities with formal health services given the scarce financing, human resource shortage, urban bias, and socio-economic barriers faced by the poor. CHWs are cheaper to train, require lower remuneration, and are less likely to migrate. However, they are only trained in a narrow number of health topics and generally provide services on a part-time basis only. On the one hand, CHWs are employed to help strengthen health systems, to extend access and improve equity, yet at the same time, 
CHW programs place burdens on the system. CHWs require training and supervision and depend on reliable procurement and distribution systems for drugs and supplies. Weaknesses in the health system are likely to hamper CHW effectiveness. While a growing number of studies have demonstrated that CHWs can help increase utilization of services, promote healthy behaviours and improve health outcomes, they are not a panacea for weak health systems.

Although there are numerous challenges to measuring the effectiveness of CHWs - problems of endogenicity, publication biases, and transferability of results - there is "robust evidence" that CHWs can contribute to improved health outcomes, especially in the area of child health. ${ }^{1}$ Lessons learned from the vast global experience with child health programs can provide valuable insight as countries and donors strategize on how to best address the MDGs on HIV/AIDS and maternal health. Use of CHWs in the field of HIV/AIDS prevention, treatment, and care represents one of the fastest growing areas of CHW responsibilities. ${ }^{2}$ As the roll-out of antiretroviral treatment (ARTs) expands, CHWs could play a pivotal role in promoting treatment compliance and preventing resistance. Of the three health MDGs, maternal health has fared the poorest, achieving virtually no progress to date. ${ }^{3}$ While some maternal health issues may require more complex interventions, requiring facility-based services, $\mathrm{CHWs}$ could do much in terms of promoting better nutrition, family planning, and use of antenatal and postnatal care. As part of the primary health care system, CHW roles should reflect these other key areas

\footnotetext{
${ }^{1}$ Uta Lehmann and David Sanders, Community health workers: What do we know about them? The state of the evidence on programmes, activities, costs and impact on health outcomes of using community health workers, Anonymous , January 2007), www.who.int/hrh/documents/community health workers brief.pdf., $\mathrm{V}$.

${ }^{3} \mathrm{http}: / /$ www.who.int/making_pregnancy_safer/topics/mdg/en/index.html
} 
of morbidity and mortality. Further investigation and experimentation into how CHWs can most effectively be employed to assist individuals with HIV/AIDS and promote improved maternal health would help strengthen primary health care systems.

While there is strong evidence for $\mathrm{CHW}$ effectiveness, the perennial problems of low motivation and retention represent serious problems. Low retention disrupts program continuity, creates gaps in service delivery and undercuts capacity building, which in the end, negatively affects effectiveness. Poor retention and motivation also reduces the cost-effectiveness of $\mathrm{CHW}$ programs. The costs associated with recruiting and training new batches of CHWs in areas marked by high dropout rates represents a large drain on program finances. Strengthening program design to reduce attrition rates and problems of low motivation is essential for improving effectiveness and maintaining program affordability. Despite the problems of low motivation and retention, many programs do not understand why their CHWs dropout. ${ }^{4}$

Community participation in recruitment, selection criteria, training, supervision, compensation, and community support emerged as key determinants of CHW motivation, retention, and effectiveness. The results of my study conducted with the Healthy Child Uganda project confirms that each of these six elements are associated with motivation, retention, and effectiveness, but yielded some surprise findings and highlighted some areas for further research.

Project CHWs demonstrated a resounding preference for community participation in recruitment and attributed community participation to stronger candidate selection and community support for the selected candidate. While community involvement in

\footnotetext{
${ }^{4}$ Karabi Bhattacharyya et al., Community Health Worker Incentives and Disincentives: How They Affect Motivation, Retention, and Sustainability, Anonymous Basic Support for Institutionalizing Child Survival Project (BASICS II) published for the United States Agency for International Development, Oct. 2001), 37.
} 
recruitment is often emphasized, there continues to be little information regarding how different models of community selection affect retention and whether various models work better in certain contexts. Community participation in selection can also help foster community ownership and strengthen the bonds between the community and the CHW. Although donors are under pressure to rapidly scale up CHW programs and demonstrate progress against the MDGs, slowing implementation to involve communities in selection may be a worthwhile trade off in terms of effectiveness. In general, communities are not involved in program evaluation. Pilot studies could help demonstrate whether community participation in evaluation contributes to motivation, retention and effectiveness.

More appropriate selection of $\mathrm{CHWs}$ may lead to improved retention, motivation, and effectiveness. According to project CHWs, married CHWs are more permanent in the community and have greater respect. Employing both male and female CHWs in each community may help CHWs reach both men and women more effectively and thus facilitate mutually reinforcing changes in health behaviours and practices among both genders. Programs may find a greater dedication to the community and willingness to volunteer or work for nominal compensation among those with lower levels of education. In contrast, age does not appear to have a large bearing on retention, motivation, or effectiveness while local council membership may have a negative influence on effectiveness. Recruiting individuals with a cooperative nature and genuine concern for community health may promote better retention, motivation, and effectiveness as such individuals are likely to be more driven and acceptable in the community. Although these findings are derived from a single, small-scale study, they provide some 
preliminary evidence and justification for further exploration into this under-emphasized area of program implementation.

Ensuring that CHWs have adequate, appropriate, and ongoing opportunities for training may be one of the best ways to improve motivation, retention, and effectiveness. Given the cost of running training sessions and lack of expertise in interactive, community-based training methodologies among much of the health workforce in developing countries, donors might play a key role in providing technical and financial assistance to strengthen training. Although communities typically demonstrate a preference for treatment, this study demonstrates that $\mathrm{CHWs}$ are able to generate demand for health promotion activities. In the long-run, emphasizing a few key health promotive activities such as breastfeeding, use of bed nets for prevention of malaria, hand washing for prevention of diarrhea, and use of contraceptives for family planning and prevention of HIV/AIDS could help decrease health system costs. Disease prevention helps decrease the strain on health systems by reducing the number of individuals who require acute care and treatment. Providing a balanced approach to curative and preventative health activities could help empower individuals to improve their own health while improving access to treatment when needed.

As a result of the higher rates of attrition associated with volunteer CHWs compared to paid ones and the ethics of seeking volunteers from the poor, compensation of CHWs is increasingly being accepted as the norm. As demonstrated in the literature and in the Healthy Child Uganda case study, however, motivation is multi-dimensional. CHWs are motivated by improved health, education, payment, community respect, gifts, identification with the health system, friendship with other CHWs, among others. Many 
CHWs are neither driven entirely by financial motivations or altruism. Qualitative surveys such as the one conducted with Healthy Child Uganda can help programs develop multiple incentive and behavioural models to plan CHW incentives and track attrition rates. ${ }^{5}$ While there is no single package of incentives that can guarantee that CHWs stay on the job, looking at motivation through a multifaceted lens can help programs address the multiple determinants of motivation and improve retention.

While CHW programs hold much potential, they should not be considered a quick-fix or a cheap substitute for strengthening the primary health care system. Program design and delivery require thorough planning and investment in community-led recruitment and selection, training, supervision, various forms of payment and incentives, and community support. Failure to adequately address each of these key program components can lead to problems of low motivation, retention, and effectiveness. The challenge is to ensure that policymakers, donors, and third party executing agencies - in their rush to implement and scale-up large CHW programs - conscientiously attend to each of the key components related to retention and motivation in their program design and implementation.

Perhaps one of the most challenging questions is how to export these lessons to large-scale national programs where financial constraints, human resource shortages, institutional capacity for planning and management, and other health system weaknesses make program administration more difficult. Despite the difficulties of scaling-up, national programs are gaining momentum. Countries such as Brazil, Venezuela, Pakistan, India, Bangladesh, Kenya, Tanzania, Ghana, Malawi, and Ethiopia have

\footnotetext{
${ }^{5}$ Bhattacharyya et al., 37.
} 
established or in the process of implementing national programs. ${ }^{6}$ In the end though, "compared with a situation of utter lack of health action, there is an indisputable benefit in scaling up even a limited package of interventions."

Where health systems are not reaching the poorest, most underserved communities, CHWs can play a vital role in filling service gaps and linking communities with formal health services. They can help act as a bridge to improve equity, utilization and effectiveness of both preventative and curative services where socioeconomic barriers complicate the delivery and acceptability of basic primary health care interventions. Put most bluntly, "CHWs may be the only feasible and acceptable link between the health sector and the community that can be developed to meet the goal of improved health in the near term."

\footnotetext{
${ }^{6}$ Nigel Crisp, Bience Gawanas, and Imogen Sharp, "Training the health workforce: scaling up, saving lives," The Lancet 371, no. 9613 (2008): 689.

${ }^{7}$ The World Health Organization, The World Health Report 2008: Primary Health Care Now More than Ever, Anonymous The World Health Organization, 2008), 29.

${ }^{8}$ Lehmann and Sanders, Community health workers: What do we know about them? The state of the evidence on programmes, activities, costs and impact on health outcomes of using community health workers, www.who.int/hrh/documents/community health_workers brief.pdf., 5 ,
} 


\section{Appendix II - Study Methods and Ethical Considerations}

\section{Study Location and Duration:}

CHWs from 18 parishes in Mbarara and Bushenyi districts of southwestern Uganda where HCU operates. Each parish consists of 6 to 16 separate villages. Research was carried out between September to December 2008.

Sources of information:

HCU project registries were consulted to determine the number of CHWs trained in each parish since 2003.

\section{Study Population and Sampling Methods:}

\section{Phase 1}

\begin{tabular}{|c|c|c|c|}
\hline $\begin{array}{l}\text { Categony of } \\
\text { Participant }\end{array}$ & $\begin{array}{l}\text { Method of Data } \\
\text { Conection }\end{array}$ & $\begin{array}{l}\text { No } \\
\text { Participants }\end{array}$ & Saípling Procedure \\
\hline $\begin{array}{l}\text { Currently } \\
\text { Serving CHWs }\end{array}$ & $\begin{array}{l}\text { Questionnaire comprised } \\
\text { of closed, open-ended and } \\
\text { matrix ranking }{ }^{1} \text { questions } \\
\text { Time required: approx. } 45 \\
\text { minutes }\end{array}$ & 46 of 356 & $\begin{array}{l}\text { Within each parish, } 25 \% \text { of } \\
\text { CHWs were randomly selected } \\
\text { by entering all names into a } \\
\text { draw. Parishes were selected } \\
\text { based on the date of the monthly } \\
\text { meetings for CHWs in each } \\
\text { parish. The first } 9 \text { parishes to } \\
\text { hold meetings were selected. }\end{array}$ \\
\hline $\begin{array}{l}\text { CHWs who } \\
\text { have resigned }\end{array}$ & $\begin{array}{l}\text { Questionnaire comprised } \\
\text { of closed, open-ended and } \\
\text { matrix ranking questions } \\
\text { Time required: approx. } 45 \\
\text { minutes }\end{array}$ & $7 *$ of 10 & $\begin{array}{l}\text { All CHWs who resigned for } \\
\text { reasons other than death, } \\
\text { sickness, or changed residence. } \\
\text { *4 CHWs were absent on the } \\
\text { appointed interview day, } 3 \\
\text { interviews were cancelled due to } \\
\text { time constraints }\end{array}$ \\
\hline Key informantw & 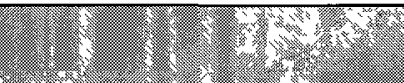 & 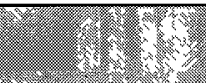 & 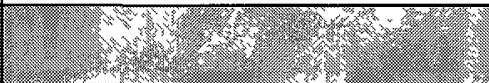 \\
\hline $\begin{array}{l}\text { Local Council } \\
\text { Representatives } \\
\text { (LC) }\end{array}$ & $\begin{array}{l}\text { Questionnaire } \\
\text { Time required: approx. } 30 \\
\text { minutes }\end{array}$ & $7 *$ & $\begin{array}{l}\text { Random sampling of } 3 \\
\text { councillors from each of the } 3 \\
\text { Health Sub-Districts (HSD). } \\
\text { Villages within each HSD were } \\
\text { selected by entering all villages } \\
\text { within that HSD into a draw. } 3 \\
\text { villages were asked to send a } \\
\text { female representative. *( } 1 \text { LC } \\
\text { representative did not attend and } \\
\text { one interview was cancelled). }\end{array}$ \\
\hline
\end{tabular}

\footnotetext{
${ }^{1}$ Matrix Ranking is a community tool that is used to allow participants to easily weigh a number of factors against each other
} 


\begin{tabular}{|l|l|l|l|}
\hline $\begin{array}{l}\text { Long-serving } \\
\text { CHW trainers }\end{array}$ & $\begin{array}{l}\text { Interview Guide } \\
\text { Time required: approx. 1 } \\
\text { hour }\end{array}$ & 2 & $\begin{array}{l}\text { Purposeful sampling of senior } \\
\text { CHW trainers who have been } \\
\text { working with the project for } \\
\text { more than 3 years. The } 2 \\
\text { individuals were selected by } \\
\text { referral from project } \\
\text { management. }\end{array}$ \\
\hline
\end{tabular}

Phase 2

\begin{tabular}{|c|c|c|c|}
\hline $\begin{array}{l}\text { Cartegory of } \\
\text { Participant }\end{array}$ & $\begin{array}{l}\text { Mephof of Data } \\
\text { Collection }\end{array}$ & 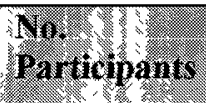 & Sampling Procedure \\
\hline $\begin{array}{l}\text { Currently } \\
\text { Serving CHWs }\end{array}$ & $\begin{array}{l}\text { Questionnaire with } \\
\text { primarily open-ended } \\
\text { questions } \\
\text { Time required: approx. } 30 \\
\text { minutes }\end{array}$ & 12 & $\begin{array}{l}3 \text { parishes with CHW meetings } \\
\text { scheduled in the week following } \\
\text { the completion of the Phase } 1 \\
\text { interviews were selected. } 4 \\
\text { CHWs from each of the } 3 \\
\text { parishes were randomly selected } \\
\text { by putting all names into a } \\
\text { draw. }\end{array}$ \\
\hline
\end{tabular}

Recruitment of currently-serving $\mathrm{CHW}$ participants:

Each month CHWs hold monthly meetings in their respective parishes. In order to minimize the time required and cost of travelling to remote sites, interviews were scheduled to coincide with the time and location of these monthly CHW meetings. Those selected for individual interviews were identified and notified in advance of the meeting. Pre-identified CHWs who were not present on the scheduled interview day were replaced by randomly selecting a new participant among those CHWs present. Given that participation was voluntary and no extra travel or time commitment was required on the part of participating CHWs, no financial compensation was offered to participating CHWs.

Recruitment of Resigned CHWs, Local Council Representatives and Long-Serving Trainers: Resigned CHWs and Local Council Representatives were given a letter of invitation inviting them to participate in this research. A reimbursement of 3000 Shillings was offered to resigned CHWs and Local Council Representatives to offset the cost of their travel to the site of the interviews. Long-serving trainers were interviewed at their convenience at the HCU office.

\section{Ethicals Approval:}

Ethics Approval was granted by the Faculty of Research and Ethics (FREC) at MUST University and from their associated external review body, the Institutional Ethical Review Committee (IERC). At each interview site, the research assistants explained the nature and purpose of the research. The consent form, which emphasized the voluntary and confidential nature of the interview, was read to each participant. Before beginning, each participant was requested to indicate their consent by signing the form. In order to maintain confidentiality, all interviews were conducted in a private location and administered by research assistants external to HCU. Carleton University Research Ethics Committee subsequently approved this research in accordance with its own guidelines and regulations.

\section{Language Considerations:}

All explanations, interviews and consent forms were administered in the local language. Questions posed to the participants were translated and back-translated by two separate individuals, fluent in both English and Ruyankore, to ensure the integrity of the translation. Following translation, a pilot session involving 3 CHWs was conducted to ensure that the questions were reliably and consistently understood by the participants. All interviews and focus group discussions were delivered verbally in the local language, Ruyankole, by trained research assistants fluent in both in the local dialect and English. In order to expedite data collection, the research assistants were tasked with translating and recording the received responses into English. 


\section{Limitations:}

Due to time and budget constraints, it was not feasible to hire an additional translator or request interviewers to translate responses following the completion of the interviews. Interviewers, were therefore, asked to conduct the interviews in the local language, but record the answers in English. Some descriptions, details, and nuanced explanations may have been reduced as result of the simultaneous translation. 


\section{Appendix III - Matrix Ranking Question}

In matrix ranking, each motivation is ranked or weighed against each of the options. This method is used to determine the relative importance afforded to a range of possible motivators. In this question, CHWs were asked to think back to the time when they were chosen to become a CHW. We asked them to compare the various reasons that motivated them to become a CHW. For example, respondents were asked whether $\mathrm{A}$ (community selection) or $\mathrm{F}$ (to help your community) was a stronger motivator at the time of recruitment. Then, $A$ would be compared to $\mathrm{E}$, then $\mathrm{A}$ to $\mathrm{D}$, and so on, moving left to right and top to bottom until all of the possible combinations have been exhausted. The letter of the stronger motivator is written in the appropriate box. The number of times each reason is chosen is added at the bottom of the page. The number of times each motivator was chosen was averaged across all participants to determine the overall strength of the motivator.

\begin{tabular}{|c|c|c|c|c|c|c|}
\hline & $\begin{array}{l}\text { To help } \\
\text { your } \\
\text { community } \\
\text { (F) }\end{array}$ & $\begin{array}{l}\text { To gain } \\
\text { knowledge } \\
\text { about health } \\
\text { problems } \\
\text { (E) }\end{array}$ & $\begin{array}{l}\text { To increase } \\
\text { your respect } \\
\text { and } \\
\text { influence in } \\
\text { the } \\
\text { comninity } \\
\text { (D) }\end{array}$ & $\begin{array}{l}\text { Expectation } \\
\text { of payment } \\
\text { (C) }\end{array}$ & $\begin{array}{l}\text { To improve } \\
\text { the health of } \\
\text { your own } \\
\text { children (B) }\end{array}$ & $\begin{array}{l}\text { Because the } \\
\text { community } \\
\text { selected you/ } \\
\text { Because the } \\
\text { local council } \\
\text { appointed you } \\
\text { (A) }\end{array}$ \\
\hline $\begin{array}{l}\text { Because the } \\
\text { community } \\
\text { selected you/ } \\
\text { Because the } \\
\text { local council } \\
\text { appointed you } \\
\text { (A) }\end{array}$ & & & & & & \\
\hline $\begin{array}{l}\text { To improve the } \\
\text { health of your } \\
\text { own children } \\
\text { (B) }\end{array}$ & & & & & & \\
\hline $\begin{array}{l}\text { Expectation of } \\
\text { payment }(C)\end{array}$ & & & & & & \\
\hline $\begin{array}{l}\text { To increase } \\
\text { your respect and } \\
\text { influence in the } \\
\text { community (D) }\end{array}$ & & & & & & \\
\hline $\begin{array}{l}\text { To gain } \\
\text { knowledge } \\
\text { about health } \\
\text { problems (E) }\end{array}$ & & (2) & $y=2$ & 1020 & & 3 \\
\hline $\begin{array}{l}\text { To help your } \\
\text { community (F) }\end{array}$ & 8 & $\sqrt{3}$ & 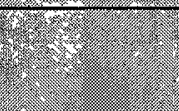 & $\sqrt{5}$ & & 2 \\
\hline
\end{tabular}

Total: Add the number of times each reason was chosen.

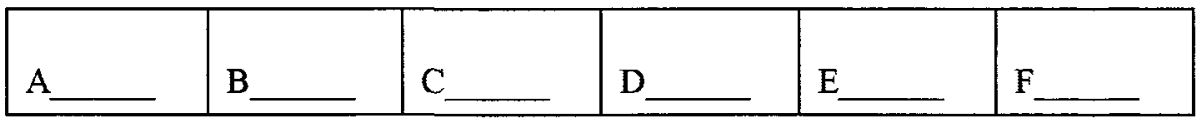




\section{References}

Abbatt, Fred. Scaling Up Health and Education Workers: Community Health Workers - A Literature Review. UK Department for International Development (DFID), March 2005.

Bailey, J. E. "Effectiveness of an Indonesian Model for Rapid Training of Guatemalan Health Workers in Diarrhea Case Management." Journal of community health 21, no. 4 (1996): 269276.

Baqui, A. H., S. El-Arifeen, G. L. Darmstadt, S. Ahmed, E. K. Williams, H. R. Seraji, I. Mannan, S. M. Rahman, R. Shah, S. K. Saha, U. Syed, P. J. Winch, A. Lefevre, M. Santosham, and R. E. Black. "Effect of Community-Based Newborn-Care Intervention Package Implemented through Two Service-Delivery Strategies in Sylhet District, Bangladesh: A ClusterRandomised Controlled Trial." The Lancet 371, no. 9628 (2008): 1936-1944.

Bess, K. D., I. Prilleltensky, D. D. Perkins, and L. V. Collins. "Participatory Organizational Change in Community-Based Health and Human Services: From Tokenism to Political Engagement." American Journal of Community Psychology 43, no. 1-2 (2009): 134-148.

Bhattacharji, S., S. Abraham, and J. P. Muliyil. "Evaluating Community Health Worker Performance in India." Health policy and planning 1, no. 3 (1986): 232-239.

Bhattacharyya, Karabi, Peter Winch, Karen LeBan, and Marie Tien. Community Health Worker Incentives and Disincentives: How they Affect Motivation, Retention, and Sustainability. Basic Support for Institutionalizing Child Survival Project (BASICS II) published for the United States Agency for International Development, Oct. 2001.

Bhutta, Zulfiqar, Tahmeed Ahmed, Robert Black, Simon Cousens, Kathryn Dewey, Elsa Giugliani, Batool Haider, Betty Kirkwood, Saul Morris, H. P. S. Sachdev, and Meera Shekar. "What Works? Interventions for Maternal and Child Undernutrition and Survival." Lancet $371: 417-440$.

Bhutta, Z. A., and S. Soofi. "Community-Based Newborn Care: Are we there Yet?" The Lancet 372 , no. 9644 (2008): 1124-1126.

Biggs-Jarrel, P. "Village Health Volunteers: Key Issues Facing Agencies in Malawi." Malawi Medical Journal 8, no. 2 (1992).

Black, R. E., L. H. Allen, Z. A. Bhutta, L. E. Caulfield, M. de Onis, M. Ezzati, C. Mathers, and J. Rivera. "Maternal and Child Undernutrition: Global and Regional Exposures and Health Consequences." The Lancet 371, no. 9608 (2008): 243-260.

Bodstein, R. "The Complexity of the Discussion on Effectiveness and Evidence in Health Promotion Practices." Promotion \& education Suppl 1, (2007): 16-20.

Bowling, Ann. Research Methods in Health: Investigating Health and Health Services. Philadelphia: Open University Press, 2000. 
Bracht, N., and A. Tsouros. "Principles and Strategies of Effective Community Participation." Health promotion international 5, no. 3 (1990): 199-208.

Braunack-Mayer, A., and J. Louise. "The Ethics of Community Empowerment: Tensions in Health Promotion Theory and Practice." Promotion \& education 15, no. 3 (2008): 5-8.

Brieger, W. R. "Health Education to Promote Community Involvement in the Control of Tropical Diseases." Acta Tropica 61, no. 2 (1996): 93-106.

Brieger, W. R., J. D. Adeniyi, K. A. Parker, and Oladepo Oladimiji. "Health Education in Africa: 1975-2000." Health education research 15, no. 4 (2000): 383-391.

Burdick, W. "Challenges and Issues in Health Professions Education in Africa." Medical teacher 29 , no. 9-10 (2007): 882-886.

Cairncross, Sandy, Eka I. Braide, and Sam Z. Bugri. "Community Participation in the Eradication of Guinea Worm Disease." Acta Tropica 61, no. 2 (1996): 121-136.

Campfens, Hubert, ed. Community Development Around the World: Practice, Theory, Research, Training. Toronto: University of Toronto Press, 1997.

Canadian International Development Agency. "The Catalytic Initiative to Save a Million Lives." in Canadian International Development Agency (CIDA) [database online]. Sept. 9, 2009Available from http://www.acdi-cida.gc.ca/acdi-cida/acdi-cida.nsf/eng/NAD-1249841JLG.

Carpenter, M. "Health for some: Global Health and Social Development since Alma Ata." Community Development Journal 35, no. 4 (2000): 336-351.

Chambers, Robert. "Participation and Poverty." Development 50, no. 2 (2007): 20-25.

Chambers, Robert. "Participatory Rural Appraisal (PRA): Analysis of Experience." World Development 22, no. 9 (1994): 1253-1268.

Community Health Workers in Africa. IDS Health and Development Information, Institute of Development Studies. February 22, 2008.

Cooke, Bill, and Uma Kothari, eds. Participation: The New Tyranny? London: ZED Books, 2001.

Crigler, Lauren, and Kathleen Hill. Rapid Assessment of Community Health Worker Programs in USAID Priority MCH Countries: Draft Tool for Field Testing. United States Agency for International Development, September 2009.

Crisp, Nigel, Bience Gawanas, and Imogen Sharp. "Training the Health Workforce: Scaling Up, Saving Lives." The Lancet 371, no. 9613 (2008): 689-691. 
Curtale, F., B. Siwakoti, C. Lagrosa, M. Laraja, and R. Guerra. "Improving Skills and Utilization of Community Health Volunteers in Nepal." Social Science and Medicine 40, no. 8 (1995): $1117-1125$.

Dawson, P., Y. V. Pradhan, R. Houston, S. Karki, D. Poudel, and S. Hodgins. "From Research to National Expansion: 20 Years' Experience of Community-Based Management of Childhood Pneumonia in Nepal." Bulletin of the World Health Organization 86, no. 5 (2008): 339-343.

Declaration of Alma-Ata International Conference on Primary Health Care, Alma-Ata, USSR.September 1978.

Delacollette, C., P. Van Der Stuyft, and K. Molima. "Using Community Health Workers for Malaria Control: Experience in Zaire." Bulletin of the World Health Organization 74, no. 4 (1996): 423-430.

DFID. "Africa Day 2009: A Snapshot of Progress Towards Meeting the Millennium Development Goals." in U.K. Department for International Development (DFID) [database online]. Available from http://www.dfid.gov.uk/Media-Room/News-Stories/2009/AfricaDay-2009/.

Elder, J. P. "Applications of Behavior Modification to Health Promotion in the Developing World." Social Science and Medicine 24, no. 4 (1987): 335-349.

Fleck, Fiona."Hand-Washing could Save the Lives of Millions of Children." Bulletin of the World Health Organization 82, no. 8 (August 2004): 631.

George, Alexandre, and Andrew Bennett. Case Studies and Theory Development in the Social Sciences. Massachusetts: MIT Press, 2005.

Gennaro, S., D. Thyangathyanga, R. Kershbaumer, and J. Thompson. "Health Promotion and Risk Reduction in Malawi, Africa, Village Women." Journal of obstetric, gynecologic, and neonatal nursing : JOGNN/NAACOG 30, no. 2 (2001): 224-230.

Gilson, Lucy, Gill Walt, Kris Heggenhougen, Lucas Owuor-Omondi, Myrtle Perera, David Ross, and Ligia Salazar. "National Community Health Worker Programs: How can they be Strengthened?" Journal of public health policy 10, no. 4 (1989): 518-532.

Guldan, G. S. "Obstacles to Community Health Promotion." Social Science and Medicine 43, no. 5 (1996): 689-695.

Haggerty, P. A., K. Muladi, B. R. Kirkwood, A. Ashworth, and M. Manunebo. "CommunityBased Hygiene Education to Reduce Diarrhoeal Disease in Rural Zaire: Impact of the Intervention on Diarrhoeal Morbidity." International journal of epidemiology 23, no. 5 (1994): 1050-1059.

Haines, A., D. Sanders, U. Lehmann, A. K. Rowe, J. E. Lawn, S. Jan, D. G. Walker, and Z. Bhutta. "Achieving Child Survival Goals: Potential Contribution of Community Health Workers." Lancet 369, no. 9579 (2007): 2121-2131. 
Hall, John, and Richard Taylor. "Health for all Beyond 2000: The Demise of the Alma-Ata Declaration and Primary Health Care in Developing Countries." Medical Journal of Australia 178, (2003): 17-20.

Hickey, Samuel, and Giles Mohan, eds. Participation: From Tyranny to Transformation? Exploring New Approaches to Participation in Development. New York: Palgrave Macmillan, 2004.

Hongoro, C., and B. McPake. "How to Bridge the Gap in Human Resources for Health." Lancet 364 , no. 9443 (2004): $1451-1456$.

Houeto, D., and A. Deccache. "Child Malaria in Sub-Saharan Africa: Effective Control and Prevention Require a Health Promotion Approach." International Quarterly of Community Health Education 28, no. 1 (2007): 51-62.

Hsieh, C. H. "A Concept Analysis of Social Capital within a Health Context." Nursing forum 43, no. 3 (2008): 151-159.

Jakab, Melitta, and Chitra Krishnan. Community Involvement in Health Care Financing: A Survey of the Literature on the Impacts, Strengths, and Weaknesses. September 2001.

Jakab, Melitta, and Chitra Krishnan. Community Involvement in Health Care Financing: $A$ Survey of the Literature on the Impacts, Strengths, and Weaknesses. Health, Nutrition, and Population Family (HNP), World Bank, September 2001.

Jewkes, R., and A. Murcott. "Community Representatives: Representing the 'Community"?" Social Science and Medicine 46, no. 7 (1998): 843-858.

Jewkes, R., and A. Murcott. "Meanings of Community." Social Science and Medicine 43, no. 4 (1996): 555-563.

Jones, G., R. W. Steketee, R. E. Black, Z. A. Bhutta, and S. S. Morris. "How Many Child Deaths can we Prevent this Year?" The Lancet 362, no. 9377: 65-71.

Kaseje, D. C. O., H. C. Spencer, and E. K. N. Sempebwa. "Characteristics and Functions of Community Health Workers in Saradidi, Kenya." Annals of Tropical Medicine and Parasitology 81, no. SUPPL. 1 (1987): 56-66.

Kelly, K. J., and H. Van Vlaenderen. "Dynamics of Participation in a Community Health Project." Social Science and Medicine 42, no. 9 (1996): 1235-1246.

Kidane, G., and R. H. Morrow. "Teaching Mothers to Provide Home Treatment of Malaria in Tigray, Ethiopia: A Randomised Trial." Lancet 356, no. 9229 (2000): 550-555.

Kohn, D. "Community Involvement Saves Newborn Infants in India." Lancet 371, no. 9620 (2008): 1235-1236.

Lamptey, P., F. Wurapa, and D. Nicholas. "The Evolution of a Primary Health Care Programme: The Danfa Experience 1970-1977." Journal of tropical pediatrics 30, no. 5 (1984): 252-256. 
Lawn, J. E., J. Rohde, S. Rifkin, M. Were, V. K. Paul, and M. Chopra. "Alma-Ata 30 Years on: Revolutionary, Relevant, and Time to Revitalise." The Lancet 372, no. 9642 (2008): 917-927.

Lehmann, Uta, and David Sanders. Community Health Workers: What do we Know about them? the State of the Evidence on Programmes, Activities, Costs and Impact on Health Outcomes of using Community Health Workers. World Health Organization. January 2007.

Lezine, D. A., and G. A. Reed. "Political Will: A Bridge between Public Health Knowledge and Action." American Journal of Public Health 97, no. 11 (2007): 2010-2013.

Linn, J. G. "Community Participation, Cultural Discourse, and Health Education Projects in Developing Areas: The Case of the Radio Communication Project in Nepal." Health Education and Behavior 35, no. 4 (2008): 455-458.

Loevinsohn, B. P. "Health Education Interventions in Developing Countries: A Methodological Review of Published Articles." International journal of epidemiology 19, no. 4 (1990): 788794.

Luby, S. P., M. Agboatwalla, D. R. Feikin, J. Painter, W. Billhimer, A. Altaf, and R. M. Hoekstra. "Effect of Handwashing on Child Health: A Randomised Controlled Trial." Lancet 366 , no. 9481 (2005): 225-233.

Lynch, M., S. West, B. Muñoz, K. D. Frick, and H. A. Mkocha. "Azithromycin Treatment Coverage in Tanzanian Children using Community Volunteers." Ophthalmic epidemiology 10 , no. 3 (2003): $167-175$.

McMichael, C., E. Waters, and J. Volmink. "Evidence-Based Public Health: What does it Offer Developing Countries?" Journal of Public Health 27, no. 2 (2005): 215-221.

Mejia, A. "Migration of Physicians and Nurses: A World Wide Picture." International journal of epidemiology 7 , no. 3 (1978): 207-215.

Millennium Development Goal 4. Department for International Development (Dfid). 2009. http://www.dfid.gov.uk/Global-Issues/Millennium-Development-Goals/4-Reducechild-mortality/

Mills, A., N. Palmer, L. Gilson, D. McIntyre, H. Schneider, E. Sinanovic, and H. Wadee. "The Performance of Different Models of Primary Care Provision in Southern Africa." Social Science and Medicine 59, no. 5 (2004): 931-943.

Morgan, L. M. "Community Participation in Health: Perpetual Allure, Persistent Challenge." Health policy and planning 16, no. 3 (2001): 221-230.

Morrow, A. L., M. L. Guerrero, J. Shults, J. J. Calva, C. Lutter, J. Bravo, G. Ruiz-Palacios, R. C. Morrow, and F. D. Butterfoss. "Efficacy of Home-Based Peer Counselling to Promote Exclusive Breastfeeding: A Randomised Controlled Trial." Lancet 353, no. 9160 (1999): $1226-1231$. 
Mosse, David. Cultivating Development: An Ethnography of Aid Policy and Practice. Ann Arbor: Pluto Press, 2005.

Msuya, Joyce. "Horizontal and Vertical Delivery of Health Services: What are the Trade Offs?" World Bank (2004): http://wwwwds.worldbank. org.proxy.library.carleton.ca/external/default/WDSContentServer/IW3P/IB/2 003/10/15/000160016 20031015125129/additional/310436360_200502761000211.pdf.pdf.

Murray, Christopher, and David Evans. Health Systems Performance Assessment: Debates, Methods and Empiricism.2003.

Murray, S. A. "Learning from Primary Care in Developing Countries. Outreach Programme in Kenya was Based on Extensive Community Participation." BMJ (Clinical research ed.) 312, no. 7025 (1996): 250.

Nathan, S., E. Harris, L. Kemp, and B. Harris-Roxas. "Health Service Staff Attitudes to Community Representatives on Committees." Journal of Health, Organisation and Management 20, no. 6 (2006): 551-559.

Nelson, Nici, and Susan Wright, eds. Power and Participatory Development Theory and Practice. Edited by Robert Chambers. London: Intermediate Technology Publications, 1995.

Nyonator, F. K., J. K. Awoonor-Williams, J. F. Phillips, T. C. Jones, and R. A. Miller. "The Ghana Community-Based Health Planning and Services Initiative for Scaling Up Service Delivery Innovation." Health policy and planning 20, no. 1 (2005): 25-34.

O'Connor, J., M. Lynch, S. Vitale, and S. West. "Characteristics of Effective Village Treatment Assistants: The Kongwa Trachoma Project." Ophthalmic epidemiology 6, no. 4 (1999): 257265.

Omaswa, Francis. "Informal Health Workers - to be Encouraged Or Condemned?" Bulletin of the World Health Organization 84, no. 2 (2006): 83.

Pandey, M. R., N. M. P. Daulaire, E. S. Starbuck, R. M. Houston, and K. McPherson. "Reduction in Total Under-Five Mortality in Western Nepal through Community-Based Antimicrobial Treatment of Pneumonia." Lancet 338, no. 8773 (1991): 993-997.

Pence, Brian, Philomena Nyarko, Cornelius Debpuur, and James Phillips. The Impact of the Navrongo Community Health and Family Planning Project on Child Mortality, 1993-2000. Brazil ed.2001.

Pence, B. W., P. Nyarko, J. F. Phillips, and C. Debpuur. "The Effect of Community Nurses and Health Volunteers on Child Mortality: The Navrongo Community Health and Family Planning Project." Scandinavian journal of public health 35, no. 6 (2007): 599-608.

Phillips, J. F., A. A. Bawah, and F. N. Bink. "Accelerating Reproductive and Child Health Programme Impact with Community-Based Services: The Navrongo Experiment in Ghana." Bulletin of the World Health Organization 84, no. 12 (2006): 949-955. 
Pitchford, Michael. Making Spaces for Community Development. Bristol: Policy Press, 2008.

Ralston, Lenore, James Anderson, and Elizabeth Colson. Voluntary Efforts in Decentralized Management: Opportunities and Constraints in Rural Development. Berkeley: Institute of International Studies, University of California, 1983.

Reid, M., Courtright, P. "How do we Sustain Village Health Volunteers?" Malawi Medical Journal 9, no. 2 (1993): 7-9.

Rifkin, S. B. "Paradigms Lost: Toward a New Understanding of Community Participation in Health Programmes." Acta Tropica 61, no. 2 (1996): 79-92.

Roberts, Marc J., William Hsiao, Peter Berman, and Michael R. Reich. Getting Health Reform Right: A Guide to Improving Performance and Equity. Oxford University Press USA, .

Roemer, M. I. "Priority for Primary Health Care: Its Development and Problems." Health policy and planning 1, no. 1 (1986): 58-66.

Rosato, M., G. Laverack, L. H. Grabman, P. Tripathy, N. Nair, C. Mwansambo, K. Azad, J. Morrison, Z. Bhutta, H. Perry, S. Rifkin, and A. Costello. "Community Participation: Lessons for Maternal, Newborn, and Child Health." The Lancet 372, no. 9642 (2008): 962-971.

Sauerbom, R., A. Nougtara, and H. J. Diesfeld. "Low Utilization of Community Health Workers: Results from a Household Interview Survey in Burkina Faso." Social Science and Medicine 29 , no. 10 (1989): 1163-1174.

Shiffman, J. "The Construction of Community Participation: Village Family Planning Groups and the Indonesian State." Social Science and Medicine 54, no. 8 (2002): 1199-1214.

Shrestha, S. "A Conceptual Model for Empowerment of the Female Community Health Volunteers in Nepal." Education for Health 16, no. 3 (2003): 318-327.

Simon, C., M. Mosavel, and D. van Stade. "Ethical Challenges in the Design and Conduct of Locally Relevant International Health Research." Social Science and Medicine 64, no. 9 (2007): 1960-1969.

Solar, O., and A. Irwin. "Social Determinants, Political Contexts and Civil Society Action: A Historical Perspective on the Commission of Social Determinants of Health." Health Promotion Joumal of Australia 17, no. 3 (2006): 180-185.

Special Programme for Research \& Training in Tropical Diseases (TDR). Community-Directed Interventions for Major Health Problems in Africa: A Multi-Country Study Final Report.

Stanback, John, Anthony Mbonyeb, and Martha Bekiitac. "Contraceptive Injections by Community Health Workers in Uganda: A Nonrandomized Community Trial." Bulletin of the World Health Organization 85, no. 10 (2007). 
Standing, H., and A. M. R. Chowdhury. "Producing Effective Knowledge Agents in a Pluralistic Environment: What Future for Community Health Workers?" Social Science and Medicine 66, no. 10 (2008): 2096-2107.

Svitone, E. C., R. Garfield, M. I. Vasconcelos, and V. A. Craveiro. "Primary Health Care Lessons from the Northeast of Brazil: The Agentes De Saude Program." Revista Panamericana de Salud Publica/Pan American Journal of Public Health 7, no. 5 (2000): 293-301.

Svitone, E. C., R. Garfield, M. I. Vasconcelos, and V. A. Craveiro. "Primary Health Care Lessons from the Northeast of Brazil: The Agentes De Saude Program." Revista Panamericana de Salud Publica/Pan American Journal of Public Health 7, no. 5 (2000): 293-301.

The World Health Report 2008: Primary Health Care Now More than Ever. The World Health Organization, 2008.

Ulin, Priscilla, Elizabeth Robinson, and Elizabeth Tolley. Qualitative Methods in Public Health: A Field Guide for Applied Research. San Francisco: Jossey-Bass, 2005.

UNICEF. "Monitoring the Situation of Children and Women." Available from http://www.childinfo.org/mortality.html.

United Nations Population Fund. "Safe Motherhood." [cited Dec. 1, 2009]. Available from http://www.unfpa,org/mothers/statistics.htm.

United Nations Program on HIV/AIDS (UNAIDS). UN AIDS Epidemic 2009.2009.

United Nations Children's Fund (UNICEF). The Under-Five Mortality Rate: The Indispensable Gauge of Child Health, 2008. http://www.unicef.org/sowc08/docs/sowc08_panels.pdf,

Uzochukwu, B. S. C., C. O. Akpala, and O. E. Onwujekwe. "How do Health Workers and Community Members Perceive and Practice Community Participation in the Bamako Initiative Programme in Nigeria? A Case Study of Oji River Local Government Area." Social Science and Medicine 59, no. 1 (2004): 157-162.

Victora, Cesar, Robert Black, and Jennifer Bryceb. "Evaluating Large-Scale Programmes in Child Survival." Bulletin of the World Health Organization 87, no. 0 (2009): 1.

Victora, C. G., K. Hanson, J. Bryce, and J. P. Vaughan. "Achieving Universal Coverage with Health Interventions." Lancet 364, no. 9444 (2004): 1541-1548.

Victora, C. G., A. Wagstaff, J. A. Schellenberg, D. Gwatkin, M. Claeson, and J. -P Habicht. "Applying an Equity Lens to Child Health and Mortality: More of the Same is Not enough." Lancet 362, no. 9379 (2003): 233-241.

Walley, J., J. E. Lawn, A. Tinker, A. de Francisco, M. Chopra, I. Rudan, Z. A. Bhutta, and R. E. Black. "Primary Health Care: Making Alma-Ata a Reality." The Lancet 372, no. 9642 (2008): 1001-1007. 
Walt, Gill. "CHWs: Are National Programmes in Crisis?" Health Policy and Planning 3, no. 1 (1988): 1-21.

Walt, G., M. Perera, and K. Heggenhougen. "Are Large-Scale Volunteer Community Health Worker Programmes Feasible? the Case of Sri Lanka." Social Science and Medicine 29, no. 5 (1989): 599-608.

Wardlaw, T., P. Salama, E. W. Johansson, and E. Mason. "Pneumonia: The Leading Killer of Children." Lancet 368, no. 9541 (2006): 1048-1050.

Winch, P. J., K. E. Gilroy, C. Wolfheim, E. S. Starbuck, M. W. Young, L. D. Walker, and R. E. Black. "Intervention Models for the Management of Children with Signs of Pneumonia Or Malaria by Community Health Workers." Health policy and planning 20, no. 4 (2005): 199212.

World Bank. World Development Report 1993: Investing in Health. Oxford University Press, 1993.

World Health Organization. The Global Burden of Disease: 2004 Update, 2008.

World Health Organization. Revitalizing Primary Health Care Country Experience: Bangladesh.August 2008.

World Health Organization. Measuring Health Systems Strengthening and Trends: A Toolkit for Countries.2008.

World Health Organization. "WHO/UNICEF Strategy of Integrated Management of Childhood Illness (IMCI)." Available from http://www.icatttraining.org/IMCL/AboutIMCI/tabid/84/Default.aspx.

World Health Organization. The World Health Report 2006. 2006.

World Health Organization. "Health Promotion Glossary." 1998 http://www.who.int/hpr/NPH/docs/hp_glossary en.pdf.

Zakus, David, and Catherine Lysack. "Revisiting Community Participation." Health Policy and Planning 13, no. 1 (1988): 1-13.

Zakus, J. D. L. "Resource Dependency and Community Participation in Primary Health Care." Social Science and Medicine 46, no. 4-5 (1998): 475-494. 